\title{
The shadow of peasant past: \\ Seven generations of inequality persistence in Northern Sweden
}

\author{
Martin Hällsten ${ }^{*}$, Martin Kolk² (alphabetical) \\ ${ }^{1}$ Department of Sociology, Stockholm University \\ ${ }^{2}$ SUDA, Department of Sociology, Stockholm University \\ ${ }^{2}$ Center for Cultural Evolution, Stockholm University \\ ${ }^{2}$ Institute for Future studies, Stockholm
}

August 30, 2022

16,722 words

\begin{abstract}
(139 words)
We use administrative data linked to parish records from Northern Sweden to study how persistent inequality is across multiple generations in education, occupation, and wealth, going from historical to contemporary time. Our data cover seven generations and allows us to follow ancestors of individuals living in Sweden around the new millennium back more than 200 years, covering the mid- $18^{\text {th }}$ century to the $21^{\text {st }}$ century. In our sample of around 75,000 traceable descendants, we analyze (a) up to $5^{\text {th }}$ cousin correlations and (b) dynastic correlations over seven generations based on aggregations of ancestors' social class/status. With both approaches, we find that past generations structure life chances many generations later, even though our results align with traditional stratification research in that mobility across multiple generations is high.. Our results implicate that today's inequality regime may have been formed many generations back.
\end{abstract}

\footnotetext{
* Corresponding author: martin.hallsten@sociology.su.se. We thank participants at presentations given at Nuffield College, Oxford (February 2019), Nordic Demographic Symposium in Reykyavik (June 2019), the ECSR conference in Lausanne (September 2019), the SUDA Demographic Colloquium in Stockholm (February 2020), the CEDAR seminar in Umeå (February 2020), the CED seminar in Lund (September 2020), the , Population and Health Research Group (PHRG) seminar in St Andrews (January 2021), the CPop seminar in Odense (October 2021), the RC28 in London (2022), and Jan Stuhler for valuable comments on our manuscript. All remaining errors are our own. We also want to thank the staff at the Demographic Database at Umeå University for digitizing the data and preparing our historical data. Funding was provided by Riksbankens jubileumsfond grant no. P17-0330:1 and the Swedish Research Council grant no. 2019-02552.
} 


\section{Introduction}

Life chances and life outcomes are correlated across generations, but over how many generations does inequality persist? This question is central for social theory as it touches on the degree to which individuals form their own life outcomes and to what degree this is imposed on them by social structures. Early studies of income mobility found the persistence, the tendency that descendants resemble their ancestor's status-wise, be it at the top or bottom, from parents to children to be so low that persistence across multiple generations was considered unlikely. Becker and Tomes (1986) coined the now-classic phrase "from shirtsleeves to shirtsleeves in three generations," meaning that "almost all earnings advantages and disadvantages of ancestors are wiped out in three generations. Poverty would not [persist] for several generations" (p. 28, 32). Since the time of Becker and Tomes, the increased focus on measurement errors (Solon 1992) has revised this conclusion for two-generation studies ${ }^{1}$, finding persistence to be rather high and thus lasting several generations, even though mobility dominates over persistence in explaining life chances in virtually all existing studies. Some early studies of class mobility examined three-generational correlations-e.g., in the United States (Hodge 1966) and Britain (Ridge 1974) — but found persistence to be limited to two generations. Later, Warren and Hauser (1997) found no direct association between grandfathers' and grandchildren's social status in Wisconsin. In recent years, these conclusions have been challenged with new data and methods. We have witnessed a virtual explosion of studies documenting substantial associations across three generations between, for example, grandfathers' and grandchildren's outcomes (Anderson, Sheppard and Monden 2018). The social panel surveys of the 1950s and 1960s now contain enough generations to link up to three generations, and the expanding use of register data in the Nordic countries also provides similar

\footnotetext{
${ }^{1}$ We follow the convention in the literature of referring to the number of generations (nodes) studied, not across how manny generations the inequality has traveled (ties). Transmissions from parents to children are commonly referred to as being two generations even though the difference between generations is only one. "Seven generations" refers to nodes, which is the same as six ties.
} 
opportunities. However, empirical analyses over more than three generations are scarce, as even these data sources encounter a limitation: linking four or more generations is rarely possible with this data infrastructure. A collection of approaches have been used in earlier multigenerational stratification, including historical data sets (Mare and Song 2014; Song, Campbell and Lee 2015; Song and Campbell 2017) and surnames (Clark 2014). However, studies following true kinship from historical into modern times are scant and are also largely limited to four generations (Dribe, Helgertz and Van de Putte 2015; Lindahl et al. 2015; Dribe and Helgertz 2016; Modalsli 2016; Kolk and Hällsten 2017), though Modalsli (2016) analyzed five generations.

We aim to expand the literature on the role of extended family background by analyzing the persistence of inequality across seven generations. Analyzing deep kinship patterns is a pioneering way to study the effect of social and kin background itself, as a direct influence from ancestors living six generations back is likely minimal. We argue that this approach answers novel questions on how individuals' social background is not just a factor of parents but related to deeper traits engaged in families. When studying long-run mobility, we examine lineages including members born in the late $18^{\text {th }}$ century as well as in the late $20^{\text {th }}$ century. The socioeconomic context, occupational structure, and mechanisms of mobility are changing over the time period we examined as society transforms from an agricultural economy where most goods are produced outside the market to an advanced service economy. Any examination of kinship's persistence across such generational depth will have to critically engage with finding measures that can trace intergenerational and multigenerational persistence across such a dynamic time period. We argue that the methodology we utilize provides a promising solution for measuring and thinking about the long-term influence lineage has on life chances in contemporary society. 
Our approach is to merge modern Swedish administrative registers with historical registers based on church books. Sweden is an interesting case since the intergenerational class and income (but not education) mobility is among the highest in western countries (Blanden 2013). Breen (2010) compares Sweden to Germany and the UK over cohorts born from the 1910 s to 1970 s and finds Sweden to begin with the highest level of mobility and that this also increases over successive birth cohorts. In Sweden, the church was responsible for national registration and kept administrative parish records of the entire population. They were used to keep track of the size of the local population but also contained events such as migrations and births recorded monthly. Church books from the Northern Swedish regions of Skellefteå and Umeå from the $18^{\text {th }}$ century to the middle of the $20^{\text {th }}$ century (Westberg, Engberg and Edvinsson 2016) have been digitalized. ${ }^{2}$ Personal identity numbers were introduced in Sweden in 1947 , are recorded both in church books and modern administrative registers, and were used to merge the two sources. This means that merging historical and modern data is both effortless and accurate. We trace ancestors in the Skellefteå and Umeå church books and analyze the social positions of their descendants in modern register data. Our target population is the kin network of descendants with ancestors living in the Skellefteå and Umeå region. Our basic research question is how much variation in a now-living person's outcomes is shared with horizontal kin (cousins) and how much that can be explained by ancestors (grandparents), both proximate and distant. Of particular importance is the role of the ancestors' distance to the now-living descendant. We address the research question using two approaches: cousin correlations and dynastic correlations, to be explained in detail below. With these analytical tools, we find persistence in education, occupations, and wealth across several generations. The persistence from distant ancestors is low, but long-lasting.

\footnotetext{
${ }^{2}$ Similar data also exist for several parishes in Southern Sweden (Bengtsson, Dribe and Svensson 2012)
} 


\section{Theoretical background}

\subsection{Mechanisms of multigenerational persistence}

Several theories can explain multigenerational kinship effects on socioeconomic outcomes (e.g., Cox and Fafchamps 2007; Mare 2011; Jaeger 2012; Anderson, Sheppard and Monden 2018). However, when discussing potential influences over several generations, we can rule out any explanation based on direct social interactions, such as those between children and grandparents. Ruling out social interactions, we are left with different structural influences. The first explanation is genetic inheritance. However, genetic relatedness attenuates quickly for distant kinships. ${ }^{3}$ If higher-order cousins are more similar in SES outcomes than this, the reason is unlikely to be genetic.

In a population that is geographically limited or where cousin marriages are common, the average relatedness will be higher than these estimates. Similarly, assortative mating increases overall genetic similarity (Robinson et al. 2017). In Northern Sweden, the frequency of cousin marriage was non-trivial and the marriage pool geographically constrained, meaning that overall inbreeding coefficients would be higher than those based on random mating for the values above (Egerbladh and Bittles 2011). Nevertheless, empirical assessments of the area's mean coefficient of inbreeding are too small to have substantial effects on higher-order cousin correlations (Bittles and Egerbladh 2005).

Although direct social interaction between an ancestor and descendants can be ruled out, kinship background may be an important factor in maintaining family norms, culture, and ideas

\footnotetext{
${ }^{3}$ Comparing kin born in the same generation, although siblings on average share 50 percent of genes, $1^{\text {st }}$ cousins share 12.5 percent and $2^{\text {nd }}$ cousins share 3.125 percent. The relatedness of cousins thus shrinks by $3 / 4$ for each generation of distance: $3^{\text {rd }}$ cousins share 0.78 percent and $4^{\text {th }}$ cousins 0.19 percent of their genes; i.e., they are virtually unrelated. These numbers would increase under assortative mating, but estimates of genetic assortative mating suggest these to be too low to have any substantial impact, i.e., a correlation in latent genetic scores between spouses of around .02 to .04 (Domingue et al. 2014; Yengo et al. 2018; Collado, Ortuño-Ortín and Stuhler 2022). From a vertical perspective, the relatedness to each ancestor shrinks by $1 / 2$ for each generation of distance (father: 50 percent; grandfather: 25 percent; great-grandfather: 12.5 percent; great-great-grandfather: 6.125 percent, and so on).
} 
of social belonging. Quasi-direct inheritance mechanisms can be thought of as influences of ancestors that do not arise in parent-child interactions but have arisen long before that and are carried more or less unchanged from one generation to the next. Statistically, we would ascribe this to parent-child transmission, while the mechanism is the sequential transfers that exist over many parent-child pairs. One quasi-direct mechanism may be normative. For example, suppose descendants of a successful ancestor continue to celebrate this success to the extent that it becomes a stable norm. In that case, this could explain how past generations have a long-lasting influence. Such influence will operate via parents even though the origin is elsewhere in the kinship structure. A critical driver here is social closure. Kinship relations often involve solidarity and prioritization over other social relations (some suggest this has an evolutionary origin, Euler 2011). When kinships are closely integrated with other aspects of the social structure, such effects of social closure can bevery substantial. In contemporary individualized high-income societies, however, a number of domains compete with kinship in terms of providing social relations between individuals, including schools, workplaces, friendship circles, and voluntary organizations, in contrast to past societies where more domains of life were integrated with kinship.

A related plausible mechanism of quasi-direct inheritance is via symbolic assets. In many past societies, more aspects of social status were directly prescribed from the family's background. The most obvious examples are inherited positions and titles, such as in aristocratic and royal families, but the land was also often passed down with little change across generations, and occupations were passed across generations in guilds. The key point is that land passes from parents to children, but the parents are not the original source of the land. In a society in which family backgrounds prescribe social status, even if an individual is less successful than their parents for occupation, income, or education, if essential assets that prescribe social status are heritable, they will be transmitted directly from grandparent to 
grandchild, even if occasional observed individual outcomes in an intermediate generation are low. Kin are often united by a common name or other symbols, which may provide a form of reputational, social capital that is valid outside the family but may also exert normative pressure within the family. Multigenerational transfers through symbolic means may sometimes be less dependent on social interaction, such as grandparents influencing later generations in their absence as role models or through inscribed social statuses. For example, Laband and Lentz (1985) argued that a rationale for politicians' children to become politicians is name recognition and voter loyalty. Second-generation politicians thus often beat first-generation politicians in elections (Feinstein 2010). Symbols are not necessarily linked only to elites but apply widely. An extreme form of symbolic mechanisms in the lower end of the social spectrum would be the stigma or labeling of being kin to a perpetrator (e.g., criminality is transmitted both across two and three generations, Frisell, Lichtenstein and Långström 2011; Eriksson et al. 2016). To the extent that social status is linked to racial and ethnic categories, such categories will also be inherited across generations with high, if not perfect, fidelity (Torche and Corvalan 2016), and that an occasional outlier individual may not transmit their status above/below that of their group. We note that our population was unusually ethnically homogenous (Alm Stenflo 1994), unlike many other parts of the world at the time.

The above mechanisms may be the more important explanation of outcomes like education or occupational careers, while outcomes such as wealth may operate differently. Here, the transfer of physical assets is also a potential quasi-direct mechanism, and bequests are a direct way family advantage is transmitted across generations. Sweden has a bilateral kinship system where all sons and daughters inherit. Until the mid- $19^{\text {th }}$ century, sons inherited $2 / 3$ and daughters $1 / 3$ of their parent's estate, and family land was protected by law, and land could not be easily sold or transferred out of the family (Dackling 2013). After the mid-19 $9^{\text {th }}$ century, sons and daughters inherit equally by law, and children could force the sale of family 
land. However, in practice it was very common throughout the 19th and 20th centuries for agricultural families to concentrate the inheritance. Hence, often a single child (usually a son) maintained ownership of the family farm. Unlike some Western countries, in contemporary Sweden children by default have the right to half of their parent's estate, and sons and daughters cannot be fully disinherited. While the inheritance system would, in practice, typically create more substantial continuity along patrilineal lines, a tendency for stronger socialization and parent-child resemblance for mother-daughter ties, as well as the role of women as "kinkeepers" (Young and Wilmott 1957; Rosenthal 1985) may result in stronger continuity among maternal lines. In the two-generational literature, sister correlations are weaker than brother correlations (Björklund and Jäntti 2020), and this is also true for intergenerational correlations (Chadwick and Solon 2002; Jäntti et al. 2006). For three-generational studies, the review by Anderson, Sheppard and Monden (2018) examined if associations differ by grandparental gender, and maternal or paternal lineage but found no clear pattern in the results, even if there were marginal differences for grandparental gender. In contemporary Western societies, some families organize generation-skipping family trust funds to facilitate such outcomes by transferring resources directly across three generations or more (Mare 2011). Ownership of firms is another case in point: a large share of all large private companies are still run by family firms using various corporate strategies to maintain family control over vast enterprises in Sweden and other Western countries (Masulis, Pham and Zein 2011). On the extreme ends of the spectrum, kinship may be a carrier of wealth (or poverty) that is strongly transmitted across generations (Kotlikoff and Summers 1981; Adermon, Lindahl and Waldenström 2018), and that also may give rise to strong normative behaviors to secure kinship advantages also in dimensions related to career chances, such as educational investments (Hällsten and Pfeffer 2017). One explanation for such normative elite behavior is that generational transfers of wealth are often seen as a loan from the family rather than a personal assets (Schaeffer 2014; Kuusela 
2018). Such dynastic thinking indicates that in some families, the family's survival is of greater importance than the will of the individual and would trigger investment in several outcome dimensions, not least education.

\subsection{Formal approaches to multigenerational persistence}

A central tool to causally represent social mobility across multiple generations is a Markov model. A $1^{\text {st }}$ order Markov model (also referred to as an autoregressive AR(1) model) postulates that inequality is only transmitted sequentially across generations from parents to children so that there is no association between grandparents' and grandchildren's outcomes once parents' resources are taken into account. Formally, a $1^{\text {st }}$ order Markov process is memoryless: knowing the present state of a (statistical) system creates predictions about future events that are as accurate as knowing the system's full history. That is, any multigenerational causal influence can be reduced to the product of subsequent intergenerational (parent-child) associations.

If a $1^{\text {st }}$ order Markov model is true, and intergenerational influences are stable over time, it is possible to compute the projected correlations between an index generation and the $k$ th generations as

$$
\operatorname{Corr}(1, k)=\operatorname{Corr}(1,2)^{k-1}
$$

This procedure of iterating intergenerational correlations with increasing exponents means that a grandparent-child correlation should equal the parent-child correlation squared. Although this logic was aimed at a vertical transmission model (where the resemblance between children and their parents and grandparents is examined), it also applies to horizontal models (where the resemblance between siblings and cousins are compared): $1^{\text {st }}$ and $2^{\text {nd }}$ order cousin correlations are projected to be the squared and cubed sibling correlations (Knigge 2016; 
Lundberg 2018). Many recent works (Stuhler 2012; Lindahl et al. 2015; Knigge 2016; Braun and Stuhler 2018) have observed higher-order correlations at higher levels than those iterated, leading them to reject the $\left(1^{\text {st }}\right.$ order$)$ Markov model. Some take this as evidence of direct grandparental effects, but drawing this conclusion is more complex as an estimated empirical function is not necessarily the true theoretical function; a wide range of theoretical models can predict such a pattern. For example, building on, Clark and Cummins (2014), Braun and Stuhler (2018) developed a more realistic model where outcomes can take the indirect route via endowments that then predict the outcome (e.g., via skills rewarded in a labor market). Such a model gives higher multigenerational predictions than the simple iterations of eq. 1 without any direct ancestor effects. A similar point has been made by Lundberg (2020), who shows that cousin correlations are not indicative in themselves of the underlying transmission processes but can be explained but a multitude of potential processes, not necessarily involving direct transmission from grandparents. Measurement errors can also distort any analyses of persistence across generations. In general, we would assume that precision is lower regarding distant historical times. In our cases, we have to rely on priests' transcripts of occupational titles, where the underlying nomenclature is based on practices, and not our own operationalization and measurement. Accordingly, even observing higher multigenerational correlations than what is predicted in the $1^{\text {st }}$ order Markov model, are not neccarily a counterargument to the idea of sequential transmission between parents and children.

\subsection{Higher-order Markov models}

The Markov model can be extended by including more lags, such as direct influences from grandparents and ancestors (i.e., AR(2) and higher). Such direct grandparental associations do not operate via parents. The three-generation literature contains many studies that document a statistical association between grandparental associations once parental characteristics have 
been netted out (Anderson, Sheppard and Monden 2018). Interestingly, many of these estimates of grandparental associations suggest that they have little dependence on actual contact, where contact is either physical proximity or generational overlap. Overall, this suggests that grandparents provide resources other than those that require direct social interaction. However, the question is whether or not the parental controls (or lower-order lags, when considering higher-order lags) are exhaustive to capture the causal influence. Unmeasured (unobserved) heterogeneity or error-prone observations of parents' attributes may show up as "phantom" grandparental effects (Kelley 1973; Hällsten 2014), which makes higher-order Markov models sensitive to specification. Engzell, Mood and Jonsson (2020) have shown that once parental characteristics are exhaustively measured, the direct three-generation association for income is small in Sweden. Still, some similar analyses, such as grandparental wealth and children's educational attainment, reach different conclusions (Hällsten and Pfeffer 2017).

Another problem with higher-order Markov models is that direct grandparental effects are also troubled by bad control (overcontrol) bias and collider bias (Elwert and Winship 2014). Parental characteristics lie on the causal path from grandparents and are essential mediators. The implicit assumption of any analysis, including mediators, is that they are exogenous; i.e., mediators' residual factors are unrelated to the outcome's residual factors, which is highly questionable. There have been attempts to relax such assumptions via, for example, marginal structural models (Robins, Hernán and Brumback 2000) for testing for multigenerational neighbor effects and wealth effects (Sharkey and Elwert 2011; Hällsten and Pfeffer 2017), but they come with new assumptions (e.g., no unmeasured confounding Cole and Hernán 2008).

\section{Previous studies}

Previous studies of inequality transmissions in contemporary times (the $20^{\text {th }}$ century) have primarily been limited to three generations. Although the first modern multigenerational study 
(Warren and Hauser 1997) found no evidence of three-generational associations in Wisconsin, new literature in most cases, find three-generational associations in Western countries (Anderson, Sheppard and Monden 2018), even for Wisconsin (Jaeger 2012). For Sweden, there are several three-generational studies due to good data availability. For example, for the town of Uppsala, Modin, Erikson and Vågerö (2013) found associations in grade marks between grandparents and children when controlling for parents' education.

Of particular interest to us are studies that analyze persistence or mobility over four or more generations. However, this is still a very limited part of the literature, also concentrated on some specific regions. Several studies have come from Swedish data. Lindahl et al. (2015) analyzed data from Malmö in Southern Sweden on individuals born in 1928, their parents, and their children and grandchildren (four generations). They found income correlations across three generations and education correlations across four, meaning that information on greatgrandparents helped predict education attainment today. Lindahl et al. (2014) directly tested and rejected the (two-generation) Becker-Tomes model. Using population registers from Sweden, Hällsten (2014) estimated positive and substantial $2^{\text {nd }}$ cousin correlations in GPA for the total Swedish population (under the conditioning of tight birth intervals). Adermon, Lindahl and Waldenström (2018) analyzed wealth across three and four generations, finding persistence to be much higher than theoretical two-generation models suggest. However, while these studies include four generations, they are rather 3.5 generation studies as the current generation is still very young, and the data thus condition on small intergenerational distances.

Other studies are entirely focused on historical time. Knigge (2016) estimated $2^{\text {nd }}$ cousins having correlations in occupational status from the $19^{\text {th }}$ century into the early $20^{\text {th }}$ century in the Netherlands. Long and Ferrie (2018) linked historical censuses for the United States and Britain and found grandparental associations in the later $19^{\text {th }}$ century. Mare and Song (2014) 
found persistence over many generations in China, from historical times to the early $20^{\text {th }}$ century.

Another part of the literature uses indirect measures. Clark (2014) uses changes over time representation of surnames within high-status occupations to calculate mobility, and finds intergenerational mobility to be very low, suggesting persistence to last over multiple generations (for a critique, see Chetty et al. 2014; Torche and Corvalan 2016). Similarly, Barone and Mocetti (2016) identify pseudo-descendants via surnames and found persistence from historical to modern times in the now-Italian city of Florence. The most relevant literature related to our study links modern and historical individual-level microdata. In a pioneering study, Campbell and Lee (2011) found persistence over many generations in China from historical times to the present. In their study, SES is measured at the group level. Dribe and Helgertz (2016) used church books from Southern Sweden linked to modern registers to study trends in mobility across three generations. They found a direct association between grandfathers' class or occupational status and grandsons' outcomes and that this threegeneration association is stable over time. Modalsli (2016) linked historical census data via surname links to modern register drawing on Modalsli (2017). He analyzed five generations through a vertical design and found persistence over four generations. Although he found a substantive persistence coefficient for great-great-grandfathers, it was not significant.

A part of the literature extends the multigenerational approach to include demographic behaviors such as marriage, fertility, and mortality. The mentioned study by Mare and Song (2014) uses simulations to show how such behaviors play an essential role in moderating or amplifying SES effects. Song (2020) analyze US data from 1850 to 2015, with a similar approach. Song, Campbell and Lee (2015) show in ancient China, that patrilineages founded by high-status males had a lower probability of extinction at each point in time, resulting in higher growth rates for the next 150 years. Kolk and Hällsten (2017) used a different 
prospective approach using data from Northern Sweden with a prospective lump model that also incorporates demographic behavior, and found a correlation between the proportion of tertiary education in great-grandchildren and great-grandparents' occupations.

In conclusion, the current literature documented persistence over four generations, with a few exceptions (Campbell and Lee 2011; Modalsli 2016). Yet, even these studies are limited by constraints in data, measurement, and sample sizes. With our current study, we overcome several of these limitations, even though we are limited to a local region within Sweden.

\section{Data}

We use population data for Sweden that have been linked to church books in the Swedish regions of Skellefteå and Umeå. Figure 1 shows our study area in the north of Sweden. The church books in this area have been digitalized as part of a large research infrastructure project (Westberg, Engberg and Edvinsson 2016). This region encompassed a population of predominantly agricultural workers before the $20^{\text {th }}$ century. The small farmers mostly owned their own land, which was typical for Northern Sweden. The end of the $19^{\text {th }}$ century saw the rise of a sawmill industry, and the early $20^{\text {th }}$ century saw the rise of mining and metallurgical industries after the discovery of an ore field near the town of Boliden. We know from prior research that inhabitants and descendants in this region have higher-than-average levels of education (Kolk and Hällsten 2017) despite the area being quite representative of Sweden socioeconomically from the middle of the $20^{\text {th }}$ century onward (Kolk and Hällsten 2017). Local estimates of two-generation income mobility are among the highest in contemporary Sweden (Brandén 2018), even though the opposite was true for occupational mobility at the end of the 19th century (Berger et al. 2021). Our historical data has been digitized by the Demographic Database at Umeå University (Edvinsson 2000; Westberg, Engberg and Edvinsson 2016), and includes parish registers for 10 different parishes in Northern Sweden. The parish records end 
at different time points between 1950 and 1970. We describe the data in further detail in Web Appendix Part A.

From 1960, we can link our church books with registers of Sweden's complete population, which allows us to follow our cohort as they disperse all over Sweden. A similar data set has been described elsewhere (Kolk and Hällsten 2017; Kolk and Skirbekk 2019). It should be noted that there is outmigration from our historical region before 1960 that we can not follow outside the region, and there is also international migration after 1960. However, internal migration (and in particular migration to the United States) was lower in our region than in the rest of Sweden at the end of the $19^{\text {th }}$ century (Berger et al. 2021).

Our sample is conditioned on residential stability across many generations from the late $18^{\text {th }}$ to early $20^{\text {th }}$ centuries. Thus, the selected sample from our local population has an overrepresentation of land-owning farming families. However, a substantial, strong point of our data set is that it allows us to follow kinship networks all over Sweden with national administrative registers following 1947 . This allows us to capture the $20^{\text {th }}$ and $21^{\text {st }}$ century kinship networks of our lineages that had members living in Skellefteå in the middle of the $20^{\text {th }}$ century regardless of where they live in Sweden, as well as to measure their socioeconomic information with high accuracy from 1960 onward.

Our population has two additional characteristics: there is a higher-than-average prevalence of cousin marriage in historical times, even though the mean coefficient of inbreeding in the area was not particularly high (Bittles and Egerbladh 2005), and the area is known for the incidence (1.5\% of the population) of a genetically transmitted neurological disease: familial amyloid polyneuropathy (named Skelleftesjukan in Swedish). ${ }^{4}$ We address these population characteristics in sensitivity analyses (part 6.4).

\footnotetext{
${ }^{4}$ The familial amyloid polyneuropathy disease has a late onset, in middle age, and even though it is genetically transmitted, only some 10 percent of those carrying the risk genes develop the disease. This means that it is unlikely that individuals are influenced by the disease in their early careers, or that they would adapt their career choices knowing that they carry risk genes.
} 


\subsection{Constructing kinship networks}

We define the index generation when we observe outcomes as cohorts born between 1940 and 1987. We trace their ancestors back in time using repeated retrospective matching on links between children and their parents from church book records. This is similar to taking all adults in the last decennia of the church books and try to find them and their children (if they exist). This creates a kinship network that goes six generations back from the index generation (covering seven generations, including the index). We thus link each index to (up to) 4 grandparents in generation -2 (minus two = two generations back), up to 8 great-grandparents in generation -3 , and so on until we reach (up to) 64 ancestors in generation -6 (with no endogamy). For example, $5^{\text {th }}$ cousins only need to share one or two great-great-great-greatgrandparents, a single couple can be the source of a large number of $5^{\text {th }}$ cousins, and the size of $5^{\text {th }}$ cousin groups are often large (though varying considerably in size).

Of course, as the linkage is not perfectly complete, we cannot reach these theoretical maxima. We reach ancestors in the Skellefteå data by either the mother's or the father's lineage for approx. $2 / 3$ of the index individuals; for $1 / 3$, we reach ancestors by both lineages. Table B1 shows the number of ancestors we can observe per generation. For the proximate generation, coverage is quite high but then declines. In the eldest generation, on average, we observe $1 / 3$ of the 64 theoretical ancestors. To be able to compare estimates of persistence across generations, we delimit the sample to cases where we can find at least one ancestor in generation -5 , where our coverage is more complete. With this restriction, we have around 75,000 cases in our index generation. Our data quality is lower for individuals born before the late $18^{\text {th }}$ century, and we therefore condition our population on having at least one $5^{\text {th }}$ generation ancestor (although we also analyze $6^{\text {th }}$ generation ancestors). In Table B6, we show the share of individuals in our parishes that are a part of the kinship networks in our analysis population. 
We code the relationships between ancestors using the gender of each ancestor in sequences: $\mathrm{m}$ is mother, $\mathrm{mm}$ is mother's mother, $\mathrm{f}$ is father, $\mathrm{fm}$ is father's mother, and so on. All in all, we have 4 sequences for grandparents ( $\mathrm{mm}, \mathrm{mf}, \mathrm{fm}, \mathrm{ff}), 8$ sequences for greatgrandparents (mmm, mmf, mfm, mfm, fmm, fmf, ffm, fff), and so on. This means that we have 64 sequences for generation -6 . The sequence $\mathrm{mmmmmm}$ is thus the ancestor following the maternal line of kinship only. As an example, we display the birth years of all individuals in this kinship line in Figure B1. There is substantial variation in birth years of past generations, but this is, of course, also driven by our wide span for the index cohort. This is motivated by power concerns but also because we know that there is great dispersion in birth years among those great-grandchildren of persons born in the mid- $19^{\text {th }}$ century in the church book data (Kolk and Hällsten 2017). We have done some sensitivity analyses of the impacts of factors such as age differences between cousins, which have no fundamental impact on our results (see Web Appendix Table F4).

Changing the perspective from the index generation to the anchor ancestors who produced the descendants is also possible. Table B2 shows the birth years and the numbers of descendants for each ancestor each generation produced. On average, an ancestor in the eldest generation produced 160 descendants, but this value went as high as over 2,000. This also means that variations in the sizes of the kinship networks are considerable, which we address later (however, our findings suggest that this is not a very important factor).

\subsection{Variable coding}

We analyze three outcomes in the index generation: education, occupation, and wealth. They represent different forms of stratification, i.e., in skill levels, realized skill levels and economic assets not necessarily generated in the labor market. Recent analyses from Sweden highlight how education and occupation are closer to each other as stratification dimensions, and in turn 
different from wealth (Hällsten and Thaning 2021). However, since we are able to measure education with the least constraint, we focus the results on this outcome and comment on differences for occupation and wealth whenever they are substantial. We measure education by the highest level in the education registers, primarily drawing on school graduation records. We then convert this to years of education. We use data from 1990, 2001, 2007, 2012, and 2017, with 30 being the youngest age of sampled individuals (if we encounter diverging information, we take the highest value).

For occupations, we code ISEI scores (Ganzeboom, De Graaf and Treiman 1992) from the Swedish occupation register of 2001-2017, which mainly contains employer-reported occupations. We prefer ISEI over CAMSIS (which we use for older generations, see below) because ISEI captures higher levels of intergenerational persistence (Hällsten 2019). We use conversion tools that translate ISCO-88(com) into ISEI scores (Ganzeboom and Treiman 1996; Bihagen 2007). We take the averages of observed ISEI when there is information for several years to represent the individual's occupational outcome. ${ }^{5}$

For wealth, we rely on the Swedish wealth register from 1999-2007. This register is based on wealth tax data that are augmented with several additional sources, and it is of very high quality compared to most existing wealth data sources in the literature. ${ }^{6}$ To reduce measurement errors, we compute the individual-level average of wealth from 1999-2007 and use this in our analyses. This measure correlates roughly 0.95 with annual wealth, allowing us to avoid some attenuation biases. The descriptive statistics for the index generation are shown in Table B3.

\footnotetext{
${ }^{5}$ This departs from the current convention of taking highest values (i.e., following the occupational maturity hypothesis). Compared to such approach, we observe slightly stronger correlations.

${ }^{6}$ Tax data information is essentially self-reported, but subject to legal responsibility (and possible prosecution for tax fraud). The additional sources cover holdings in banks, insurance companies, and the like, as well as estate registers. This information is not censored. Importantly, all types of estates are rated at their market value (rather than some nominal tax value). What the wealth data do not cover is assets held outside Sweden that are thus not disclosed to the Swedish Tax Authority.
} 
We use each of these variables in rank form. The rank provides a robust metric for intergenerational transmissions (Dahl and DeLeire 2008; Chetty et al. 2014), which reducing the impact of specification and measurement errors (Nybom and Stuhler 2017). For wealth, where skew is extreme, rank provides the most optimal scaling of alternatives (Killewald, Pfeffer and Schachner 2017). The transformation method is inconsequential as estimates using original scales for education and occupation (this makes little sense for wealth) show similar results (e.g., compared Table 1 and Table S1).

The historical church book data contain information about an ancestor's occupation, as written down by the priests (but no other information on SES such as education). These occupational titles have been coded to a Swedish nomenclature and then translated into HISCO (see Leeuwen and Maas 2010). As with much historical data, the text strings that describe occupations are sometimes ambiguous because there was no standard format or nomenclature. There is also a male or husband bias in the text strings, where wives were given their husband's occupation (e.g., farmer's wife). We have prioritized unique information and only use information that refers to a specific person, and disregard information that is indirect (i.e., titles achieved by son/daughter or wife relation). By construction, we get a higher incidence of missing information for females than for males (compare Figure B2 in the web appendix). Since we can encounter multiple information, we take the occupation associated with the highest achieved class position or status score (according to HISCLASS or HISCAM, see below). ${ }^{7}$

We have coded HISCO to the HISCAM status scale (Lambert et al. 2013, version 1.3.1, November 2013). ${ }^{8}$ The HISCAM is a historical version of the CAMSIS scale that ranks occupations based on marriage patterns under some idea of social closure (Prandy and Lambert

\footnotetext{
${ }^{7}$ We have also tested to drop female ancestors as a source of information under the assumption that their occupational information may be less valid as an indicator of the family's status in historical time but this does not change our results (not shown). The analyses uses information from both males and females.

${ }^{8}$ For the HISCAM, we used the universal U2 scheme at http://www.camsis.stir.ac.uk/hiscam/. We take averages of different HISCAM scores when there is more than one observation per individual.
} 
2003). However, this may not be the optimal scale to capture intergenerational processes (Hällsten 2019), but unfortunately, historical versions of the ISEI that we use as an outcome are unavailable. Moreover, Song et al. (2020) discuss that some high-status occupations may become less prestigious over time. The HISCAM assumes a constant occupational score for a given occupation, which may bias multigenerational correlations. This may be particularly the case for agricultural occupations. Therefore we also use an alternative approach. We have also coded HISCO to HISCLASS (Maas and Van Leeuwen 2016), a measure that resembles EGP social class (Erikson and Goldthorpe 1992) with 12 categories. Table B4 shows examples of how HISCO occupations are linked to HISCLASS classes. We will use a modified version HISCLASS to empirically construct an index of ancestors' class position using all observed discrete HISCLASS classes (see section 5.4 below).

Figure B2 shows the proportion of missing occupation information by birth cohort (grouped in periods of ten years) and gender. Although the information is limited before 1750, the amount of missing data is down to approximately 30 percent around 1840 for males. For females, it is never below 40 percent. Even with this high-quality data, we experience a limitation due to missing information that biases estimates, but we employ strategies to reduce this bias as explained below. The historical data cover birth cohorts up until 1930. As some ancestors are rather young (i.e., grandparents and great-grandparents of our youngest index generation cohorts), their occupations are not recorded in the historical data. We therefore used the 1960-1990 census information for complementary occupational information. As these data do not contain HISCO, we used crosswalks from the native ISCO-58/NYK codes to EGP and Microclasses (Jonsson et al. 2009; Erikson, Goldthorpe and Hällsten 2012) to generate close matches to HISCLASS. CAMSIS codes are available for the ISCO-58 in the censuses without crosswalks (Bihagen 2007), allowing us to substitute CAMSIS for the HISCAM when the latter is missing (they have the same mean and variance). This may create less optimal measures for 
parents and grandparents, but as the information in historical data constrains us, we prioritize consistency. Table B5 shows the HISCLASS classes of ancestors by generation and their HISCAM scores. Unsurprisingly, the occupation structure is dominated by farmers and farm laborers. However, there is also great change over time following the industrial transformation in the region. Figure B3 describes the class structure in the historical church book data by birth cohort (grouped in periods of ten years; we have grouped the 12 detailed HISCLASS categories into six broader categories; see Table B4). The class structure changes considerably across our study period, where the share of agricultural occupations declines rapidly at the end of the period and where we see the rise of both manual and service-class occupations. This dynamic is not captured as well by CAMSIS, which has a mean close to 50 for all years, even though variance increases strongly over time. One important limitation in our data (and in HISCO) is that it does not differentiate between farmers of different land wealth. Our sample is dominated by farmers in the historical time; we can separate between land tenure (if they own their land), but not between land size, which varies considerably from larger land owners to close to subsistence farmers. This will cause a measurement error so that we underestimate multigenerational correlations.

\section{Methods}

Our target estimand in this paper is how much variance ancestors, distant and proximate, explain of their descendants' outcomes. Although some of the earlier multigenerational studies were motivated by a conceptual and methodological critique of the Becker and Tomes type of two-generation models (Mare 2011; Stuhler 2012; Clark 2014; Lindahl et al. 2014), new findings have spurred a critical debate regarding the interpretation of multigenerational effects (Solon 2014; Torche and Corvalan 2016; Braun and Stuhler 2018; Breen 2018; Lundberg 2018; Solon 2018; Engzell, Mood and Jonsson 2020). The majority of the literature relies on a vertical 
model that uses measured characteristics of all prior generations and then estimates intergenerational transfers. Here, single observations of an ancestor's SES are more often than not the rule, and they can be seen as more or less erroneous realizations of that ancestor's true SES. The standard method of minimizing these issues by averaging over many repeated observations (Solon 1992), assuming measurement errors to be random, is often not possible because of data limitations. The vertical models are also limited to assessing the variance in outcomes that can be linked to ancestors' observed characteristics.

A new addition in this field is dynastic correlations (Adermon, Lindahl and Palme 2021), an extension of vertical models. The core idea is not only to view single observations of SES in an ancestor's life as a potentially erroneous realization (Solon 1992) but also to view individuals themselves as a potentially erroneous realization from their kinship lineage. Following the standard treatment of classical measurement errors, the latent SES of the kinship lineage can be captured by averaging the characteristics of entire clusters of kin. Adermon, Lindahl and Palme (2021) incorporated horizontal parts of the extended family (parents' siblings and cousins, their spouses, and the spouses' siblings) as well as vertical parts (grandparents). They found the total dynastic persistence to be much higher than estimates from two-generation models, and the horizontal aspect largely drives this. In a similar vein, and closer to the cousin correlation approach, Collado, Ortuño-Ortín and Stuhler (2022) developed a more systemic approach that uses three generations of kin but also extends the kinship network horizontally to cousins and in-law relationships to integrate intergenerational and assortative mating processes. They found that conventional measures based on observable characteristics greatly understated the importance of family background and the extent to which latent advantages correlate between kin. Even sibling correlations, known to be a more comprehensive measure of family background, underestimate latent advantages by about 50 
percent. They also found that a purely genetic transmission model cannot fit their system of kinship correlations.

A smaller portion of the literature instead bypasses much of the measurement problems by using a horizontal model where, for example, cousins within the same generation are compared at the same point in time (Jaeger 2012; Hällsten 2014). Measures of ancestors' statuses taken from dubious-quality sources never enter the model, which is identified with kinship links only. This is a great strength when working with historical data where SES measurement is unavoidably less precise (see discussion below). An advantage compared to vertical models is that horizontal models include persistence both due to observable and unobservable characteristics of ancestors. The horizontal concept of family or kinship background is broad and contains everything shared, including local contexts. This means that e.g., effects of neighborhoods and schools are included in the measure (most likely only for siblings), but most mobility scholars would agree that segregation in neighborhoods and schools are important ways in which a family background helps to reproduce advantage.

Although the cousin correlation framework is a rather new addition in the multigenerational mobility field, it has a stronger heritage in studies within psychology (e.g., Bouchard and McGue 1981) and epidemiology (e.g., Hsueh et al. 2000), and there are also examples of studies that have examined cousin correlations in criminal behavior (Frisell, Lichtenstein and Långström 2011). A potential drawback of the cousin correlation method is that it can be estimated for one lineage only or averaged over several lineages as we do below. Still, the total influence of all lineages is not captured (Hällsten 2014). To some extent this is a matter of perspective: seen from the ancestor, the cousin correlation captures his or her total influence; but seen from the descendant, there are many sets of cousins, each with their potential contribution. For example, the sibling correlation captures the influence of both parents (in nuclear families), but the $1^{\text {st }}$ cousin correlation either captures the maternal or paternal 
grandparents (or their average), not their joint influence. Compared to our estimand that aims at the influence of all ancestors, the cousin correlation is therefore an underestimate of the influence, but likely a small one. ${ }^{9}$ It should be noted that sibling correlations will include a component that stems from siblings mutually affecting each other, whereas this is not the case for the intergenerational correlation. A mutual component is still possible for cousin correlations, even though social interactions between distant cousins will decay strongly by generational distance.

\subsection{Study methodology}

Our target population is the kinship network of descendants and their ancestors living in the Skellefteå and Umeå region. We will use two different methodological approaches: 1), cousin correlations and 2), dynastic correlations as estimators to assess multigenerational persistence, our estimand, in this population. Multigenerational persistence is the share of the variation of an index individual's outcome that is explained by ancestors, separately by ancestor generation. We explain these methods in more detail in the next two sections. Measures based on dynastic correlations, and designs based on surnames (Clark 2014; van Dongen, Eriksson and Dribe 2018), are particularly advantageous if historical measurements of SES involve a large share of measurement errors. This is also the case if cross-sectional measurements of historical occupations poorly reflect social positions in a pre-industrial society. For example, because social status is primarily prescribed by family background, social capital, and community networks or is related to the quantity and quality of land ownership. Measures

\footnotetext{
${ }^{9}$ To scrutinize this issue would require some more advanced statistical analyses or a formal model. One could in principle estimate a multilevel model with cross-classified ancestor random effects, but in reality, such a model is not estimable. We have instead attempted to predict the cousin component (i.e., the predicted random effect the best linear unbiased prediction, BLUP - for ancestor) from separate models for each lineage, assuming lineages are independent. The overlap of lineage effects are very large: combining the independently estimated BLUPs for several different ancestors (e.g., paternal and maternal grandparents or great grandparents) in an outcome regression does not increase $\mathrm{R}^{2}$ substantively compared to only including one of the BLUPs. We therefore believe the underestimation is rather modest.
} 
based on large aggregations of occupations (dynastic correlations), or surnames themselves, are likely measured with relatively smaller measurement errors. Similarly, our horizontal approach (cousin correlations) is powerful if historical SES measurements have low precision, as they rely on highly accurate contemporary measurements of descendants' socioeconomic status.

\subsection{First approach: Cousin correlations}

Figure 2 describes the kinship structure we use to estimate sibling and higher-order cousin correlations. We use a methods-of-moments estimator (e.g., Solon, Page and Duncan 2000) extended to cousins (Hällsten 2014). The methods-of-moments estimator uses the unique pairs of cousins (siblings) sharing an ancestor to estimate pairwise covariance terms in outcomes (omitting pairs sharing an ancestor at a lower level): $\mathrm{Y}_{\text {cousin } \mathrm{i}}{ }^{*} \mathrm{Y}_{\text {cousin } \mathrm{j}}(\mathrm{i} \neq \mathrm{j})$, where $\mathrm{Y}$ is measured in deviation-from-mean form. This pairwise term is summarized, with different weighting schemes to handle linages of different sizes (see Web Appendix, Part E) to generate the covariance, and in turn the cousin correlation (rho = covariance/variance). ${ }^{10}$ Because we cover

\footnotetext{
${ }^{10}$ For siblings, the number of pairs generated by $n$ children are $n(n-1) / 2$, but for cousins this is more complex (depending on how grandchildren are split among children, and so on). We simply generated all pairs of cousin sharing an ancestor. Most sibling correlation estimates now employ a parametric multilevel model estimated with REML (following Mazumder 2008). However, the methods-of-moments estimator method has some advantages in our case. First, as we prefer to analyze outcomes in a rank form that follows a uniform distribution, the method has the advantage, as Jäntti and Jenkins (2015) suggested, of making no formal distributional assumptions (as opposed to parametric multilevel models that assume that random effects are normal). Second, the methods-ofmoments estimator makes is possible to stack cousins from different lineages and estimate a generic cousin correlation, whereas the multilevel method only allows lineage-specific correlations, effectively not making use of all available data (even though we only average, and do not examine the joint impact of lineages). Third, the parametric model would require a complex structure of nested random effects (one for each cousin order). The methods-of-moments estimator only requires that we remove lower order shared relations (e.g., sharing parents for $1^{\text {st }}$ cousin correlations, and sharing parents and grandparents for $2^{\text {nd }}$ cousin correlations etc). A final advantage is that because the level of observation is cousin pairs, we can take relational information into account in sensitivity analyses (e.g., age differences between cousins), which the parametric model does not allow for as easily. One disadvantage is that because we rely on bootstrapped standard errors, the methods-of-moments estimator is has wider standard errors and thus has less statistical power compared to the true (but unknown) standard errors. However, as the unit of analysis is unique relations, this lower power is somewhat counteracted by a large number of relations for higher-order cousins.
} 
large spans of birth cohorts in our index generation, where there is a strong drift in education due to education expansion, and where this drift is unequal across genders because of women's liberalization (taking up education, entering the labor market), we control for this by birth-year interaction dummies and gender in all models. We do this by residualizing our outcome variables on gender $\times$ birth-year fixed effects (this also transforms $Y$ to deviation-from-mean form). We compute bootstrap standard errors, which we cluster on the ancestor who generated the kinship relations. Since the number of pairs per ancestor becomes very large for higher order cousins, we sample among pairs for $4^{\text {th }}$ and $5^{\text {th }}$ cousins to reduce computation burded. In our sampling, we stratify by ancestor and sample 50 or 15 percent, respectively, of pairs that exceed 5 in number per ancestor (to guarantee that all ancestors contribute) for $4^{\text {th }}$ and $5^{\text {th }}$ cousins respectively.

\subsection{Measurement errors, cousin correlations, and Markov iterations}

Lundberg (2018) raised concerns about measurement errors when using cousin correlations to project cousin correlation over generations and evaluate the $1^{\text {st }}$ order Markov assumption. Both siblings and cousins are exposed to the same measurement errors in outcomes, which will then depress both to the same extent if the measurement errors are classical. This will impact the likelihood that the process is a $1^{\text {st }}$ order Markov assumption, as the attenuation bias in sibling correlations will have a proportionally larger effect on the projected cousin correlation iterated from the sibling correlation than the attenuation bias in cousin correlations itself. Lundberg (2018) proposed a simple method to adjust for classical measurement errors by making ad hoc assumptions about the reliability of outcomes. A classical measurement error is a typical suspect when using survey data because test-retest reliability is imperfect, and the attention to measurement error has revolutionized the study of income mobility (e.g., Solon 1992). 
However, the variables in our study are not from self-reports in surveys but are administratively generated. The chief data source for our first outcome measure, education, is administrative school records, with some 30 percent of the information in the oldest cohorts coming from censuses (see Figure B4). Even though census data are essentially self-reported survey data, the vast majority of the information we use does not change in any random way over time. It should also be noted that education itself, being cumulative, is rather time stable. ${ }^{11}$

Our second outcome measure, occupations, comes partly from self-reports in the censuses in 1985 and 1990 and partly from employer reports in the occupation register from 2001-2017. The measurement error properties of this variable have not been studied, but it should contain a greater number of classical errors due to self-reporting and occupations being truly timevarying. It is important to note that occupational volatility is considered low compared to income, even though occupations are not as stable in younger birth cohorts as they were for older cohorts. We have nonetheless used averages of multiple measurements to net out any volatility or classical errors.

Our third outcome variable is wealth. This variable, coming from the wealth register, is also a blend of information: tax records, which are essentially self-reports (but under formal sanctions by the state), and administrative data from banks, insurance companies, and estate registers. The measurement error properties for this composite are unknown to us; however, as wealth holdings will vary over time, we have averaged over the eight years (1999-2007) to remove some of this volatility.

\footnotetext{
${ }^{11}$ Statistics Sweden has rather extensively studied measurement errors in our education measure, as reported in Isacsson (2004). The conclusion is that measurement errors are not near classical, but systematic (for example, constant over- or underestimate, rather than fluctuations). Importantly, Isacsson found that this systematic measurement error's effect on estimates of income returns on education is zero in cross-sectional OLS regressions. This is an indication that our specific systematic measurement errors produce little bias in our case. More importantly, following Isacsson (2004), it is clear that applying corrections for classical measurement errors as in the errors-in-variables framework, which is often routinely done in the mobility literature, for processes where measurement is not classical can lead to over-adjustment bias.
} 
In sum, our approach is to measure outcomes with the highest precision possible, using as much data as possible to net out potential measurement errors, but without making ad hoc adjustments that could do more harm than good if the true measurement error properties are unknown.

\subsection{Second approach: Dynastic correlations}

Figure 3 describes the main idea of dynastic correlations (Adermon, Lindahl and Palme 2021): instead of estimating the correlations between single ancestors and the current generations, we measure the correlation between the entire kinship structure and the current generation. The idea is that we can tap the latent SES of all observed ancestors by averaging across their individual SES values. In our application of dynastic correlations, we take the average of all kin in each past generation (the average of all observed parents, all grandparents, etc.). As opposed to Adermon et al, we do not study any horizontal (in-law) relations, as we want our cousin correlations to generalize more directly to vertical transmission of status.

We construct the SES information of our ancestors through two different approaches (Table B5 shows the data used). First, we use occupational status scores measured using the historical HISCAM version of the CAMSIS status scale. However, compared to other occupational scales, such as prestige (SIOPS) or the status scale ISEI, intergenerational persistence between two generations is estimated to be lower with CAMSIS (Hällsten 2019); thus, we expect our results for the HISCAM to be lower bound. Second, we empirically construct a "kin class scale" by using the ancestors' HISCLASS codes and inferring their relative socioeconomic status by how well they predict the outcomes of offspring many generations later. The idea is to rescale the discrete class categories to the expected levels of the descendants' outcomes (Björklund and Sundström 2006; Hällsten and Pfeffer 2017). This means that we do not assume that status is constant over time (as in the HISCAM), only that 
the HISCLASS grouping is stable over time (compare discussion of status decline in Song et al. 2020).

For each ancestor we can identify in the data, we regress the outcome in our index generation on the ancestor's social class while controlling for the birth year. In this way, we make no assumptions about any structure of correlations between kin with certain relations to our index individuals; this is entirely decided by the data. We take the predicted margins for each class as the expected value that the descendant contributes. This is a continuous measure (although with lumpy distribution), and something that we can average across kin. We then summarize all the non-missing predicted margins of various combinations of ancestors and produce what we denote a "kin class scale." We have used three different approaches to define this occupational scale: by ancestor relation, by ancestor generation, and by type of ancestor generation; we describe this in more detail in Web Appendix D. We choose the last of these schemes, which is conservative (and should be robust). We then take averages of these HISCAM or kin class scale scores separately for each ancestor generation, generating six different measures per approach (from generation -1 to -6). A major advantage of this approach is that we get robust measures of SES by generation across different lineages where we often do not observe all potential ancestors, and this varies systematically by lineage (e.g., some lineages are smaller than others, and others have primarily maternal rather than paternal kin). Our approach also minimizes measurement errors by using a large amount of information for each lineage.

Table D1 shows how these measures correlate across generations. These correlations are far from perfect, suggesting that each generation contributes independent information (also implying substantial mobility across generations in historical times). We also note that the correlations attenuate more strongly for the HISCAM than for the empirical kin class scale, suggesting that it may be more limited for multigenerational transmission. We normalize all the 
measures to mean 0 and standard deviation 1, but for interpretation, we will focus on standardized coefficients equivalent to intergenerational correlations (IGC), but for the multigenerational case (MGC).

Our final analytical step is to correlate the value of each ancestry generation with our youngest index generation, both separately for each ancestor's generation and in a joint model. We do this in a linear regression model, controlling for index generations with birth year interacted with gender. Following Adermon, Lindahl and Palme (2021), we use robust standard errors. We expect our occupational class measure to be imperfect, and thus for the estimates to be subject to (most likely) attenuation bias. As such, we believe these dynastic measures of ancestors' class will provide lower bound estimates of persistence.

\section{Results}

We present our main results in two sections for our two approaches and then proceed with sensitivity analyses. The sensitivity analyses do not invalidate our findings.

\subsection{Cousin correlations}

We begin our analyses with the horizontal perspective and estimate sibling and cousin correlations. Figure 4 shows cousin correlations in education, starting with sibling correlations. We find the $1^{\text {st }}$ cousin correlation in education to be around .13 , but we also estimate the sibling correlation to be around .32. Compared to previous estimates for Sweden, the sibling correlation (Björklund and Jäntti 2012), and $1^{\text {st }}$ cousin correlation (Hällsten 2014) are slightly weaker in our data. This is in line with intergenerational estimates (Brandén 2018) showing weaker correlations in our area in modern time. Still, it may also reflect some homogeneity selectivity (what Solon 1989 refer to as homogeneity bias) as our sample is largely descendants of farmers from a specific region. 
As we would expect, the size of the cousin correlation drops sharply across generations. For $2^{\text {nd }}$ cousins, it is estimated to around .05 and for 3 rd cousins it is .021 . but it remains substantial for $4^{\text {th }}$ cousins where the estimate is .011 and even for $5^{\text {th }}$ cousins where it is 0.005 . All these correlations are statistically significant (the smallest t-value is 12). It should be noted that cousin correlations are of the same dimension as explained variance $\left(\mathrm{R}^{2}\right)$. For example, our coefficient of 0.011 for $4^{\text {th }}$ cousins is comparable to a multigenerational correlation $r$ of 0.10 $\left(.011^{1 / 2}\right)$, and our estimate of .005 for $5^{\text {th }}$ cousins translates to an $r$ of .07 , which is certainly nonnegligible.

We compare our estimated correlations to iterations of the sibling correlation to test whether a $1^{\text {st }}$ order Markov process would fit the data, in which resemblance between distant kin is just a function of transmission of social status between parents and children repeatedly over many generations. We find that all our cousin correlations are substantially higher than this projection. For $3^{\text {rd }}, 4^{\text {th }}$ and $5^{\text {th }}$ cousins, the estimated correlations a twice as high as the projection or more. However, these projections may depend on the point of departure, and we have therefore computed what the sibling correlation would be under a Markov model, based on the different cousin correlations. This is shown in Figure C1 (in the web appendix). All cousin correlations imply stronger sibling correlations than what we observe, and this increases with higher cousin order, and so the rejection of the Markov model is robust.

We can also translate these numbers into substantive differences in education. We use the back-of-the-envelope method of Solon, Page and Duncan (2000, p. 390) that translates the sibling correlation, as an effect of a latent variable, into shifts in the standard deviation of the outcome. Using estimates on (untransformed) years of education displayed in Table S1 (that very similar to those using ranks), we have a sibling correlation of around .32, i.e., the variation in education is more than 3 times as large as the latent kinship factor (1/.32) and the standard deviation is then 1.75 times larger $\left([1 / .32]^{1 / 2}\right)$. One standard deviation change in kinship is 
associated with $1 / 1.75=0.57$ standard deviation changes in years of education. We can translate this into mean differences using the standard deviation of education displayed in Table B3 in the web appendix: the SD is 2.47 (with a mean of 12.66). One standard deviation (out of essentially four possible) change in the latent kinship factor is associated with 1.41 more years of education $\left(2.47^{*} 0.57\right)$. Using this calculation, we find that one SD of the latent $1^{\text {st }}$ cousin factor increases education by 0.88 years, the $2^{\text {nd }}$ cousin factor gives 0.55 more years, and the $3^{\text {rd }}$ and $4^{\text {th }}$ cousin factors give 0.36 and 0.26 more years respectively. The $5^{\text {th }}$ cousin correlation translates to .17 more years of education. Would we use the translation offered by Duncan and Raudenbush (1999, p. 33), the effect sizes corresponding to our ICCs would be even larger. ${ }^{12}$ Even though these calculations are only indicative at best, they suggest kinship to have a substantial bearing on inequality.

How do these results apply to occupation and wealth? Table 1 displays the results for education and adds occupation and wealth. For occupation, the correlations are marginally smaller, for example, the $1^{\text {st }}$ cousin correlation is now .114, and the $3^{\text {rd }}$ is .020 . However, the same conclusion that the $1^{\text {st }}$ order Markov process does not fit the data still holds as observed correlations are higher than the iterated sibling correlation. Hence, both outcomes that have a strong relation to skills in the labor market come out similarly. For wealth, we can see different results. While the sibling correlation is similar in magnitude, there is a strong difference between the sibling correlation, on the one hand, and all the cousin correlations, on the other. The cousin correlations follow the same decay pattern as before but are smaller in magnitude compared to the sibling correlation.

This means that the multigenerational part is weaker, but kin close to the index kin matter as much as for other outcomes. Still, the $5^{\text {th }}$ cousin correlation in wealth is very similar to

\footnotetext{
${ }^{12}$ They use that for two equal sized experimental groups, ICC $=\mathrm{R}^{2}=\mathrm{d}^{2}\left(\mathrm{~d}^{2}+4\right)$, where $\mathrm{d}$ is the SD difference in group means (effect). Solving for $d$ yields $d=\left[-4 R^{2} /\left(R^{2}-1\right)\right]^{1 / 2}$, and with a sibling correlation of .32 , we get $d=1.38$ and a difference of 3.42 years of education $(1.38 * 2.47)$ instead of 1.41 .
} 
education and occupation. Iterating from the sibling correlations, the projection from a $1^{\text {st }}$ order Markov model now provides better fit for $1^{\text {st }}$ cousins, but then the observed correlations are larger than the projection. Taking into consideration that wealth stems from a different process and is generated more by direct inheritance and less from labor market activities, the results are remarkably similar rather than different.

Still, we find statistically significant $5^{\text {th }}$ cousin correlations of very similar magnitude across all outcomes (.004 to .005, with t-values between 9 and 12). All in all, these results suggest that within our local sample, inequality tends to persist across five generations with a more complex transmission mechanism than simple parents-child transfer.

\subsection{Heterogeneity by ancestor position}

In Figure 5 and Table S2, we estimate cousin correlation separately by ancestors' class positions. We have used the class position of the cousin base, i.e., the ancestor that is the shared ancestor of the cousins. We have given priority to information of the male person, but used information on the female spouse if information is missing (e.g. using information on a maternal grandfather and if missing a maternal grandmother). We code HISCLASS classes into five groups: Farm, Service, Skilled, Lower/Unskilled, and Upper using the collapsed scheme of Table B4 (we group lower/unskilled together ignoring the farm distinction). Because we are most interested in the long term impact, we zoom in on $2^{\text {nd }}$ to $5^{\text {th }}$ cousin in Figure 5 (Table F1 in the web appendix provides info also for siblings and $1^{\text {st }}$ cousins).

For all cousin orders, , we find strikingly larger correlations for those descending from Upperclass positions (the correlation is larger because of larger covariance; the variance is rather stable across categories, see Table F5 in web appendix). The size of the higher correlation in the Upper category almost compares to going up one generation, e.g., the 3rd cousin correlation of Upper is similar to the 2nd cousin correlation for the rest of the ancestor 
classes. for $5^{\text {th }}$ cousins, the Upper category stand out very much in relative terms. Moreover, for $2^{\text {nd }}$ and $3^{\text {rd }}$ cousins, farm stand out for having lower correlations, but this is not the case for higher-order cousins. In sum, it seems that farm descendants, if anything, have lower cousin correlations. This is important because it suggests that we can then rule out the whole persistence process being merely about the farm versus non-farm divide.

\subsection{Dynastic correlations}

We then shift to a vertical perspective and estimate dynastic correlations. First, we estimate models between our index generation and each ancestor generation separately to quantify gross persistence over many generations. Second, we include all generations simultaneously in order to estimate the net contributions of each generation. Figure 6 shows dynastic correlations for education both estimated from the average HISCAM and our constructed kin class scale (see section 5.4 above). The full regression output results are displayed in Table D2, and Web Appendix D contains additional discussion regarding different specifications of our dynastic correlation approach.

In Figure 6, the first estimate (-1 generations back, for parents) comes from a (separate) regression of the index generation's education rank on parents' average occupational characteristics, the second estimate ( -2 generations back) comes from a regression on grandparents' occupational characteristics, and so on. We focus on the standardized coefficient, i.e., the intergenerational correlation, IGC $(b *[\mathrm{SD}(\mathrm{X}) / \mathrm{SD}(\mathrm{Y})])$ but apply this for the multigenerational case. We denote this multigenerational correlation, MGC. The results for parents reveal that the estimates are lower than what has been found in prior literature, especially for the HISCAM (even though the current estimates are a hybrid across SES dimensions, descendants' education on ancestors' occupations, this also holds for HISCAM- 
on-HISCAM analysis). ${ }^{13}$ Thus, it seems that the HISCAM fails to fully capture the persistence across generations. Even the better fitting constructed kin class scale may not be fully optimal, but this is a trade-off to have one consistent measure for all generations. Nonetheless, for both scales, the results strongly reject the $1^{\text {st }}$ order Markov model. We generally find that the kin class scale achieves stronger dynastic correlation than the HISCAM, but otherwise, the patterns are remarkably similar, with only weak decay in the more distant generations. With the HISCAM, we find that the point estimate is more stable for the last generation of ancestors than the preceding one. This lack of decay is likely an effect of more effectively reducing measurement (or realization) errors by averaging across a fast-growing number of ancestor kin for each prior generation.

Table 2 summarizes our findings and includes estimates for occupation and wealth (essentially summarizing the model structure from Table C2). The first column again displays the MGC (and the second column its standard error). For reference, the third column presents the addition in $\mathrm{R}^{2}$ compared to an empty model, which is very close to the square root of the MGC, and the fourth and fifth columns display $\mathrm{R}^{2}$ and the number of observations for reference. ${ }^{14}$ The first row shows an empty model for comparison, followed by separate regressions by generation on the following five rows. We find somewhat stronger correlations for occupation, which may not be surprising given that occupation is both dependent and independent variable. For wealth, the dynastic correlations are generally weaker, which is mainly because the grandparental correlation is weaker. However, for the more distant kin, the correlations are very similar across the three outcome measures. When we compare the results

\footnotetext{
${ }^{13}$ Björklund and Jäntti (2012) estimated the father-daughter correlation in education to be around $0.33\left(0.11^{1 / 2}\right)$ and the father-son correlation to be $0.39\left(0.15^{1 / 2}\right)$ for individuals born from 1951-1967 (see Table 4). The parent-child correlation in CAMSIS for individuals born from 1956-1982 is estimated to be 0.31 (Hällsten 2019).

${ }^{14}$ We note that there are some differences between $\mathrm{R}^{2}$ and $\Delta \mathrm{R}^{2}$ to the multigenerational correlations derived from b-coefficients, which is an indication of homogeneity biases (Solon 1989). We therefore do not focus much on $R^{2}$ and $\Delta \mathrm{R}^{2}$.
} 
to cousin correlations, the main difference is for wealth and for proximate kin. With cousin correlations, we found relatively strong $1^{\text {st }}$ cousin correlation (i.e., reflecting grandparents), but with dynastic correlations, the grandparent correlations are relatively weaker. We speculate that this is because occupation and class are more generic stratification markers in historic time (and strongly linked to wealth) while they are more exclusively linked to labor market inequality in modern time and less to wealth (cf. Hällsten and Thaning 2021). For wealth, we also find a larger discrepancy between the HISCAM and the kin class scale optimized for wealth; the HISCAM captures a smaller part of the association from the empirical scale.

We also estimate a higher-order Markov model for education by including all generations (-1 to -6$)$ jointly in the same regression; i.e., an AR(6) model. The results for education are shown in Figure S1 (Model 8 in Table D2). The dynastic correlations for each of the generations are now mutually controlled. All generations have substantially weak but significant contributions, except for generation -5 in the HISCAM specification, and generation -6 in the kin class scale, meaning that the model provides some acceptable fit to the data (in alternative specifications of the kin class scale, generation -6 turns out positive; see Web Appendix Part D, Figures D1 and D2). However, the difference between parents and later generations is substantial: the estimates for the middle generations are much lower, meaning that parents contain most of the information from these past generations, a conclusion similar to that of Björklund and Jäntti (2020), Engzell, Mood and Jonsson (2020) and Lundberg (2020). Nonetheless, the sum of the MGC for each separate generation is the total dynastic correlation (Adermon, Lindahl and Palme 2021). The final row of Table 2 shows the sum of the MGC coefficient in the joint specification. This figure is very similar for education and occupation, at above 0.40 with the kinship scale and 0.36 to 0.38 with the HISCAM. For wealth, the total dynastic correlation is lower $(0.18-0.25)$. When we compare the total dynastic correlation with the parental correlation, we find that it is substantially larger, similar to Adermon et al (2019). 
For wealth, where the parent association is rather weak, the total dynastic correlation is up to twice as high. To sum up our findings, even though the level of inequality transmitted over generations is generally low, it is persistent over generations, and a two-generation parent-child model underestimates this persistence. Even though wealth is less connected to education and occupation, the similarity in results in all three outcomes for distant kinship are striking.

\subsection{Sensitivity analyses}

We have conducted a number of sensitivity analyses, as shown in Web Appendices D to H to address heterogeneity of our estimates (differences across subgroups), population selectivity (how different features of our population influence our estimates) and bias (how our sample estimates are representative of the population).

Our study design spans an immense sociocultural transformation over the $19^{\text {th }}$ and $20^{\text {th }}$ centuries. In Web Appendix D, we examine the assumption of the dynastic correlation approach (Adermon, Lindahl and Palme 2021), namely that averaging over ancestor will increase the signal-to-noise ratio and capture latent SES, holds up empirically. We have variation in the number of ancestors we observe, and we find that the multigenerational correlations are stronger the more ancestors we average over. Historical occupational measures provide social status measurement with relatively high imprecision, and the more ancestors you average over, the more is measurement error reduced and the signal-to-noise ratio improved. Using dynastic correlation methods is thus an advantage for analyzing multigenerational transmission for historical data. This also suggests that our main estimates presented above may be underestimating persistence.

Also in Appendix D, we examine how the intergenerational parent-child correlation has changed across generations (as estimated by averages by generations, using the scales for our dynastic correlation approach). To understand long-range social mobility across five or more 
generations, it is helpful to understand how parent-child status transmissions have changed over time, as multigenerational resemblance is shaped by multiple correlations in this realm. We find the intergenerational correlations to be remarkably stable (typically around 0.3 , ranging from $0.2-0.35$ ) when using both the observed occupational class (CAMSIS) and a kin class scale approach. In Web Appendix E, we examine the impact of the size of the kinship network and conclude that size is not a strong driver of the cousin correlations we observe. We examine heterogeneity in cousin correlations in Web Appendix F. We find that cousin correlations are somewhat stronger along maternal lineages, but not stronger among strictly paternal lineages, suggesting that inheritance (surnames, and to a lesser extent wealth) from father-to-son is not driving our results. . We also find that cousin correlation are somewhat stronger among men and weaker among women (despite gender having been residualized) and mixed-gender cousins. In another analysis, we also find that there is some substantial variation in sibling correlations by age for individuals in our index generation, yet for cousins of any order, there is not any clear pattern. In the web appendix, we also provide a methodological discussion of our analyses of cousin correlations split by ancestor's class.

In Web Appendix G, we examine the impact of kin marriage by a sensitivity analysis where we discard the $1 / 3$ of the kinship networks where any cousin marriage is prevalent, but the results are virtually unchanged (see Web Appendix G). We therefore argue that cousin or kin marriages are unlikely to drive our main findings. In Web Appendix $\mathrm{H}$, we address selectivity by comparing our local Northern population to a Swedish reference population. We find that our locale does not deviate much from the reference in terms of education, occupation, and wealth, and we generally find lower persistence in our local sample than in the population, indicating that our estimates are likely to be lower bound compared to the rest of Sweden.

The main source of bias with reference to our target population is (selective) outmigration. In Web Appendix I, we analyze migration patterns in historical times. We find that our local 
sample is influenced by selective migration biased toward ancestors being farmers and ancestors who were residentially stable for other reasons. In order to assess the impact of selective outmigration, we conduct a simple simulation of multigenerational correlations where sample truncation occurs selectively based on intermediary generations' outcome levels (so that we remove an entire kinship if G2 and/or G3 have high SES) in part J. This reveals that multigenerational correlations attenuate with such positive selectivity. Our simulation is based on the premise that as a strategy for upward mobility, high-status individuals are more likely to outmigrate. We underestimate rather than overestimate true dynastic or cousin correlations with such a scenario. In part K, we address whether our kinship effects may reflect geographical clustering. While this is an intriguing question of causality, and we lack data to properly evaluate this (since neither kinship nor location is exogenous), we find that our estimated kinship effects exist beyond geographical clustering, so our finding cannot be reduced to geography in disguise.

\section{Discussion}

Our findings suggest that prior generations may structure life chances more than 200 years later. Distant family members - even if they are not necessarily aware of each other's existenceshow much more resemblance than expected from a simple sequential transmission from parents to children.. At the same time, the role of ancestors is small overall, and mobility far outweighs persistence. The highest long-term transmission of inequality we have estimated is for descendants' education, where the $4^{\text {th }}$ cousin correlation (including unobserved factors) of 0.011 would amount to a multigenerational correlation of $0.10\left(0.011^{1 / 2}\right)$, and the dynastic correlation (only including observed occupations) for generation -6 is 0.031 (HISCAM) or .036 (our kin class scale). This may still be seen as substantive transmission, given how far it has traveled, yet mobility strongly dominates over persistence. However, we also observe more 
substantial persistence at the top. For descendants of ancestors with advantaged class positions, long-term persistence is much stronger (the $3 \mathrm{rd}$ cousin correlation of $.047 \mathrm{in}$ this group, see Table S2, which would amount to a multigenerational correlation of .22 over five generations). This suggests that social peristence is larger at top of society, something that a few prior studies have found for two and three generations (Björklund, Roine and Waldenström 2012; Hällsten 2014), but which we know can generalize to many more generations.

We also find that the results for occupation closely resemble those for education, whereas wealth, not surprisingly, is slightly different. This is due mainly to mobility patterns in proximate generations. However, when we focus on the role of more distant kinship, the similarity in persistence is very striking. It is interesting to note that, similar to several current studies, the persistence rate across generations beyond grandparents is rather stable and incompatible with a first-order (parent-child) Markov process. However, even though we can fit up to a sixth-order Markov model with the dynastic correlations approach (i.e., with generational lags under mutual control), the direct associations from more distant generations are small and do not contribute much more inequality than what already resides in parental and grandparental coefficients. Taken together, these findings suggest the following: (a) most transmissions in the eldest generations are sequential from generation to generation, but what is transferred remains mostly intact rather than decaying; and (b) what is transferred is only a partial explanation of life chances within that generation. This is close to the latent factor model of Clark and Cummins (2014) and Braun and Stuhler (2018), where some endowment is transferred across generations and then translated into inequality within that generation. In their model, high multigenerational correlations will exist without the existence of transfers that skip a generation. The important point here is that the model implies that the transfer of a trait from parents to children is strong and that the translation of the trait into outcomes is weak; this is what creates this persistent pattern. 
Due to the lack of direct social interaction across distant generations, we can rule out any larger direct ancestor effects, but the scope for quasi-direct effects (transfers from parents not originating in parents) is much larger. We may only speculate about this, but physical assets, such as farmland or property, strong norms or skills, or symbolic assets, may be potential explanations. This scenario would also fit with an inheritance of racial or ethnic categories (Torche and Corvalan 2016); that is, something more precisely inherited (depending on closure), and which may structure life chances, but not perfectly so (depending on exclusion and marginalization). ${ }^{15}$ Nonetheless, shifting the perspective to kinship structures as social groups, where social reproduction works at the group level, appears to be a fruitful endeavor, and it should be a future aim to identify more kin group-level characteristics that explain persistence.

Our findings on the long-run persistence of family background are in agreement with increasing attention to discussions of multigenerational effects and a broader conceptualization of family background beyond the influence only of parents (Mare 2011). While mobility in most western countries is high as measured in traditional stratification research, we also observe clear social closure in elite societal positions. We argue that our empirical findings can be interpreted as support for the existence of long-lasting family background effects that may help explain such phenomena. Some aspects of status that may explain our findings are family symbols, cultural capital, and other cultural aspects of family identity that may not be measured in observed parental (or grandparental) characteristics.

Our results are from a society that is often characterized as both mobile and equal. However, if we find clear evidence of long-lasting effects of kinship in a society such as Sweden, this raises the issue of similar or larger effects being found in societies with higher social closure, such as the US. Future research should examine the long shadow of family

\footnotetext{
${ }^{15}$ Although Northern Sweden has an indigenous population of Samis, their prevalence in our region is low (Alm-Stenflo 1994).
} 
backgrounds in societies such as the US with greater income inequality and continental European societies that are characterized by a more rigid class structure, where an entrenched gentry with a monopoly on economic and political power has played a more important historical societal role. Researchers may also want to explore the role to which explicitly kin-oriented social institutions such as family businesses, occupational inheritance (e.g., among medical doctors), the kind of dynastic identities reflected in naming practices such John D Rockerfeller III, or generation-skipping trusts may explain our findings (cf. Mare 2011).

Given the long time period that our kinship networks evolve over, where ancestors experienced the industrial revolution and significant demographic transitions, our findings are also likely contingent on several period effects, given how kinship, the occupational structure, and social mobility have changed over the period (Lee 2003; Song et al. 2020). We want to stress, however, that these changing processes are simply a reflection of the research question we ask. When we examine the influence of great-great-great-grandparents on current life chances, these ancestors will have lived in vastly different circumstances, and any long-run mobility is shaped just as much by social mobility in the late $19^{\text {th }}$ century as by Sweden's contemporary education system. We think our approaches are attractive, as they can detect the extent of resemblances across family members living in a present society without extensive modeling on inter- and multigenerational mobility across dramatically different socioeconomic contexts. Looking for the influence of long-run multigenerational persistence in a society that is unchanging over hundreds of years may be an interesting theoretical exercise through which we may learn about social mobility. Still, it is not empirically reflective of extended family background structures or family chances in an early $21^{\text {st }}$ century industrialized country. Interestingly, to the extent that we can examine intergenerational mobility with our estimates, it appears to be largely stable (Web Appendix D). 
Our data set is local in nature in two ways: it comes from Sweden, which is one of the most egalitarian countries in the world for social mobility and equality of life chances, but our region is also one of the most egalitarian parts of Sweden. A considerable share of agricultural workers owned their own land. Unlike large parts of Europe and Sweden, the extent of "proletarianization" of agriculture (where agricultural workers work without tenure on someone else's land) was low (Alm Stenflo 1994). The region has also been described as having a history of above-average social and cultural capital, reflected in, for example, high literacy (Sörlin 2014). ${ }^{16}$ Our results must be seen in the light of coming from an egalitarian corner of one of the most egalitarian countries in Europe. Finally, measurement errors play an important role in mobility research. With historical data, these problems are even more acute. We have used cousin and dynastic correlations as methodological approaches that handle measurement errors well, but we do not think we have been able to cancel all biases. With more data covering many generations becoming available, it is necessary to use but also to further develop methods than can handle measurement errors in historical data. It may be that reliance on methods grounded in noisy measurements of historical occupations has led researchers of historical stratification to underestimate the role of family background. Our results from dynastic correlations may help reconcile popular and narrative conceptions of historical Europe as consisting of rigid and immobile societies where social status was primarily prescribed at birth with the sometimes surprisingly high measurements of social mobility from stratification research (e.g. Leeuwen and Maas 2010).

\section{References}

Adermon, Adrian, Mikael Lindahl, and Mårten Palme. 2021. "Dynastic human capital, inequality and intergenerational mobility." American Economic Review 111:1523-48.

\footnotetext{
${ }^{16}$ To underline this, we can add that a number of famous authors stem from this specific region: PO Enqvist, Stieg Larsson (known for the bestselling Millennium trilogy), Stig Larsson (a different one), Sara Lidman, Torgny Lindgren, and Nikanor Teratologen.
} 
Adermon, Adrian, Mikael Lindahl, and Daniel Waldenström. 2018. "Intergenerational wealth mobility and the role of inheritance: Evidence from multiple generations." The Economic Journal 128:F482-F513.

Alm Stenflo, Gun 1994. Demographic description of the Skelleftea and Sundsvall regions during the 19th century: Univ., Demografiska databasen.

Anderson, Lewis R., Paula Sheppard, and Christiaan W.S. Monden. 2018. "Grandparent effects on educational outcomes: a systematic review." Sociological Science 5:114142.

Barone, Guglielmo, and Sauro Mocetti. 2016. "Intergenerational mobility in the very long run: Florence 1427-2011." Bank of Italy Temi di Discussione (Working Paper) No. 1060.

Becker, Gary S., and Nigel Tomes. 1986. "Human Capital and the Rise and Fall of Families." Journal of Labor Economics 4:1.

Bengtsson, Tommy, Martin Dribe, and Patrick Svensson. 2012. "The Scanian Economic Demographic Database Version 3.0 (Machine-readable database).". Lund: Lund University, Centre for Economic Demography.

Berger, Thor, Per Engzell, Björn Eriksson, and Jakob Molinder. 2021. "Social Mobility in Sweden Before the Welfare State." SocArxiv https:/osf.io/preprints/socarxiv/ebmva/.

Bihagen, Erik. 2007. "Nya möjligheter för stratifieringsforskning i Sverige: Internationella yrkesklassificeringar och stratifieringsmått över tid [New opportunities for social stratification research in Sweden: International occupational classifications and stratification measures over time]." Sociologisk Forskning 44:52-67.

Bittles, Alan H., and Inez Egerbladh. 2005. "The Influence of Past Endogamy and Consanguinity on Genetic Disorders in Northern Sweden." Annals of Human Genetics 69:549-558.

Björklund, Anders, and Markus Jäntti. 2012. "How important is family background for laboreconomic outcomes?" Labour Economics 19:465-474.

—. 2020. "Intergenerational mobility, intergenerational effects, sibling correlations, and equality of opportunity: a comparison of four approaches." Research in Social Stratification and Mobility In Press, Corrected Proof.

Björklund, Anders, Jesper Roine, and Daniel Waldenström. 2012. "Intergenerational top income mobility in Sweden: Capitalist dynasties in the land of equal opportunity?" Journal of Public Economics 96:474-484.

Björklund, Anders, and Marianne Sundström. 2006. "Parental Separation and Children's Educational Attainment: A Siblings Analysis on Swedish Register Data." Economica 73:605-624.

Blanden, Jo. 2013. "Cross-country rankings in intergenerational mobility: a comparison of approaches from economics and sociology." Journal of Economic Surveys 27:38-73.

Bouchard, Thomas J., and Matt McGue. 1981. "Familial studies of intelligence: a review." Science 212:1055-1059.

Brandén, Gunnar. 2018. "Paper I. Does inequality reduce mobility? The Great Gatsby Curve and its mechanisms." Dissertation, Department of Economics, Uppsala University.

Braun, Sebastian Till, and Jan Stuhler. 2018. "The Transmission of Inequality Across Multiple Generations: Testing Recent Theories with Evidence from Germany." The Economic Journal 128:576-611.

Breen, Richard. 2010. "Educational Expansion and Social Mobility in the 20th Century." Social Forces 89:365-388.

—. 2018. "Some Methodological Problems in the Study of Multigenerational Mobility." European Sociological Review 34:603-611. 
Campbell, Cameron, and James Z Lee. 2011. "Kinship and the long-term persistence of inequality in Liaoning, China, 1749-2005." Chinese Sociological Review 44:71-103.

Chadwick, Laura, and Gary Solon. 2002. "Intergenerational Income Mobility among Daughters." The American Economic Review 92:335-344.

Chetty, Raj, Nathaniel Hendren, Patrick Kline, and Emmanuel Saez. 2014. "Where is the land of Opportunity? The Geography of Intergenerational Mobility in the United States." The Quarterly Journal of Economics 129:1553-1623.

Clark, Gregory. 2014. The son also rises: Surnames and the history of social mobility: Princeton University Press.

Clark, Gregory, and Neil Cummins. 2014. "Intergenerational Wealth Mobility in England, 1858-2012: Surnames and Social Mobility." The Economic Journal 125:61-85.

Cole, Stephen R., and Miguel A. Hernán. 2008. "Constructing Inverse Probability Weights for Marginal Structural Models." American Journal of Epidemiology 168:656-664.

Collado, M. Dolores , Ignacio Ortuño-Ortín, and Jan Stuhler. 2022. "Estimating Intergenerational and Assortative Processes in Extended Family Data." https://janstuhler.files.wordpress.com/2022/02/manucript_v44_paper.pdf.

Cox, Donald, and Marcel Fafchamps. 2007. "Chapter 58 Extended Family and Kinship Networks: Economic Insights and Evolutionary Directions." Pp. 3711-3784 in Handbook of Development Economics, edited by T. Paul Schultz and John A. Strauss: Elsevier.

Dackling, Martin. 2013. Släktgårdens uppkomst: jord och marknad i Skaraborg 1845-1945. Göteborg: Institutionen för historiska studier, Göteborgs universitet.

Dahl, Molly W, and Thomas DeLeire. 2008. The association between children's earnings and fathers' lifetime earnings: estimates using administrative data: University of Wisconsin-Madison, Institute for Research on Poverty, Discussion Paper No. 1342-08.

Domingue, Benjamin W., Jason Fletcher, Dalton Conley, and Jason D. Boardman. 2014. "Genetic and educational assortative mating among US adults." Proceedings of the National Academy of Sciences 111:7996-8000.

Dribe, Martin, and Jonas Helgertz. 2016. "The lasting impact of grandfathers: class, occupational status, and earnings over three generations in Sweden 1815-2011." The Journal of Economic History 76:969-1000.

Dribe, Martin, Jonas Helgertz, and Bart Van de Putte. 2015. "Did social mobility increase during the industrialization process? A micro-level study of a transforming community in southern Sweden 1828-1968." Research in Social Stratification and Mobility 41:25-39.

Duncan, Greg J., and Stephen W. Raudenbush. 1999. "Assesing the effects of context in studies of child and youth development." Educational Psychologist 34:29 - 41.

Edvinsson, S. 2000. "The Demographic Data Base at Umeå University—a resource for historical studies." Handbook of international historical microdata for population research:231-248.

Egerbladh, Inez, and Alan H. Bittles. 2011. "Socioeconomic, demographic and legal influences on consanguinity and kinship in northern coastal sweden 1780-1899." Journal of Biosocial Science 43:413-435.

Elwert, Felix, and Christopher Winship. 2014. "Endogenous Selection Bias: The Problem of Conditioning on a Collider Variable." Annual Review of Sociology 40:31-53.

Engzell, Per, Carina Mood, and Jan O Jonsson. 2020. "It's All about the Parents: Inequality Transmission across Three Generations in Sweden." Sociological Science June 1, 2020.

Erikson, Robert, and John H. Goldthorpe. 1992. The Constant Flux: A Study of Class Mobility in Industrial Societies. Oxford: Clarendon Press. 
Erikson, Robert, John H. Goldthorpe, and Martin Hällsten. 2012. "No way back up from ratcheting down? A critique of the 'microclass' approach to the analysis of social mobility." Acta Sociologica 55:211-229.

Eriksson, Karin Hederos, Randi Hjalmarsson, Matthew J. Lindquist, and Anna Sandberg. 2016. "The importance of family background and neighborhood effects as determinants of crime." Journal of Population Economics 29:219-262.

Euler, Harald A. 2011. "Grandparents and extended kin." Pp. 181-210 in The Oxford handbook of evolutionary family psychology. Oxford University Press, New York, edited by Catherine Salmon and Todd K. Shackelford.

Feinstein, Brian D. 2010. "The Dynasty Advantage: Family Ties in Congressional Elections." Legislative Studies Quarterly 35:571-598.

Frisell, Thomas, Paul Lichtenstein, and Niklas Långström. 2011. "Violent crime runs in families: a total population study of 12.5 million individuals." Psychological Medicine 41:97-105.

Ganzeboom, Harry B. G., Paul M. De Graaf, and Donald J. Treiman. 1992. "A standard international socio-economic index of occupational status." Social Science Research $21: 1-56$

Ganzeboom, Harry B.G., and Donald J. Treiman. 1996. "International Stratification and Mobility File: Conversion Tools." http://www.harryganzeboom.nl/ISMF/index.htm, last accessed 2020-04-06.

Hodge, Robert W. 1966. "Occupational mobility as a probability process." Demography 3:1934.

Hsueh, W C, B D Mitchell, R Aburomia, T Pollin, H Sakul, M Gelder Ehm, ... A R Shuldiner. 2000. "Diabetes in the Old Order Amish: characterization and heritability analysis of the Amish Family Diabetes Study." Diabetes Care 23:595-601.

Hällsten, Martin. 2014. "Inequality across three and four generations in Egalitarian Sweden: 1st and 2nd cousin correlations in socio-economic outcomes." Research in Social Stratification and Mobility 35:19-33.

—. 2019. "Scaling Occupations in Intergenerational Research - An evaluation with Swedish register data." Socarxiv https://osf.io/preprints/socarxiv/uxy9q/.

Hällsten, Martin, and Fabian T. Pfeffer. 2017. "Grand Advantage. Family Wealth and Grandchildren's Educational Achievement in Sweden." American Sociological Review 82:328-360.

Hällsten, Martin, and Max Thaning. 2021. "Wealth as One of the "Big Four" SES Dimensions in Intergenerational Transmissions." Social Forces Forthcoming.

Isacsson, Gunnar. 2004. "Estimating the economic return to educational levels using data on twins." Journal of Applied Econometrics 19:99-119.

Jaeger, Mads Meier. 2012. "The Extended Family and Children's Educational Success." American Sociological Review 77:903-922.

Jonsson, Jan O., David B. Grusky, Matthew Di Carlo, Reinhard Pollak, and Mary C. Brinton. 2009. "Micro-class Mobility: Social Reproduction in Four Countries." American Journal of Sociology 114:977-1036.

Jäntti, Markus, Bernt Bratsberg, Knut Roed, Oddbjorn Raaum, Robin Naylor, Eva Österbacka, ... Tor Eriksson. 2006. "American exceptionalism in a new light: a comparison of intergenerational earnings mobility in the Nordic countries, the United Kingdom and the United States." in IZA DP No. 1938.

Jäntti, Markus, and Stephen P. Jenkins. 2015. "Chapter 10 - Income Mobility." Pp. 807-935 in Handbook of Income Distribution, edited by Anthony B. Atkinson and François Bourguignon: Elsevier. 
Kelley, Jonathan. 1973. "Causal Chain Models for the Socioeconomic Career." American Sociological Review 38:481-493.

Killewald, Alexandra, Fabian T. Pfeffer, and Jared Schachner. 2017. "Wealth Inequality and Accumulation." Annual Review of Sociology 43:379-404.

Knigge, Antonie. 2016. "Beyond the parental generation: The influence of grandfathers and great-grandfathers on status attainment." Demography 53:1219-1244.

Kolk, Martin, and Martin Hällsten. 2017. "Demographic and Educational Success of Lineages in Northern Sweden." Population and Development Review 43:491-512.

Kolk, Martin, and Vegard Skirbekk. 2019. "Fading Family Lines - Women and Men without Children, Grandchildren and Great-grantchildren in 19th, 20th, and 21st Century Northern Sweden." Stockholm Research Reports in Demography 2019:24.

Kotlikoff, Laurence J., and Lawrence H. Summers. 1981. "The Role of Intergenerational Transfers in Aggregate Capital Accumulation." Journal of Political Economy 89:706732.

Kuusela, Hanna. 2018. "Learning to own: Cross-generational meanings of wealth and classmaking in wealthy Finnish families." The Sociological Review 66:1161-1176.

Laband, David N., and Bernard F. Lentz. 1985. "Favorite sons: intergenerational wealth transfers among politicians." Economic Inquiry 23:395-414.

Lambert, Paul S., Richard L. Zijdeman, Marco H. D. Van Leeuwen, Ineke Maas, and Kenneth Prandy. 2013. "The Construction of HISCAM: A Stratification Scale Based on Social Interactions for Historical Comparative Research." Historical Methods: A Journal of Quantitative and Interdisciplinary History 46:77-89.

Lee, Ronald. 2003. "The Demographic Transition: Three Centuries of Fundamental Change." Journal of Economic Perspectives 17:167-190.

Leeuwen, Marco H.D. van, and Ineke Maas. 2010. "Historical Studies of Social Mobility and Stratification." Annual Review of Sociology 36:429-451.

Lindahl, Mikael, Mårten Palme, Sofia Sandgren Massih, and Anna Sjögren. 2015. "LongTerm Intergenerational Persistence of Human Capital: An Empirical Analysis of Four Generations." Journal of Human Resources 50:1-33.

Lindahl, Mikael, Mårten Palme, Sofia Sandgren-Massih, and Anna Sjögren. 2014. "A Test of the Becker-Tomes Model of Human Capital Transmission Using Microdata on Four Generations." Journal of Human Capital 8:80-96.

Long, Jason, and Joseph Ferrie. 2018. "Grandfathers Matter(ed): Occupational Mobility Across Three Generations in the US and Britain, 1850-1911." The Economic Journal 128:F422-F445.

Lundberg, Ian. 2018. "Measuring Multigenerational Mobility: What Can we Learn from Cousin Correlations." Princeton, NJ: Office of Population Research.

—. 2020. "Does Opportunity Skip Generations? Reassessing Evidence From Sibling and Cousin Correlations." Demography 57:1193-1213.

Maas, Ineke, and Marco Van Leeuwen. 2016. "HISCLASS." https://hdl.handle.net/10622/HEFSW2, IISH Data Collection, V1.

Mare, Robert. 2011. "A Multigenerational View of Inequality." Demography 48:1-23.

Mare, Robert D., and Xi Song. 2014. "Social mobility in multiple generations." California Center for Population Research, On-Line Working Paper Series No. 14-2014.

Masulis, Ronald W., Peter Kien Pham, and Jason Zein. 2011. "Family Business Groups around the World: Financing Advantages, Control Motivations, and Organizational Choices." The Review of Financial Studies 24:3556-3600.

Mazumder, Bhashkar. 2008. "Sibling similarities and economic inequality in the US." Journal of Population Economics 21:685-701. 
Modalsli, Jørgen. 2016. "Multigenerational persistence: Evidence from 146 years of administrative data." Statistics Norway Research department, Discussion Papers, No. 850 .

—. 2017. "Intergenerational Mobility in Norway, 1865-2011." The Scandinavian Journal of Economics 119:34-71.

Modin, Bitte, Robert Erikson, and Denny Vågerö. 2013. "Intergenerational Continuity in School Performance: Do Grandparents Matter?" European Sociological Review 29:858-870.

Nybom, Martin, and Jan Stuhler. 2017. "Biases in standard measures of intergenerational income dependence." Journal of Human Resources 52:800-825.

Prandy, Kenneth, and Paul Lambert. 2003. "Marriage, Social Distance and the Social Space::An Alternative Derivation and Validation of the Cambridge Scale." Sociology 37:397-411.

Ridge, John M. 1974. Mobility in Britain reconsidered: Clarendon Press.

Robins, James M., Miguel A. Hernán, and Babette Brumback. 2000. "Marginal Structural Models and Causal Inference in Epidemiology." Epidemiology 11:550-560.

Robinson, Matthew R., Aaron Kleinman, Mariaelisa Graff, Anna A. E. Vinkhuyzen, David Couper, Michael B. Miller, . . consortium Genetic Investigation of Anthropometric Traits. 2017. "Genetic evidence of assortative mating in humans." Nature Human Behaviour 1:0016.

Rosenthal, Carolyn J. 1985. "Kinkeeping in the Familial Division of Labor." Journal of Marriage and Family 47:965-974.

Schaeffer, Merlin. 2014. "The Social Meaning of Inherited Financial Assets. Moral Ambivalences of Intergenerational Transfers." Historical Social Research / Historische Sozialforschung 39:289-317.

Sharkey, Patrick, and Felix Elwert. 2011. "The Legacy of Disadvantage: Multigenerational Neighborhood Effects on Cognitive Ability." American Journal of Sociology 116:1934-81.

Solon, Gary. 1989. "Biases in the Estimation of Intergenerational Earnings Correlations." The Review of Economics and Statistics 71:172-174.

—. 1992. "Intergenerational Income Mobility in the United States." The American Economic Review 82:393-408.

—. 2014. "Theoretical models of inequality transmission across multiple generations." Research in Social Stratification and Mobility 35:13-18.

—. 2018. "What Do We Know So Far about Multigenerational Mobility?" The Economic Journal 128:F340-F352.

Solon, Gary, Marianne E. Page, and Greg J. Duncan. 2000. "Correlations between Neighboring Children in Their Subsequent Educational Attainment." The Review of Economics and Statistics 82:383-392.

Song, Xi. 2020. "Multigenerational Social Mobility: A Demographic Approach." University of Pennsylvania Population Center Working Paper (PSC/PARC), 2020-52. .

Song, Xi, and Cameron D Campbell. 2017. "Genealogical microdata and their significance for social science." Annual Review of Sociology 43:75-99.

Song, Xi, Cameron D. Campbell, and James Z. Lee. 2015. "Ancestry Matters: Patrilineage Growth and Extinction." American Sociological Review 80:574-602.

Song, Xi, Catherine G. Massey, Karen A. Rolf, Joseph P. Ferrie, Jonathan L. Rothbaum, and Yu Xie. 2020. "Long-term decline in intergenerational mobility in the United States since the 1850s." Proceedings of the National Academy of Sciences 117:251-258.

Stuhler, Jan. 2012. "Mobility Across Multiple Generations: The Iterated Regression Fallacy." IZA Working Paper 7072. 
Sörlin, Sverker. 2014. Pianona i Västerbotten: det politiska och politikens platser: Premiss förlag.

Torche, Florencia, and Alejandro Corvalan. 2016. "Estimating Intergenerational Mobility With Grouped Data: A Critique of Clark's the Son Also Rises." Sociological Methods \& Research 47:787-811

van Dongen, Elien, Björn Eriksson, and Martin Dribe. 2018. "Does Anders' Son Also Rise? Class Heterogeneity in Intergenerational Occupational Persistence during Swedish Industrialization." Paper presented at the 2018 PAA meeting, April 26-28 Denver.

Warren, John Robert, and Robert M. Hauser. 1997. "Social Stratification across Three Generations: New Evidence from the Wisconsin Longitudinal Study." American Sociological Review 62:561-572.

Westberg, Annika, Elisabeth Engberg, and Sören Edvinsson. 2016. "A unique source for innovative longitudinal research: The POPLINK database." Historical Life Course Studies 3:20-31.

Yengo, Loic, Matthew R. Robinson, Matthew C. Keller, Kathryn E. Kemper, Yuanhao Yang, Maciej Trzaskowski, .. . Peter M. Visscher. 2018. "Imprint of assortative mating on the human genome." Nature Human Behaviour 2:948-954.

Young, Michael, and Peter Wilmott. 1957. Family and kinship in East London. Glencoce, Ill: Free Press. 

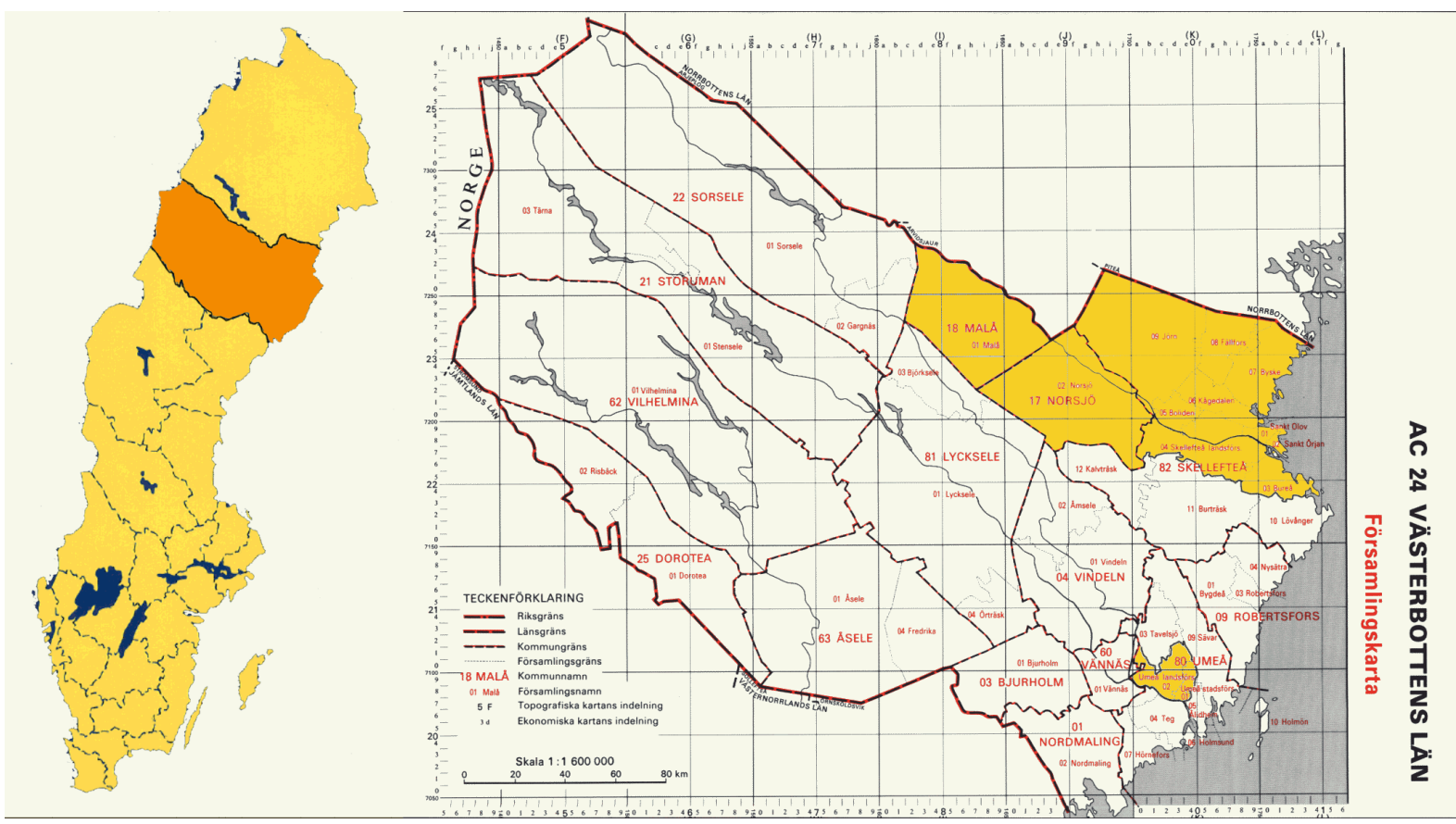

Figure 1. Map of Skellefteå and Umeå region. The yellow area marks the parishes in our historical data.

Source: Lantmäteriet

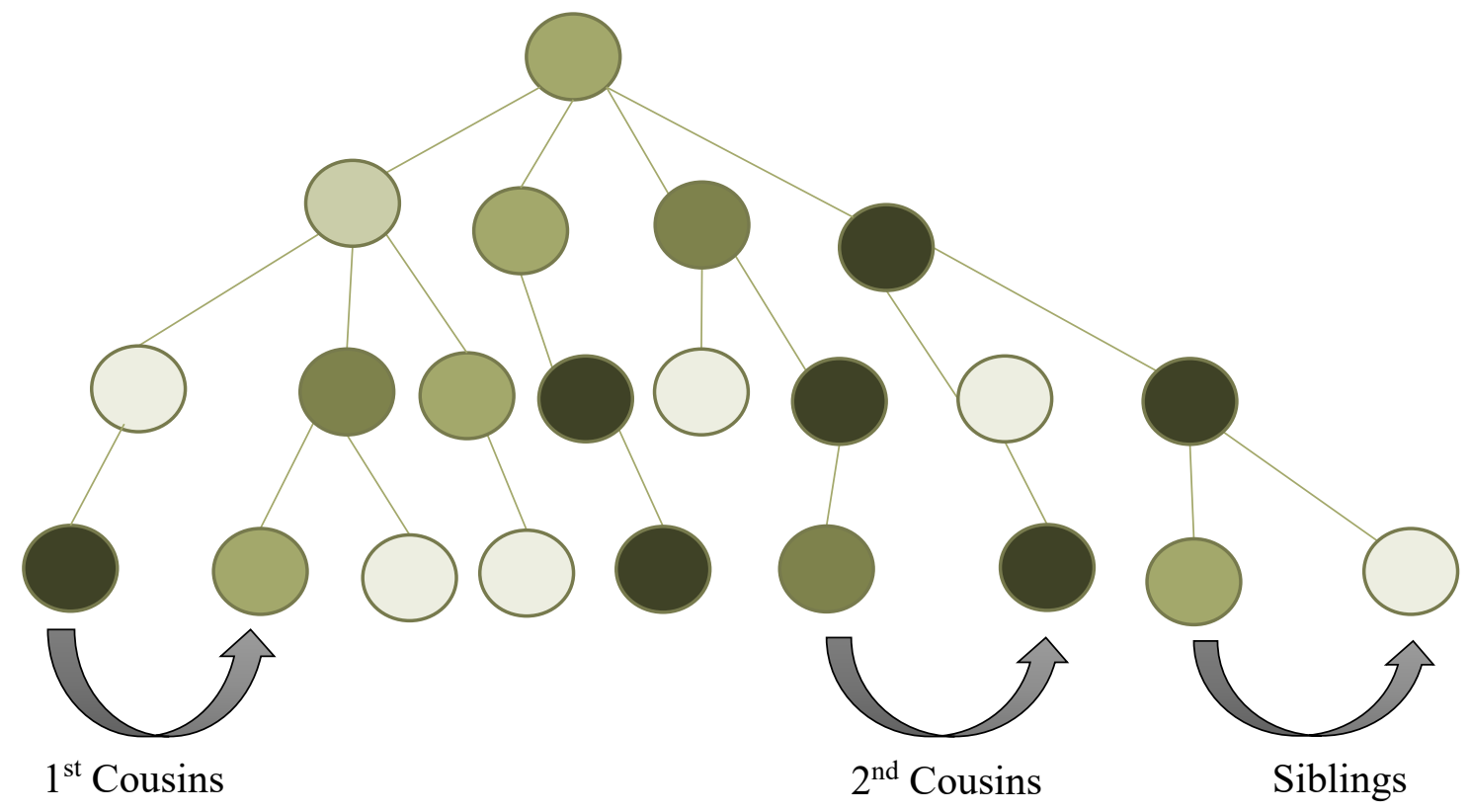

Figure 2. Data structure for cousin correlations 


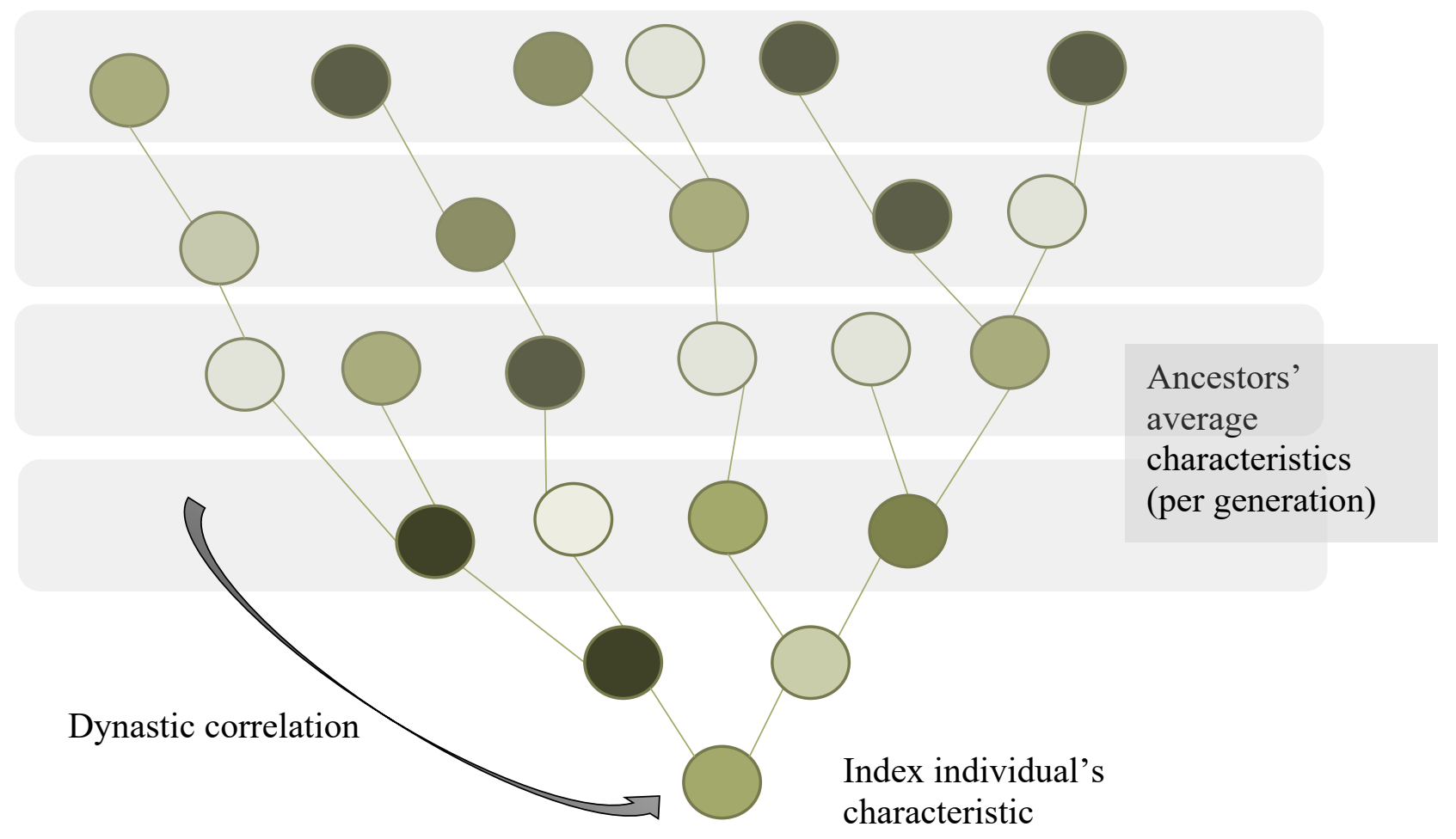

Figure 3. Data structure for dynastic correlations 


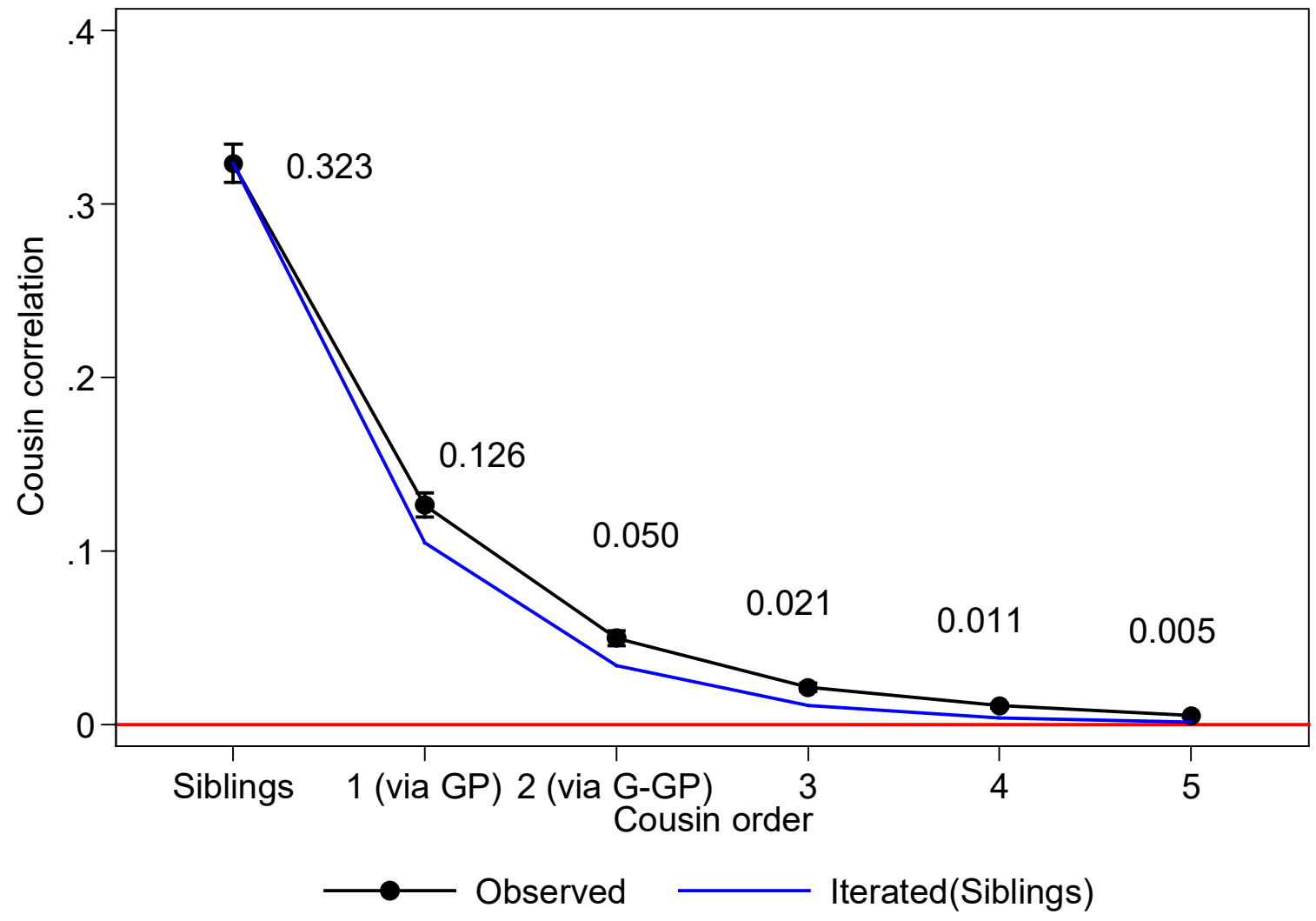

Figure 4. Cousin correlations in years of education with iteration based on sibling correlation. Note: Men and women born 1940-1987 in Sweden with a $5^{\text {th }}$ generation descendant in Northern Sweden. 


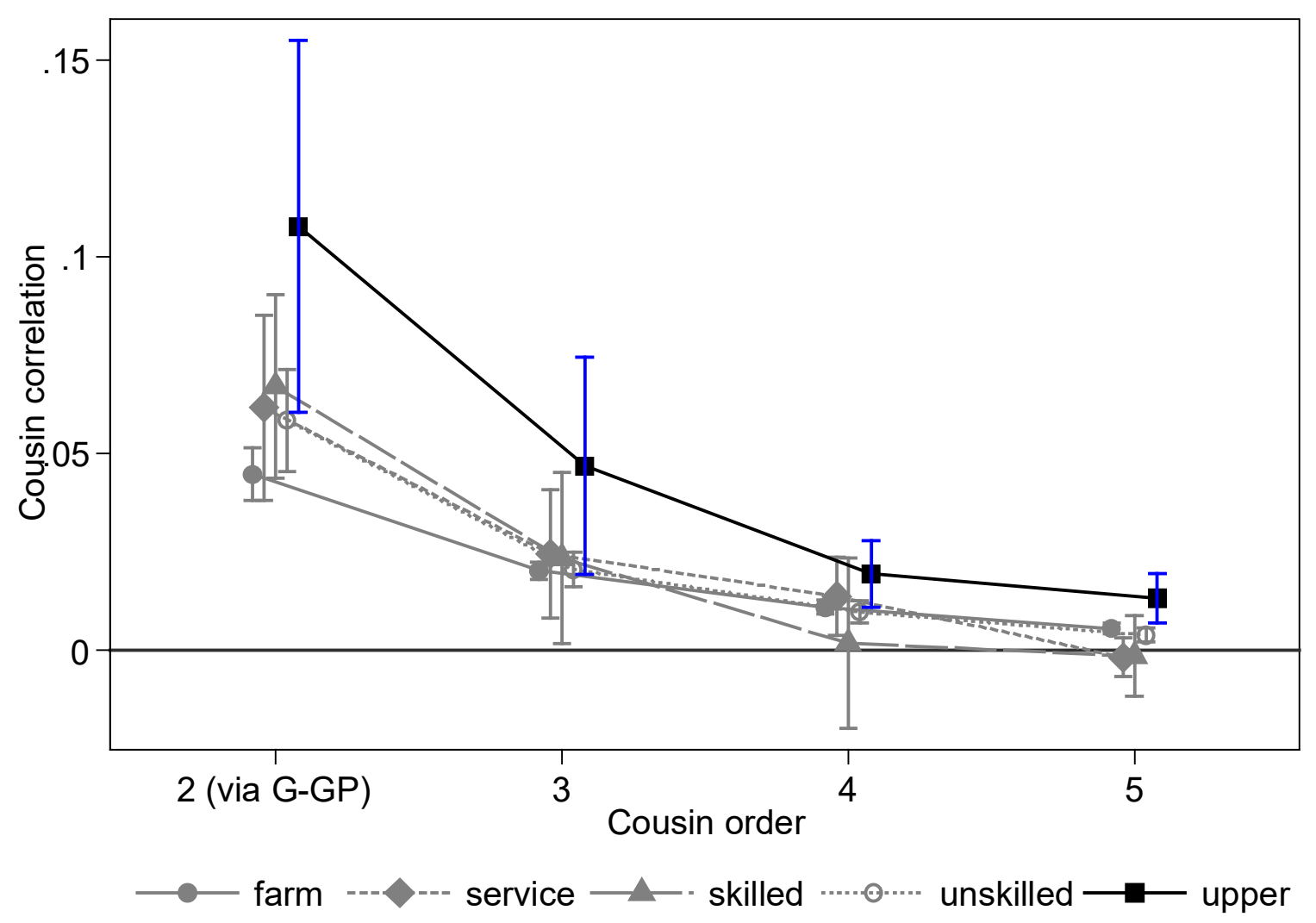

Figure 5. Higher order cousin correlations in years of education by ancestor's SES.

Note: Men and women born 1940-1987 in Sweden with a $5^{\text {th }}$ generation descendant in Northern Sweden.
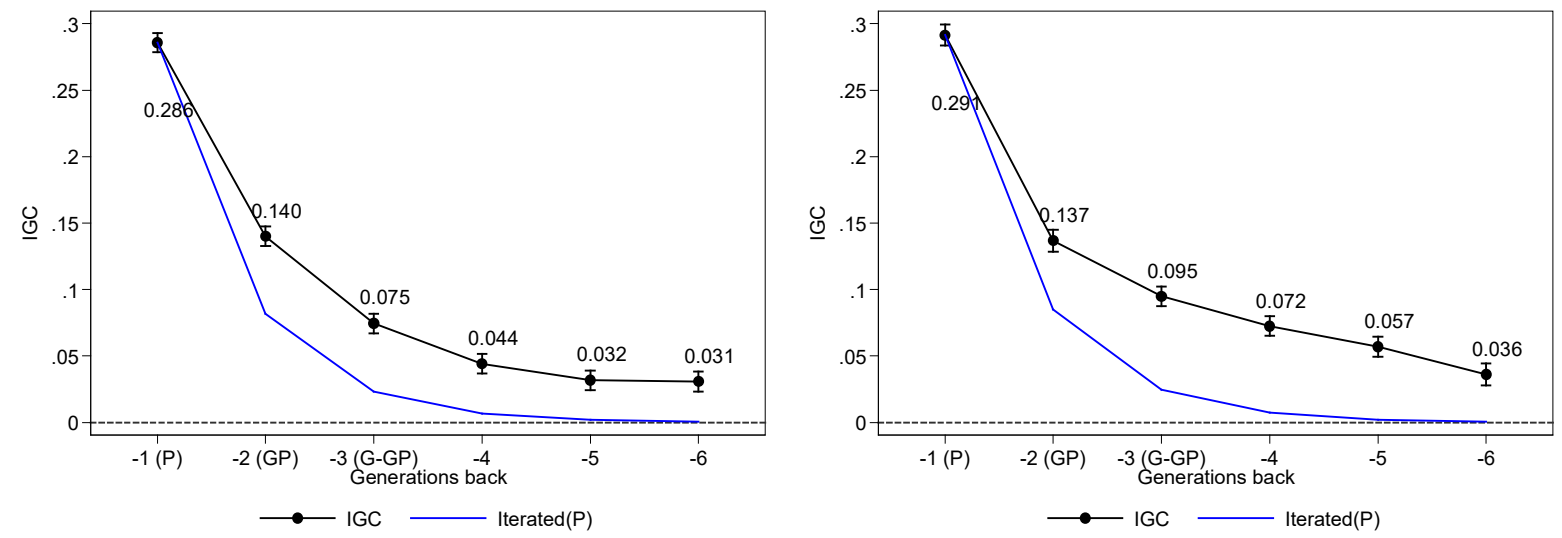

Figure 6. Dynastic correlations in years of education in separate models by generation using HISCAM (left) and kin class scale (right).

Note: Men and women born 1940-1987 in Sweden with a $5^{\text {th }}$ generation descendant in Northern Sweden. 
Table 1. Cousin and sibling correlations in years of education, occupation (ISEI scores), and wealth. Men and women born 1940-1987 in Sweden with a $5^{\text {th }}$ generation descendant in Northern Sweden.

\begin{tabular}{|c|c|c|c|c|c|c|c|c|c|c|}
\hline Outcome & $\begin{array}{l}\text { Cousin } \\
\text { order }\end{array}$ & Rho & s.e. & $\mathrm{t}$ & $\begin{array}{l}95 \% \text { CI } \\
\text { (lower) }\end{array}$ & $\begin{array}{l}95 \% \text { CI } \\
\text { (upper) }\end{array}$ & $\begin{array}{l}\text { Iterated } \\
\text { (Sibling) }\end{array}$ & Difference & $\begin{array}{c}\text { Unique } \\
\text { Ancestors }\end{array}$ & No. ties \\
\hline \multirow[t]{6}{*}{ Education } & 0 (sibs) & 0.323 & 0.006 & 57.8 & 0.312 & 0.334 & 0.323 & & 25,030 & 52,123 \\
\hline & 1 & 0.126 & 0.004 & 35.1 & 0.119 & 0.133 & 0.105 & 0.022 & 12,573 & 251,396 \\
\hline & 2 & 0.050 & 0.002 & 22.6 & 0.045 & 0.054 & 0.034 & 0.016 & 9,481 & $1,274,838$ \\
\hline & 3 & 0.021 & 0.001 & 17.7 & 0.019 & 0.024 & 0.011 & 0.010 & 12,447 & $10,789,168$ \\
\hline & 4 & 0.011 & 0.001 & 17.7 & 0.009 & 0.012 & 0.004 & 0.007 & 8,503 & $21,536,050^{*}$ \\
\hline & 5 & 0.005 & 0.000 & 12.3 & 0.004 & 0.006 & 0.001 & 0.004 & 5,841 & $35,416,306^{*}$ \\
\hline \multirow[t]{6}{*}{ Occupation } & 0 (sibs) & 0.289 & 0.006 & 47.4 & 0.277 & 0.301 & 0.289 & & 24,111 & 49,135 \\
\hline & 1 & 0.114 & 0.003 & 36.7 & 0.108 & 0.120 & 0.084 & 0.030 & 12,436 & 238,446 \\
\hline & 2 & 0.046 & 0.002 & 19.0 & 0.041 & 0.050 & 0.024 & 0.022 & 9,430 & $1,209,023$ \\
\hline & 3 & 0.020 & 0.001 & 16.6 & 0.018 & 0.022 & 0.007 & 0.013 & 12,403 & $10,235,505$ \\
\hline & 4 & 0.009 & 0.001 & 14.8 & 0.008 & 0.010 & 0.002 & 0.007 & 8,474 & $20,379,704 *$ \\
\hline & 5 & 0.004 & 0.001 & 8.8 & 0.003 & 0.005 & 0.001 & 0.004 & 5,822 & $33,528,817^{*}$ \\
\hline \multirow[t]{6}{*}{ Wealth } & 0 (sibs) & 0.304 & 0.005 & 60.8 & 0.294 & 0.314 & 0.304 & & 23,916 & 48,426 \\
\hline & 1 & 0.076 & 0.004 & 21.7 & 0.069 & 0.083 & 0.092 & -0.016 & 12,415 & 234,382 \\
\hline & 2 & 0.030 & 0.002 & 14.8 & 0.026 & 0.034 & 0.028 & 0.002 & 9,419 & $1,190,794$ \\
\hline & 3 & 0.013 & 0.001 & 12.6 & 0.011 & 0.015 & 0.009 & 0.004 & 12,399 & $10,068,614$ \\
\hline & 4 & 0.008 & 0.001 & 13.2 & 0.007 & 0.009 & 0.003 & 0.005 & 8,470 & $20,031,320 *$ \\
\hline & 5 & 0.005 & 0.001 & 9.8 & 0.004 & 0.006 & 0.001 & 0.004 & 5,819 & $32,965,923 *$ \\
\hline
\end{tabular}

Note: all estimates are based on ranks and weighting scheme $2 .{ }^{*}$ sample of pairs (see text for details) 
Table 2. Different specifications of dynastic correlations

\begin{tabular}{|c|c|c|c|c|c|c|c|c|c|c|c|c|c|c|c|}
\hline & \multicolumn{5}{|c|}{ Years of education } & \multicolumn{5}{|c|}{ Occupation (ISES scores) } & \multicolumn{5}{|l|}{ Wealth } \\
\hline & $\mathrm{MGC}^{\mathrm{a}}$ & s.e. & $\Delta \mathrm{R} 2$ & $\mathrm{R} 2$ & $\mathrm{~N}$ & $\mathrm{MGC}^{\mathrm{a}}$ & s.e. & $\Delta \mathrm{R} 2$ & $\mathrm{R} 2$ & $\mathrm{~N}$ & $\mathrm{MGC}^{\mathrm{a}}$ & s.e. & $\Delta \mathrm{R} 2$ & $\mathrm{R} 2$ & $\mathrm{~N}$ \\
\hline \multicolumn{16}{|l|}{ Average HISCAM } \\
\hline Empty (only controls) & & & & 0.047 & 67,884 & & & & 0.007 & 66,072 & & & & 0.006 & 67,563 \\
\hline Generation $-1, \mathrm{P}$ & 0.286 & 0.003 & 0.079 & 0.126 & 67,884 & 0.306 & 0.003 & 0.091 & 0.098 & 66,072 & 0.111 & 0.003 & 0.012 & 0.018 & 67,563 \\
\hline Generation -2, GP & 0.140 & 0.003 & 0.019 & 0.066 & 67,884 & 0.153 & 0.003 & 0.023 & 0.03 & 66,072 & 0.061 & 0.003 & 0.004 & 0.01 & 67,563 \\
\hline Generation -3, G-GP & 0.075 & 0.003 & 0.005 & 0.053 & 67,884 & 0.082 & 0.003 & 0.007 & 0.014 & 66,072 & 0.033 & 0.003 & 0.001 & 0.007 & 67,563 \\
\hline Generation -4 & 0.044 & 0.003 & 0.002 & 0.049 & 67,884 & 0.052 & 0.003 & 0.003 & 0.01 & 66,072 & 0.032 & 0.003 & 0.001 & 0.007 & 67,563 \\
\hline Generation -5 & 0.032 & 0.003 & 0.001 & 0.048 & 67,884 & 0.028 & 0.003 & 0.001 & 0.008 & 66,072 & 0.035 & 0.003 & 0.001 & 0.007 & 67,563 \\
\hline Generation -6 & 0.031 & 0.003 & 0.001 & 0.048 & 67,884 & 0.026 & 0.003 & 0.001 & 0.008 & 66,072 & 0.032 & 0.003 & 0.001 & 0.007 & 67,563 \\
\hline Generation -1 to -6 jointly ${ }^{\text {a }}$ & 0.360 & & 0.083 & 0.13 & 67,884 & 0.382 & & 0.095 & 0.102 & 66,072 & 0.182 & & 0.014 & 0.02 & 67,563 \\
\hline \multicolumn{16}{|l|}{ Kin class scale } \\
\hline Empty (only controls) & & & & 0.047 & 67,826 & & & & 0.007 & 66,014 & & & & 0.006 & 67,505 \\
\hline Generation $-1, \mathrm{P}$ & 0.291 & 0.004 & 0.069 & 0.116 & 67,826 & 0.318 & 0.004 & 0.083 & 0.09 & 66,014 & 0.121 & 0.003 & 0.014 & 0.020 & 67,505 \\
\hline Generation -2, GP & 0.137 & 0.004 & 0.015 & 0.062 & 67,826 & 0.179 & 0.004 & 0.023 & 0.031 & 66,014 & 0.080 & 0.003 & 0.006 & 0.012 & 67,505 \\
\hline Generation -3, G-GP & 0.095 & 0.003 & 0.009 & 0.056 & 67,826 & 0.092 & 0.003 & 0.008 & 0.015 & 66,014 & 0.083 & 0.003 & 0.007 & 0.013 & 67,505 \\
\hline Generation -4 & 0.072 & 0.003 & 0.005 & 0.052 & 67,826 & 0.073 & 0.003 & 0.005 & 0.013 & 66,014 & 0.056 & 0.003 & 0.003 & 0.009 & 67,505 \\
\hline Generation -5 & 0.057 & 0.003 & 0.003 & 0.050 & 67,826 & 0.053 & 0.003 & 0.003 & 0.01 & 66,014 & 0.048 & 0.003 & 0.002 & 0.008 & 67,505 \\
\hline Generation -6 & 0.036 & 0.004 & 0.001 & 0.048 & 67,826 & 0.043 & 0.003 & 0.002 & 0.009 & 66,014 & 0.035 & 0.003 & 0.001 & 0.007 & 67,505 \\
\hline Generation -1 to -6 jointly a & 0.411 & & 0.076 & 0.123 & 67,826 & 0.453 & & 0.091 & 0.099 & 66,014 & 0.247 & & 0.022 & 0.028 & 67,505 \\
\hline
\end{tabular}

Note: all outcomes are in rank form. $\mathrm{MGC}=\mathrm{b}^{*}[\mathrm{SD}(\mathrm{X}) / \mathrm{SD}(\mathrm{Y})] .{ }^{\text {a }}$ For the joint specification, the MGC is summed over all generations. 


\section{Supplementary Figures and Tables}
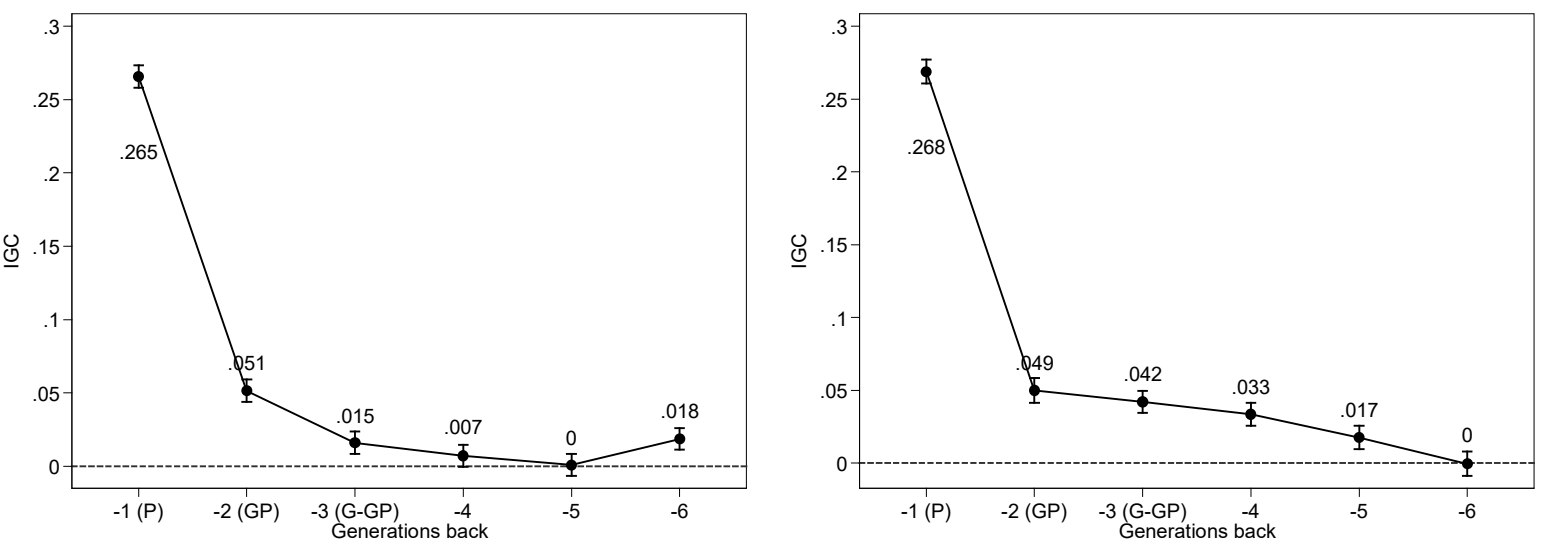

Figure S1. Dynastic correlations in years of education in joint models by generation using HISCAM (left) and kin class scale (right). Men and women born 1940-1987 in Sweden with a $5^{\text {th }}$ generation descendant in Northern Sweden. 
Table S1. Cousin and sibling correlations in absolute years of education and occupation (absolute ISEI scores). Men and women born 1940-1987 in

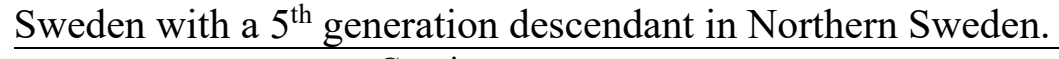

\begin{tabular}{|c|c|c|c|c|c|c|c|c|c|c|}
\hline Outcome & $\begin{array}{l}\text { Cousin } \\
\text { order }\end{array}$ & Rho & s.e. & $\mathrm{t}$ & $\begin{array}{l}95 \% \mathrm{CI} \\
\text { (lower) }\end{array}$ & $\begin{array}{l}95 \% \mathrm{CI} \\
\text { (upper) }\end{array}$ & $\begin{array}{l}\text { Iterated } \\
\text { (Sibling) }\end{array}$ & Difference & $\begin{array}{c}\text { Unique } \\
\text { Ancestors }\end{array}$ & No. ties \\
\hline \multirow[t]{6}{*}{ Education } & 0 (sibs) & 0.327 & 0.005 & 62.8 & 0.317 & 0.337 & 0.327 & & 25,030 & 52,123 \\
\hline & 1 & 0.127 & 0.004 & 28.8 & 0.118 & 0.135 & 0.107 & 0.02 & 12,573 & 251,396 \\
\hline & 2 & 0.050 & 0.003 & 19.8 & 0.045 & 0.054 & 0.035 & 0.015 & 9,481 & $1,274,838$ \\
\hline & 3 & 0.021 & 0.001 & 17.8 & 0.019 & 0.024 & 0.011 & 0.01 & 12,447 & $10,789,168$ \\
\hline & 4 & 0.011 & 0.001 & 18.2 & 0.010 & 0.012 & 0.004 & 0.007 & 8,503 & $21,536,050$ \\
\hline & 5 & 0.005 & 0.001 & 10.2 & 0.004 & 0.006 & 0.001 & 0.004 & 5,841 & $35,416,306$ \\
\hline \multirow[t]{6}{*}{ Occupation } & 0 (sibs) & 0.311 & 0.006 & 47.8 & 0.298 & 0.323 & 0.311 & & 24,111 & 49,135 \\
\hline & 1 & 0.122 & 0.003 & 35.9 & 0.115 & 0.129 & 0.096 & 0.026 & 12,436 & 238,446 \\
\hline & 2 & 0.050 & 0.003 & 18.5 & 0.045 & 0.055 & 0.03 & 0.02 & 9,430 & $1,209,023$ \\
\hline & 3 & 0.022 & 0.001 & 16.8 & 0.019 & 0.024 & 0.009 & 0.012 & 12,403 & $10,235,505$ \\
\hline & 4 & 0.010 & 0.001 & 13.9 & 0.008 & 0.011 & 0.003 & 0.007 & 8,474 & $20,379,704$ \\
\hline & 5 & 0.005 & 0.001 & 9.6 & 0.004 & 0.006 & 0.001 & 0.004 & 5,822 & $33,528,817$ \\
\hline
\end{tabular}

Note: all estimates are based on untransformed outcomes (i.e., not using rank transform) and weighting scheme 2. 
Table S2. Cousin correlations in years of education by class position of ancestor.

\begin{tabular}{|c|c|c|c|c|c|c|c|c|c|c|}
\hline $\begin{array}{l}\text { Cousin } \\
\text { order }\end{array}$ & $\begin{array}{l}\text { Class of ancestor } \\
\text { defining cousins }\end{array}$ & Rho & s.e. & $\mathrm{t}$ & CI- & $\mathrm{CI}+$ & $\begin{array}{l}\text { Iterated } \\
\text { (Sibling) }\end{array}$ & Difference & $\begin{array}{c}\text { Unique } \\
\text { Ancestors }\end{array}$ & No. ties \\
\hline \multirow[t]{5}{*}{0} & Farm & 0.284 & 0.021 & 13.7 & 0.244 & 0.325 & 0.284 & & 1,647 & 4,811 \\
\hline & Service & 0.277 & 0.011 & 26.1 & 0.256 & 0.298 & 0.277 & & 7,903 & 15,013 \\
\hline & Skilled & 0.304 & 0.009 & 32.0 & 0.285 & 0.323 & 0.304 & & 7,805 & 16,208 \\
\hline & Lower/Unskilled & 0.348 & 0.015 & 23.2 & 0.319 & 0.377 & 0.348 & & 3,251 & 6,945 \\
\hline & Upper & 0.433 & 0.013 & 32.4 & 0.407 & 0.460 & 0.433 & & 4,353 & 8,969 \\
\hline \multirow[t]{5}{*}{1} & Farm & 0.112 & 0.006 & 19.0 & 0.100 & 0.124 & 0.081 & 0.031 & 5,000 & 144,414 \\
\hline & Service & 0.170 & 0.011 & 16.2 & 0.149 & 0.190 & 0.077 & 0.093 & 1,535 & 17,511 \\
\hline & Skilled & 0.126 & 0.012 & 10.6 & 0.103 & 0.150 & 0.092 & 0.034 & 2,381 & 30,566 \\
\hline & Lower/Unskilled & 0.128 & 0.008 & 16.7 & 0.113 & 0.143 & 0.121 & 0.007 & 2,958 & 51,460 \\
\hline & Upper & 0.212 & 0.028 & 7.5 & 0.157 & 0.267 & 0.188 & 0.024 & 555 & 6,020 \\
\hline \multirow[t]{5}{*}{2} & Farm & 0.045 & 0.003 & 13.1 & 0.038 & 0.051 & 0.023 & 0.022 & 6,207 & $1,006,645$ \\
\hline & Service & 0.062 & 0.012 & 5.1 & 0.038 & 0.085 & 0.021 & 0.04 & 561 & 39,394 \\
\hline & Skilled & 0.067 & 0.012 & 5.6 & 0.044 & 0.090 & 0.028 & 0.039 & 741 & 54,561 \\
\hline & Lower/Unskilled & 0.058 & 0.007 & 8.8 & 0.045 & 0.071 & 0.042 & 0.016 & 1,785 & 160,379 \\
\hline & Upper & 0.108 & 0.024 & 4.5 & 0.060 & 0.155 & 0.081 & 0.026 & 126 & 12,367 \\
\hline \multirow[t]{5}{*}{3} & Farm & 0.020 & 0.001 & 18.4 & 0.018 & 0.022 & 0.007 & 0.014 & 7,724 & $7,483,641$ \\
\hline & Service & 0.025 & 0.008 & 3.0 & 0.008 & 0.041 & 0.006 & 0.019 & 299 & 114,520 \\
\hline & Skilled & 0.023 & 0.011 & 2.1 & 0.002 & 0.045 & 0.009 & 0.015 & 379 & 107,789 \\
\hline & Lower/Unskilled & 0.021 & 0.002 & 9.3 & 0.016 & 0.025 & 0.015 & 0.006 & 3,789 & $2,847,852$ \\
\hline & Upper & 0.047 & 0.014 & 3.3 & 0.019 & 0.074 & 0.035 & 0.011 & 178 & 92,976 \\
\hline \multirow[t]{5}{*}{4} & Farm & 0.011 & 0.001 & 12.1 & 0.009 & 0.013 & 0.002 & 0.009 & 4,655 & $12,337,519$ \\
\hline & Service & 0.014 & 0.005 & 2.7 & 0.004 & 0.024 & 0.002 & 0.012 & 196 & 357,497 \\
\hline & Skilled & 0.002 & 0.011 & 0.2 & -0.020 & 0.023 & 0.003 & -0.001 & 135 & 147,234 \\
\hline & Lower/Unskilled & 0.010 & 0.001 & 6.9 & 0.007 & 0.012 & 0.005 & 0.005 & 2,849 & $7,419,814$ \\
\hline & Upper & 0.019 & 0.004 & 4.5 & 0.011 & 0.028 & 0.015 & 0.004 & 171 & 588,769 \\
\hline \multirow[t]{5}{*}{5} & Farm & 0.005 & 0.001 & 7.9 & 0.004 & 0.007 & 0.001 & 0.005 & 2,524 & $14,270,205$ \\
\hline & Service & -0.002 & 0.003 & -0.7 & -0.007 & 0.003 & 0 & -0.002 & 149 & 878,716 \\
\hline & Skilled & -0.002 & 0.005 & -0.3 & -0.012 & 0.009 & 0.001 & -0.002 & 63 & 210,817 \\
\hline & Lower/Unskilled & 0.004 & 0.001 & 4.2 & 0.002 & 0.006 & 0.002 & 0.002 & 1,909 & $7,835,121$ \\
\hline & Upper & 0.013 & 0.003 & 4.1 & 0.007 & 0.019 & 0.007 & 0.007 & 147 & $2,069,653$ \\
\hline
\end{tabular}

Note: all estimates are based on weighting scheme 2. 


\section{Web Appendix for}

The shadow of peasant past: Seven generations of inequality persistence in Northern Sweden

\section{Part A: Description of historical parish registers}

The historical parish data are based on a selection of different registers kept by the local church for administrative reasons. Nilsdotter Jeub (1993) and Alm Stenflo (1994) describes the nature and content of Swedish parish data. The data has been digitized by the Demographic Data Base at Umeå University (Edvinsson 2000; Engberg, Westberg and Edvinsson 2016). Our data contains 10 parishes in the contemporary Västerbotten county in northern Sweden. The parishes are based in the Skellefteå region and the Umeå region. The registration for the Umeå region begins later, and it, therefore, contributes substantially fewer cases to our analyses. In Table A1 we describe the different parishes. A demographic and historical description of the area is given by (Alm Stenflo 1994). In Figure A1 we compare demographic trends in the area with that of all of Sweden. The fertility transition occurred somewhat later in the area than in the rest of Sweden (Kolk 2011).

Our historical registers end at different periods between 1950 and 1970. Our contemporary registers begin with the 1960 and 1965 census, and from 1968 yearly registers. This means that we have information for both sources for some periods, but there are some years for which we have less information. However, in 1947, individuals in our registers were assigned personal identification numbers, which we can use to link everyone present in our historical region in 1947 with contemporary registers later on. The Swedish national multigenerational register also contains parent-child links going back to 1932, which means we have accurate information on kinship links across time. Before 1800 our data contains mostly vital events, while after that period, we have complete registration of critical events, migration records, and occupations. Individuals born before 1800 will only be systematically and reliably observed in our data if they survived until this time point (though we have records from somewhat less representative data before this period). The population in region was small in the mid- $18^{\text {th }}$ century, restricting the usefulness of pre- $19^{\text {th }}$ century, though our area had strong 
population growth over our period (Alm Stenflo 1994). Because of this we mostly focus on cohorts born in 1785 and after, and have designed our multigenerational structure with these period constraints in mind.

In our historical data after 1800 , our registers are complete and our intergenerational linkages across generations (match rates) are nearly complete, except where the father was unknown to the register holders. We do not need to use probabilistic match rates (a great advantage in a multigenerational design) as the registers rely on rich birth records. As our local parish registers also include personal identity numbers after 1947, we also do not lose matches when transferring from historical to contemporary registers. In contemporary Swedish registers, the proportion of unknown fathers is also very low (Statistics Sweden 2010), partly due to rigorous paternity investigations in case of unknown fathers. The reason we get incomplete kinship networks are, therefore mostly a consequence of the fact that we observe a geographically limited geographical area in our historical registers and that we cannot follow emigration in our contemporary data. We explore these issues in appendices G, H \& I.

Our historical database contains in total 294,500 individuals from 1720 to 1970 in our 10 parishes. Some further information of our dataset can be found using the DOI of our dataset: http://dx.doi.org/10.17197/U15002 
Table A1. Description of the 10 parishes in our data.

\begin{tabular}{clcl}
\hline Region & Parish & Start date & End date \\
\hline Skellefteå & Bureå församling & 1921 & 1959 \\
Skellefteå & Byske församling & 1871 & 1950 \\
Skellefteå & Jörn församling & 1831 & 1951 \\
Skellefteå & Malå församling & 1862 & 1958 \\
Skellefteå & Norsjö församling & 1811 & 1959 \\
Skellefteå & Skellefteå landsförsamling & 1720 & 1955 \\
Skellefteå & Skellefteå stadsförsamling & 1913 & 1953 \\
Skellefteå & Ytterstfors församling & 1846 & 1870 \\
Umeå & Umeå landsförsamling & 1895 & 1970 \\
Umeå & Umeå stadsförsamling & 1872 & 1951 \\
\hline
\end{tabular}

Note: The parishes were split and merged multiple times over the time period, but cover a largely comparable area over time (though the registers in the Umeå region starting later). In the beginning of the period most of the area was covered by Skellefteå Landsförsamling. Start date refers to the first date of our records from our parish records, some individuals are born before this time point. See also Figure 1.
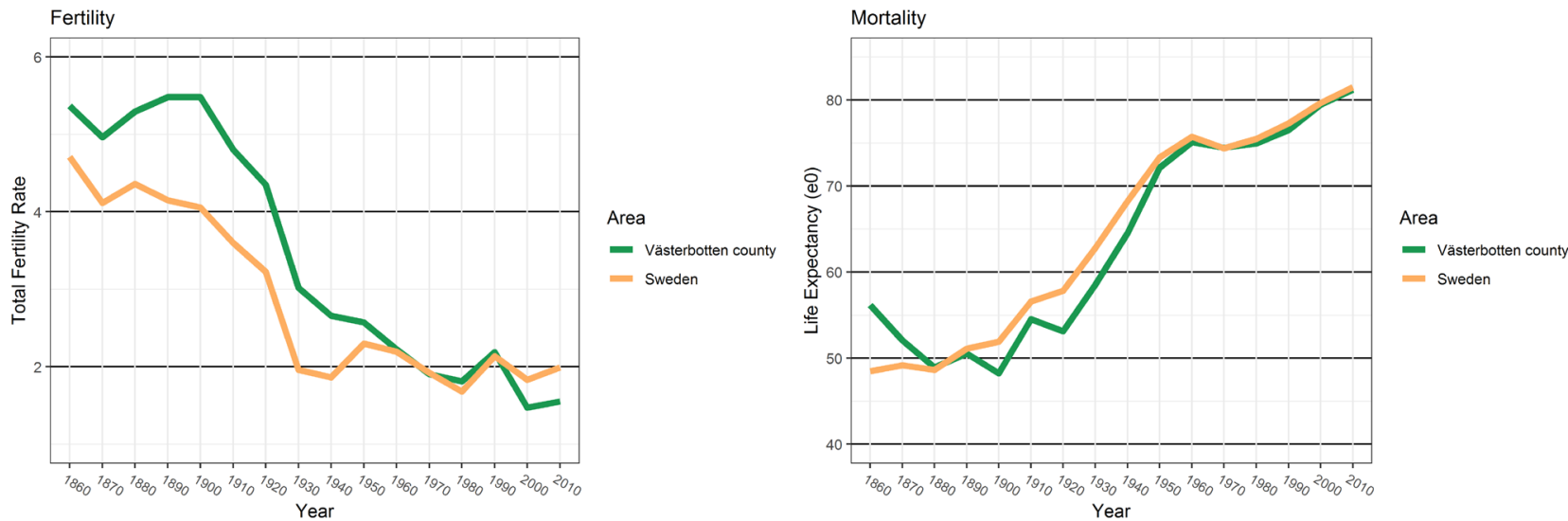

Figure A1: Trends in mortality and fertility from 1860-2000 for Västerbotten county (see Figure 1) and all of Sweden.

Source: (Statistics Sweden 1999), Murphy (2004), and Statistikdatabasen (2016).

Note: Mortality for years 1860 to 1960 calculated from 10 year age-specific data for ages 0 to 79 , and fitted with the "Coale-Demeny life table north-female" using the software Mortpak. Mortality based on years:1861;1871;1881;1889-1892;1899-1902;1909-1912;1919-1922;1929-1932;1939-1942;1949-1952;19591962;1966-1970;1976-1980;1986-199;1998-2002;2008-2012. 


\section{Part B. Descriptive statistics for index generation and ancestors}

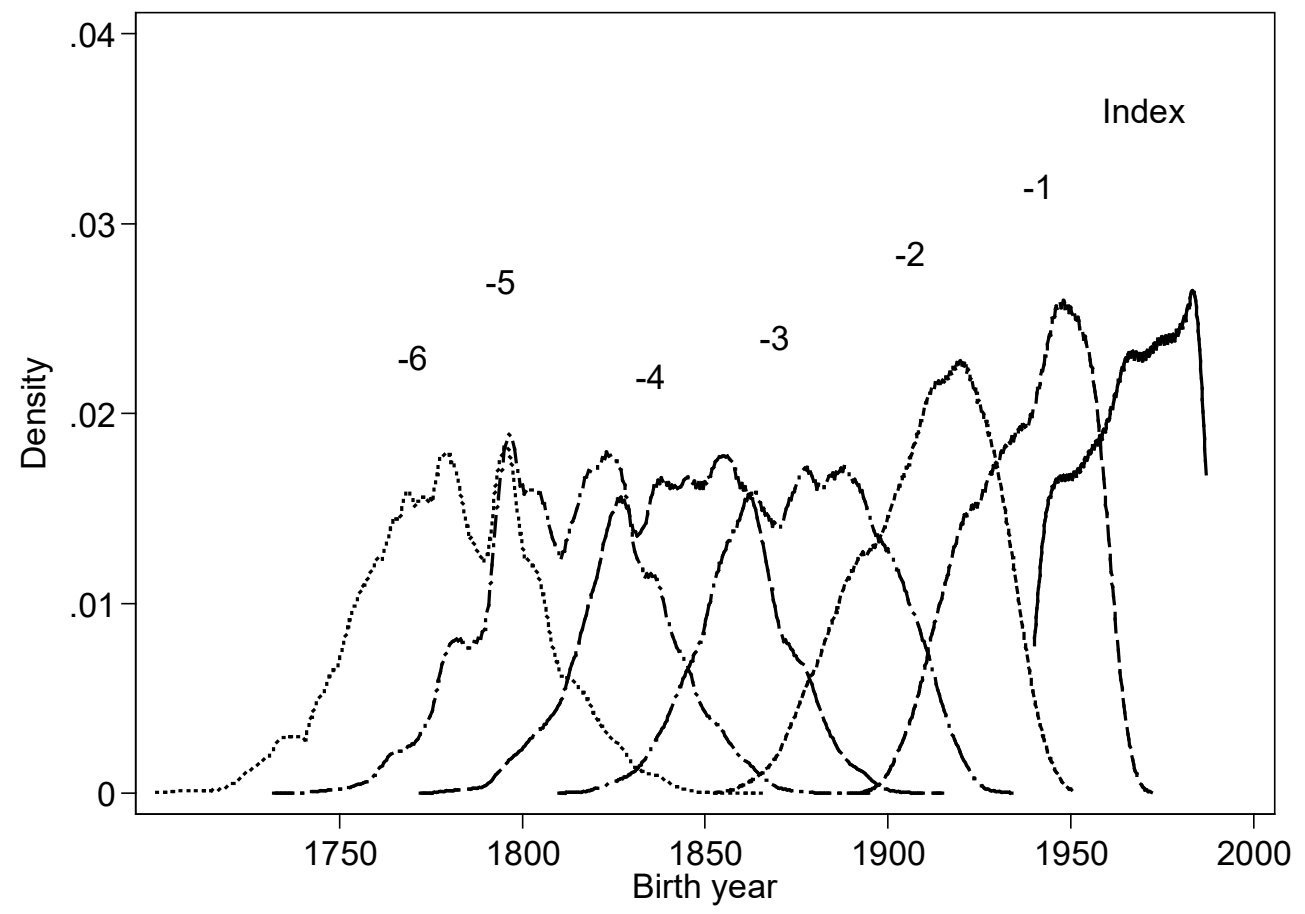

Figure B1. Density of birth years in prior generations following maternal lineage (the sequence mmmmmm, see text)
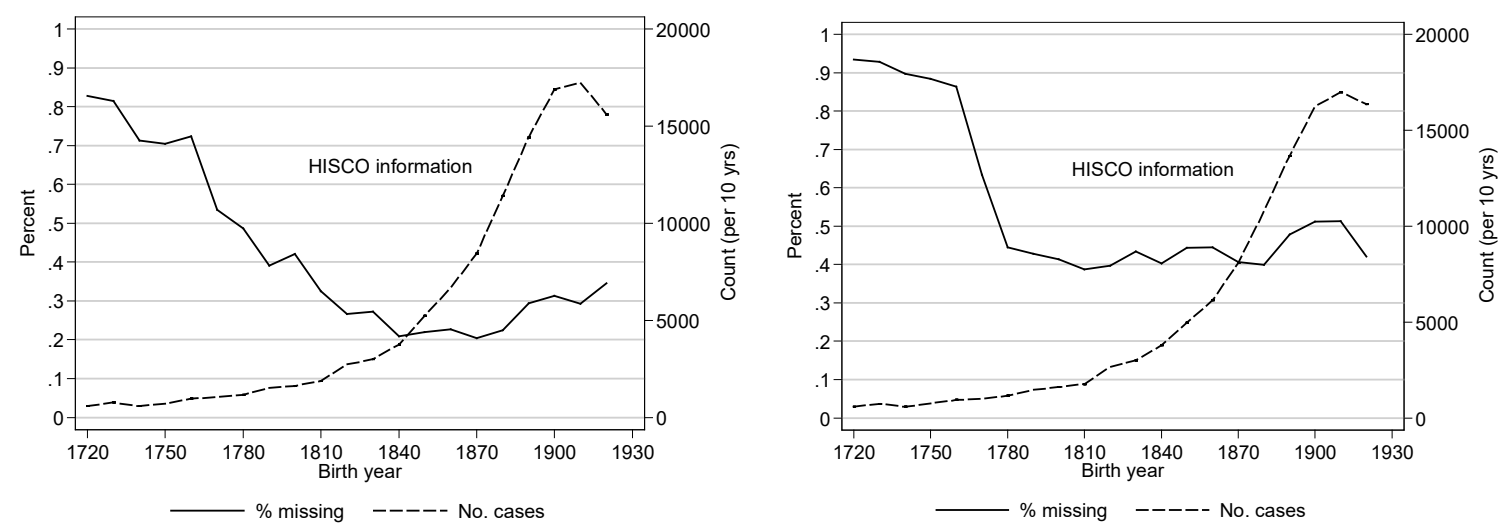

Figure B2. Valid HISCO occupation information by birth year for males (left) and females (right) 

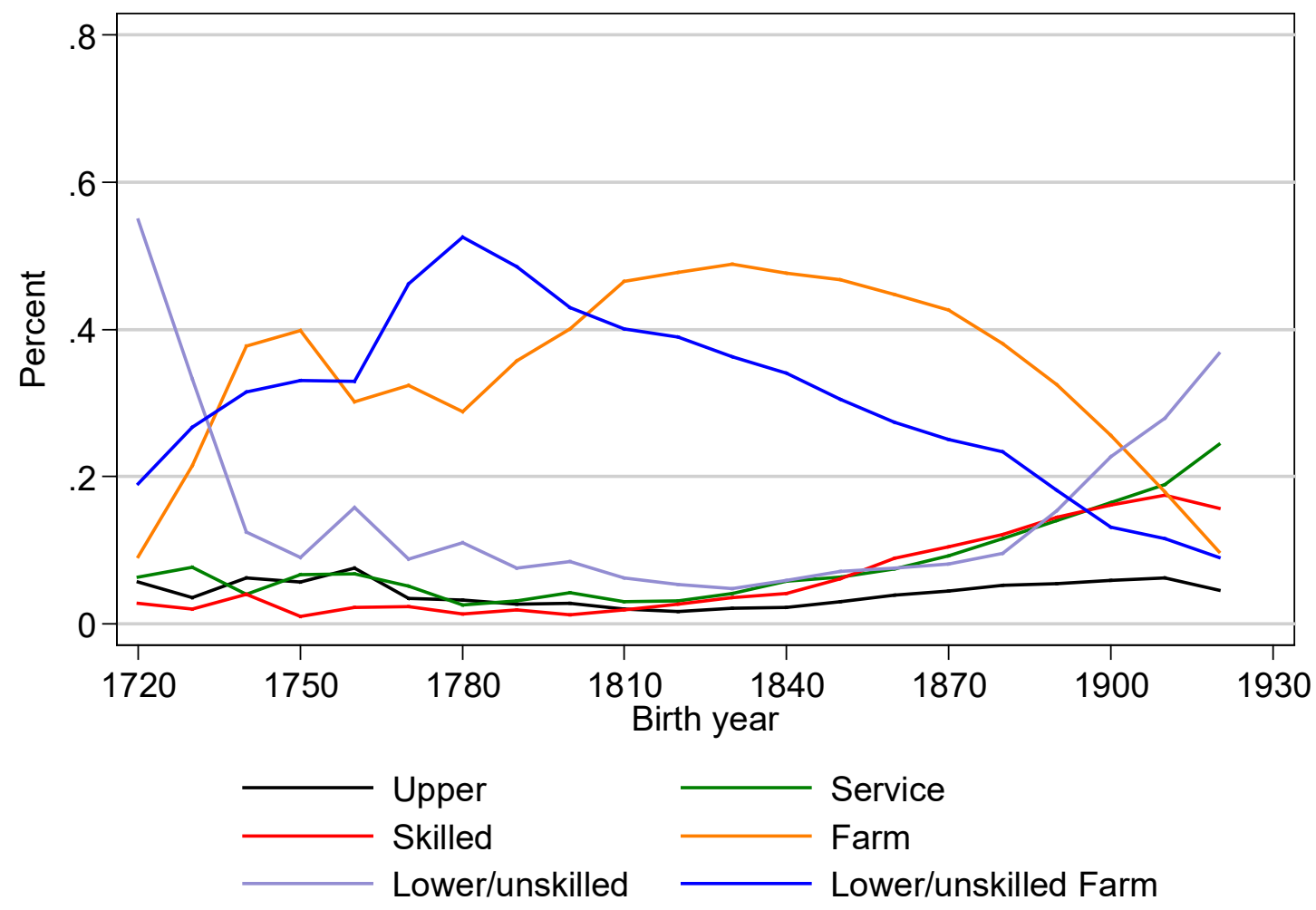

Figure B3. Class codes according to HISCLASS by birth year.

Note: Birth years aggregated to groups of ten years.

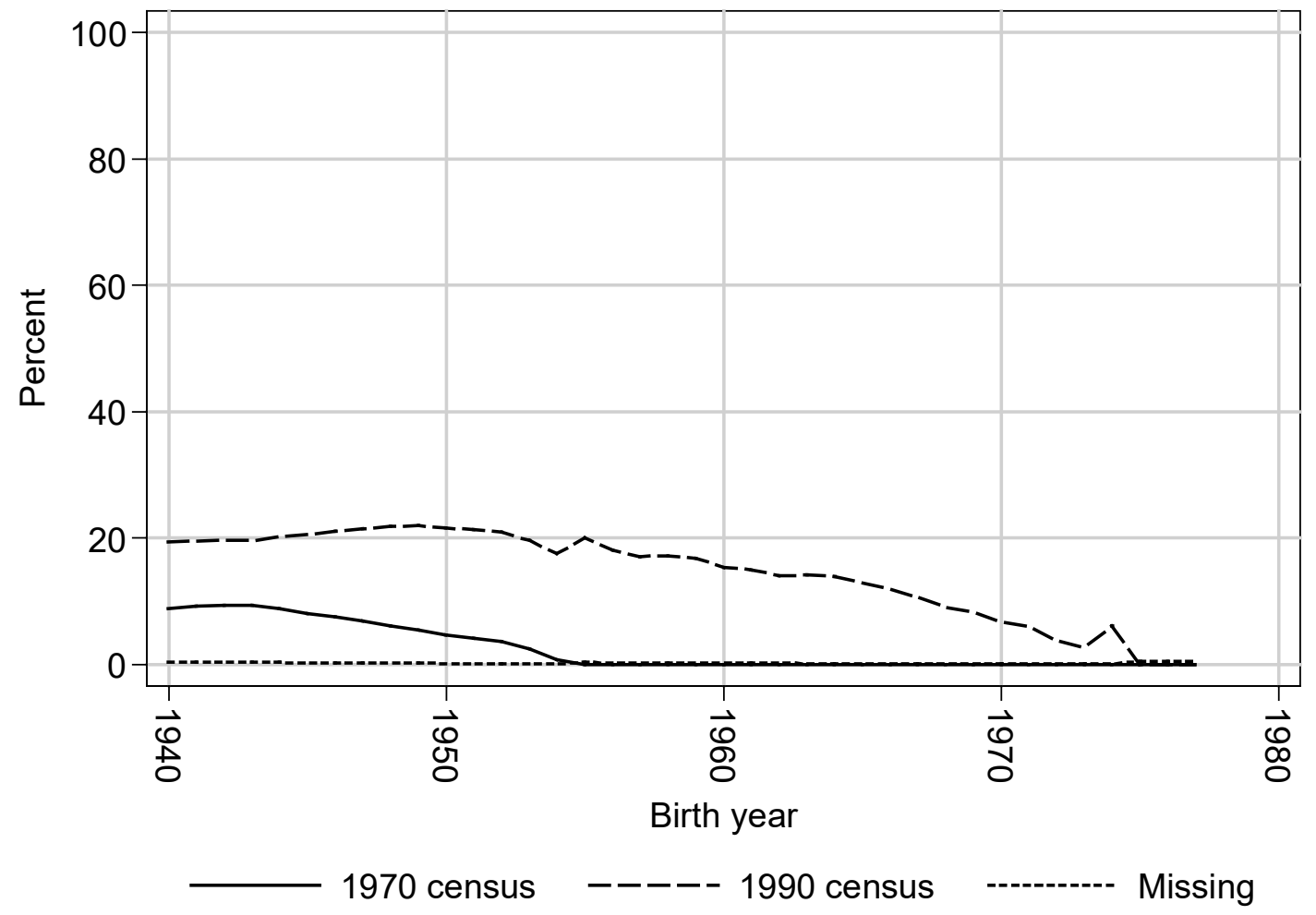

Figure B4. The extent of self-reports in education measured in Swedish registers by 2012. Note: the population is delimited to Swedish-born only. 
Table B1. Descriptive statistics for ancestors seen from index generation, per generation

Number of observed ancestors per index descendant

\begin{tabular}{|c|c|c|c|c|c|c|c|c|c|c|c|c|}
\hline & \multirow[b]{2}{*}{ Relation to index } & \multirow[b]{2}{*}{$\begin{array}{l}\text { Common } \\
\text { ancestor of }\end{array}$} & & \multirow[b]{2}{*}{$\begin{array}{l}\text { No. descendants } \\
\text { with traceable } \\
\text { ancestors }\end{array}$} & \multirow[b]{2}{*}{$\begin{array}{c}\text { No. descendants } \\
\text { with valid } \\
\text { occupation } \\
\text { information }\end{array}$} \\
\hline & & & $\begin{array}{l}\text { Theor. } \\
\text { Max }\end{array}$ & Mean & p10 & p25 & p50 & p75 & p90 & $\begin{array}{l}\text { Mean with } \\
\text { valid } \\
\text { occupation }\end{array}$ & & \\
\hline Gen -1 & Parents (P) & Siblings & 2 & 1.99 & 2 & 2 & 2 & 2 & 2 & 1.9 & 75,414 & 75,022 \\
\hline Gen -2 & Grandparents (GP) & $1^{\text {st }}$ cousins & 4 & 3.56 & 2 & 4 & 4 & 4 & 4 & 3.09 & 75,414 & 75,281 \\
\hline Gen -3 & Great GP & $2^{\text {nd }}$ cousin & 8 & 4.71 & 2 & 4 & 4 & 6 & 8 & 4.37 & 75,414 & 75,353 \\
\hline Gen -4 & Gr-Gr-GP & $3^{\text {rd }}$ cousins & 16 & 7.74 & 4 & 4 & 8 & 10 & 14 & 7.32 & 75,414 & 75,396 \\
\hline Gen $-5^{\text {a }}$ & Gr-Gr-Gr-GP & $4^{\text {th }}$ cousins & 32 & 12.89 & 4 & 8 & 12 & 16 & 25 & 11.56 & 75,384 & 74,574 \\
\hline Gen -6 & Gr-Gr-Gr-Gr-GP & $5^{\text {th }}$ cousins & 64 & 22.75 & 6 & 12 & 20 & 30 & 44 & 13.64 & 71,471 & 70,560 \\
\hline
\end{tabular}

Note: the kinship network is repeated matching using links between individuals and their fathers and mothers. The matching is retrospective, meaning that it starts with descendants in the index generation (born in 1940-1987). ${ }^{\mathrm{a}}$ The sample is conditioned on having ancestors at least in generation -5 .

Table B2. Descriptive statistics for ancestors seen from index generation, per generation (continued)

\begin{tabular}{|c|c|c|c|c|c|c|c|c|c|c|c|c|c|c|c|c|}
\hline & \multirow[b]{2}{*}{ Relation to index } & \multicolumn{6}{|c|}{ Birth years } & \multicolumn{9}{|c|}{ Number of descendants per ancestor } \\
\hline & & $\begin{array}{l}\text { Common } \\
\text { ancestor of }\end{array}$ & $\begin{array}{c}\text { Unique } \\
\text { ancestors }\end{array}$ & Mean & SD & Min & $\operatorname{Max}$ & Mean & SD & $\min$ & p10 & p25 & p50 & p75 & p90 & $\max$ \\
\hline Gen -1 & Parents $(\mathrm{P})$ & & 77,892 & 1937.4 & $(16.2)$ & 1877 & 1972 & 1.9 & $(1.0)$ & 1 & 1 & 1 & 2 & 2 & 3 & 9 \\
\hline Gen -2 & Grandparents (GP) & $1^{\text {st }}$ cousins & 79,736 & 1912.5 & (18.7) & 1837 & 1952 & 3.4 & $(3.2)$ & 1 & 1 & 1 & 2 & 4 & 7 & 50 \\
\hline Gen -3 & Great GP & $2^{\text {nd }}$ cousin & 40,692 & 1881.3 & (26.3) & 1784 & 1932 & 8.7 & (11.3) & 1 & 1 & 2 & 4 & 11 & 23 & 136 \\
\hline Gen -4 & Gr-Gr-GP & $3^{\text {rd }}$ cousins & 23,628 & 1845.3 & (28.1) & 1745 & 1915 & 24.7 & (33.1) & 1 & 2 & 4 & 12 & 33 & 64 & 488 \\
\hline Gen $-5^{a}$ & Gr-Gr-Gr-GP & $4^{\text {th }}$ cousins & 15,703 & 1821.1 & $(27.8)$ & 1699 & 1896 & 62 & $(96.3)$ & 1 & 2 & 6 & 24 & 78 & 167 & 1,360 \\
\hline Gen -6 & Gr-Gr-Gr-Gr-GP & $5^{\text {th }}$ cousins & 10,199 & 1797.4 & $(30.0)$ & 1645 & 1866 & 160.5 & $(267.9)$ & 1 & 3 & 11 & 53 & 196 & 460 & 2,987 \\
\hline
\end{tabular}

Note: ${ }^{a}$ The sample is conditioned on having ancestors at least in generation $-5 .{ }^{b}$ In total, there are 161,487 unique ancestors that appear in 247,850 relations to index persons. Figures are before any sampling of $4^{\text {th }}$ and $5^{\text {th }}$ cousins. 
Table B3. Descriptive statistics for index generation

\begin{tabular}{|c|c|c|c|c|c|c|}
\hline & Mean & SD & Min & Max & Valid Count & Definition \\
\hline Birth year & 1966.26 & $(13.55)$ & 1940 & 1987 & 75,414 & Year of birth \\
\hline Woman & 0.49 & $(0.50)$ & 0 & 1 & 75,414 & Woman $=1$, Man $=0$ \\
\hline Years of education & 12.66 & $(2.47)$ & 6 & 19 & 73,241 & $\begin{array}{l}\text { Information on highest attained education from school } \\
\text { registers and censuses (Statistics Sweden 2005). } \\
\text { SUN2000 nomenclature recoded to years. Highest } \\
\text { observed value up until } 2017 \text {. }\end{array}$ \\
\hline ISEI & 44.0 & $(15.4)$ & 11.9 & 90.0 & 71,233 & $\begin{array}{l}\text { Information from censuses } 1985 \text { and 1990, occupation } \\
\text { register (2001-2017), linked to ISEI via ISCO-88(com) } \\
\text { using tools by Ganzeboom and Treiman (1996). Average } \\
\text { of observed values up until } 2017 \text {. }\end{array}$ \\
\hline Wealth (thousand SEK) & 280.18 & $(1003.95)$ & $-9,700^{\mathrm{a}}$ & $80,700^{\mathrm{a}}$ & 72,908 & $\begin{array}{l}\text { Information from wealth register (see text) in 1999-2007. } \\
\text { Averages over 1999-2007. }\end{array}$ \\
\hline
\end{tabular}


Table B4. HISCLASS with three most common HISCO codes in historical data.

\begin{tabular}{|c|c|c|c|c|}
\hline HISCLASS & Collapsed Scheme & Description & HISCO & Description \\
\hline \multirow[t]{3}{*}{1} & Upper & Higher managers & 58320 & Officer \\
\hline & & & 21110 & General Manager \\
\hline & & & 51020 & Working Proprietor (Hotel and Restaurant) \\
\hline \multirow[t]{3}{*}{2} & Upper & Higher professionals & 13000 & Teacher, Level and Subject Unknown \\
\hline & & & 2000 & Engineer, Specialisation Unknown \\
\hline & & & 14120 & Minister of Religion \\
\hline \multirow[t]{3}{*}{3} & Service & Lower managers & 58330 & Non-Commissioned Officer \\
\hline & & & 22610 & Production Supervisor or Foreman, General \\
\hline & & & 4217 & Ship's Master (Sea or Inland Waterways) \\
\hline \multirow[t]{3}{*}{4} & Service & Lower prof and clerical, sales & 41025 & Working Proprietor (Wholesale or Retail Trade) \\
\hline & & & 13320 & First Level Education Teacher \\
\hline & & & 7110 & Professional Nurse, General \\
\hline \multirow[t]{3}{*}{5} & Service & Lower clerical and sales & 45130 & Retail Trade Salesperson \\
\hline & & & 39310 & Office Clerk, General \\
\hline & & & 45190 & Other Salesmen, Shop Assistants and Demonstrators \\
\hline \multirow[t]{3}{*}{6} & Skilled & Foremen & 22430 & Housekeeper (Private Service) \\
\hline & & & 22425 & Housekeeper (Private Service, in Hotels, or in Other Institutions) \\
\hline & & & 22675 & Supervisor and General Foreman (Construction Work) \\
\hline \multirow[t]{3}{*}{7} & Skilled & Skilled workers & 79100 & Tailor, Specialisation Unknown \\
\hline & & & 95410 & Carpenter, General \\
\hline & & & 77610 & Baker, General \\
\hline \multirow[t]{3}{*}{8} & Farmers & Farmers & 61110 & General Farmer \\
\hline & & & 63240 & Timber Cruiser \\
\hline & & & 61240 & Livestock Farmer \\
\hline \multirow[t]{3}{*}{9} & Lower/ & Lower skilled workers & 58340 & Other Military Ranks \\
\hline & Unskilled & & 54010 & Domestic Servant, General \\
\hline & & & 73210 & Sawyer, General \\
\hline \multirow[t]{3}{*}{10} & Lower/ & Lower skilled farm workers & 63110 & Logger (General) \\
\hline & Unskilled (farm) & & 61115 & Small Subsistence Farmer (Husbandman) \\
\hline & & & 62120 & Farm Servant \\
\hline \multirow[t]{3}{*}{11} & Lower/ & Unskilled workers & 54020 & House Servant \\
\hline & Unskilled & & 99910 & Labourer \\
\hline & & & 98135 & Seaman, Able or Ordinary \\
\hline \multirow[t]{3}{*}{12} & Lower/ & Unskilled farm workers & 99900 & Worker, No Further Information \\
\hline & Unskilled (farm) & & 62105 & Farm-Worker, General \\
\hline & & & 99920 & Day-Labourer \\
\hline
\end{tabular}


Table B5. Unique ancestors' occupational class

\begin{tabular}{|c|c|c|c|c|c|c|}
\hline & $\begin{array}{l}\text { Gen -1 } \\
\text { Parents } \\
\text { Siblings }\end{array}$ & $\begin{array}{c}\text { Gen }-2 \\
\text { Grandparents } \\
1^{\text {st }} \text { cousins }\end{array}$ & Gen -3 & $\begin{array}{c}\text { Gen }-4 \\
\ldots \\
\ldots \\
\end{array}$ & Gen -5 & $\begin{array}{c}\text { Gen }-6 \\
\text { Gr-Gr-Gr-Gr GP } \\
5^{\text {th }} \text { cousins }\end{array}$ \\
\hline Average HISCAM score & 50.16 & 49.83 & 50.38 & 50.3 & 49.9 & 49.97 \\
\hline SD average HISCAM score & 12.03 & 11.27 & 8.52 & 6.25 & 6.34 & 6.96 \\
\hline Higher managers & 5,571 & 2,591 & 228 & 100 & 89 & 67 \\
\hline Higher professionals & 3,667 & 2,459 & 534 & 229 & 150 & 109 \\
\hline Lower managers & 3,410 & 2,281 & 649 & 292 & 171 & 123 \\
\hline Lower prof and clerical, sales & 20,184 & 9,115 & 1,208 & 317 & 139 & 73 \\
\hline Lower clerical and sales & 7,014 & 4,619 & 535 & 50 & 26 & 14 \\
\hline Foremen & 593 & 1,043 & 575 & 114 & 21 & 7 \\
\hline Skilled workers & 14,267 & 11,874 & 3,072 & 756 & 262 & 102 \\
\hline Farmers & 4,776 & 15,148 & 16,754 & 12,534 & 7,248 & 3,684 \\
\hline Lower skilled workers & 2,152 & 3,822 & 2,192 & 925 & 637 & 532 \\
\hline Lower skilled farm workers & 335 & 695 & 762 & 646 & 396 & 146 \\
\hline Unskilled workers & 10,601 & 10,725 & 2,241 & 133 & 33 & 9 \\
\hline Unskilled farm workers & 907 & 3,909 & 5,596 & 5,564 & 4,021 & 2,485 \\
\hline $\begin{array}{l}\text { Unique ancestors with HISCO } \\
\text { occupation information }\end{array}$ & 73,477 & 68,281 & 34,348 & 21,670 & 13,245 & 7,403 \\
\hline
\end{tabular}

Note: These class categories are entered as dummies in the regressions creating the kinship class scales, per relation to index individual. 
Table B6. Share of individuals in our original data set from parish registers, where we can find a traceable descendant in modern register who have a 5th generation decendant, by birth cohort of individual.

\begin{tabular}{|c|c|c|}
\hline $\begin{array}{l}\text { Birth cohort } \\
\text { (entire decade) }\end{array}$ & $\begin{array}{l}\text { Share with } \\
\text { traceable } \\
\text { descendants }\end{array}$ & $\begin{array}{l}\mathrm{N} \text { in parish } \\
\text { registers }\end{array}$ \\
\hline 1700 & 0.53 & 490 \\
\hline 1710 & 0.50 & 472 \\
\hline 1720 & 0.52 & 637 \\
\hline 1730 & 0.57 & 836 \\
\hline 1740 & 0.57 & 741 \\
\hline 1750 & 0.59 & 958 \\
\hline 1760 & 0.53 & 1,106 \\
\hline 1770 & 0.55 & 1,383 \\
\hline 1780 & 0.53 & 1,516 \\
\hline 1790 & 0.60 & 2,004 \\
\hline 1800 & 0.60 & 2,075 \\
\hline 1810 & 0.52 & 2,709 \\
\hline 1820 & 0.52 & 4,297 \\
\hline 1830 & 0.48 & 4,703 \\
\hline 1840 & 0.46 & 6,393 \\
\hline 1850 & 0.44 & 8,322 \\
\hline 1860 & 0.39 & 10,206 \\
\hline 1870 & 0.34 & 13,430 \\
\hline 1880 & 0.30 & 18,003 \\
\hline 1890 & 0.29 & 21,849 \\
\hline 1900 & 0.30 & 25,017 \\
\hline Total & 0.37 & 127,147 \\
\hline
\end{tabular}

Note: The denominator is everyone observed born in our parish source registers, and observed to at least at age 15 in the parish registers (not having died or out-migrated).

Numerator is if these individuals have a descendant in contemporary Sweden, and are a part of kinship network with at least one ancestor in G -5 . Ancestor birth cohort coded in 10-year intervals $(1700=1700-1709)$. All cohorts in DDB database, with conditioning on 1$)$ ancestors alive at age 15,2$)$ ancestors without missing information on outmigration/death. The lower shares in the final cohorts partly reflect that we have more data from the Umeå region, where we have less historically deep kinship networks. 
Part C. Additional results

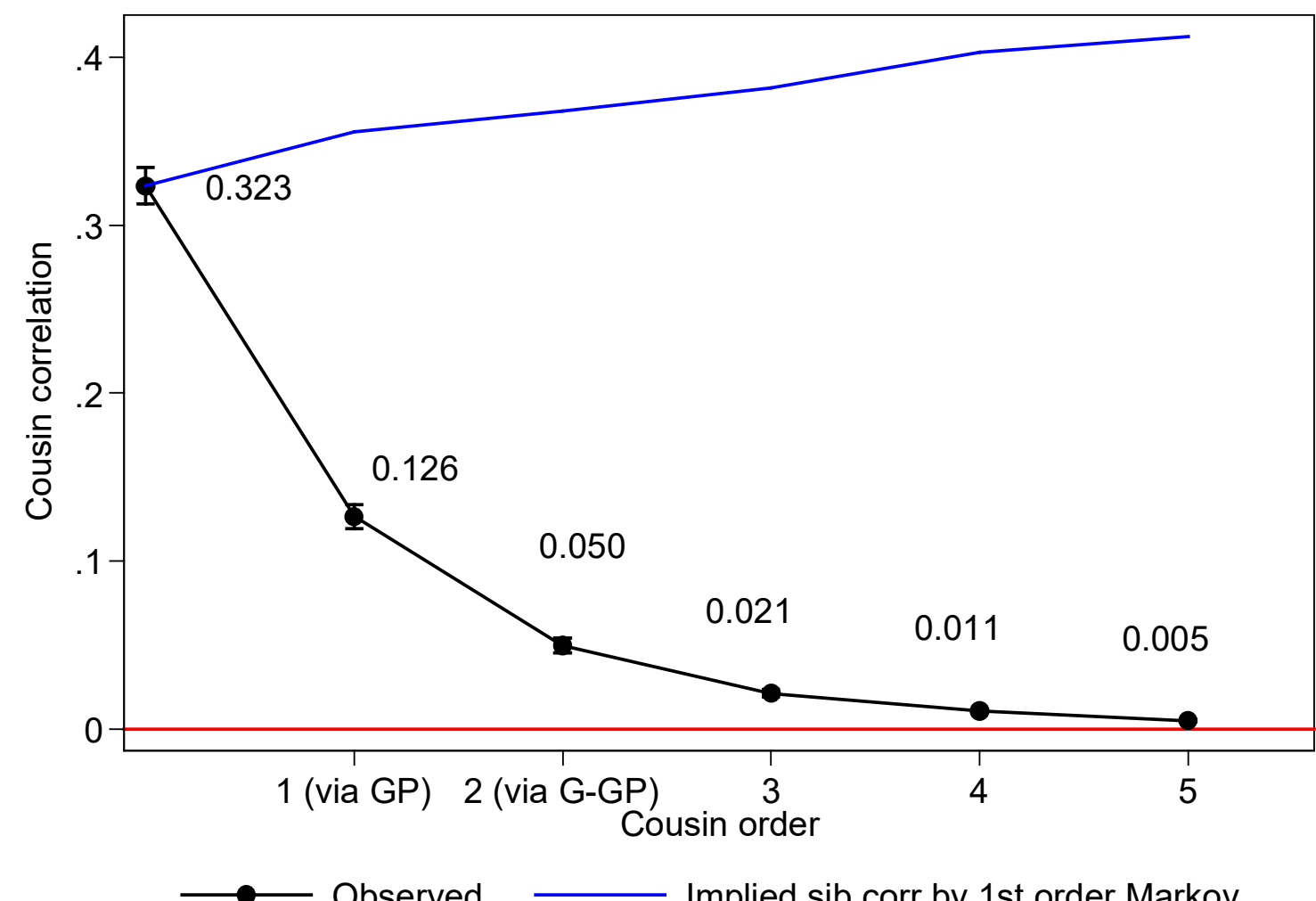

Figure S1. Cousin correlations in years of education with their implied sibling correlation

Note: Sample is men and women born 1940-1987 in Sweden with a $5^{\text {th }}$ generation descendant in Northern Sweden. The implied sibling correlation is the cousin correlation

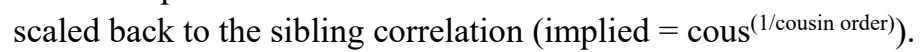




\section{Part D. Construction of kinship occupation scales and sensitivity analyses}

For the dynastic correlations, we rely on averages of the HISCAM scale and also on a more flexible specification where we empirically define the scale (see, e.g., Björklund and Sundström 2006; Hällsten and Pfeffer 2017) using information on HISCO coded into HISCLASS. The HISCAM is but one of several possible ways of coding occupations in the past. It may be contingent on context, meaning that it may not perfectly capture dynastic correlations. Our point of departure for the empirical scale is HISCLASS. As a nominal class scale, it has no apparent continuous scaling, which is necessary in order to average over ancestors. We have empirically defined the scale by regressing the descendant's outcome on a dummy representation of the ancestor's class (with control for ancestors' birth years). The regression coefficients (predicted margins) then form the values of the scale for each class category. The benefit of this approach is that the scaling will be optimized for the association we study so that we capture as much of the true multigenerational association as possible. Instead of assuming the HISCAM values or ad hoc values of the 12 different HISCLASS categories, which is quite difficult given the historical nature of the data and the still-limited knowledge of multigenerational transmissions, we use the sample to define these values. However, one problem is that the scale is estimated from data, and therefore contains uncertainties. This may be especially problematic in our case, given that the associations we examine are naturally weak, as the generations are far removed. The class variable also has limited variation in historical time. To target the uncertainty, we have varied how we treat ancestors in order to balance specificity and sample size in each data cell:

1) Regress descendants' outcomes on ancestors' social class by their relation (kinship sequence). This means that we estimate 124 regressions $(4+8+16+32+64)$, one per unique kinship sequence. This yields the lowest number of observations per ancestor class category in each regression. 
(treating all relations within generations as being the same). Then, we pool data and only estimate 8 regression models ( 1 per generation). This yields the highest number of observations per ancestor class category, but entirely disregards the relation between ancestor and descendant.

Regress descendants' outcomes on ancestors' social class by the ancestor's relation type and generation (maternal/paternal lineage and ancestor's gender; e.g., for generation -4, we constrain the genders at the start and end of the sequence, leaving the middle free to vary: $\mathrm{mXXm}, \mathrm{mXXf}$, fXXm, fXXf). This treats all relations within generations/types as being the same. We pool data estimates for 20 regressions $(4+4+4+4+4)$. This should be some form of middle ground balancing sample size and relation type.

The third approach is a compromise between using relational information and using large sample sizes and our preferred method. It would principally be possible to weigh the scale by the uncertainty (standard error) of the predicted margins so that less precise information would have less influence on the scale. However, as our nominal class variable is dominated by one category of farmers, it would mean that we also disregard any deviations from farm class, which is the source of variation we are most interested in. Weighting is, therefore, not feasible in our case (and would lead to an underestimate of the dynastic correlation).

The graphs D1 to D4 below show results from these different approaches. We use the descendants' rank years of education as the outcome for these analyses (however, the results also apply to the other outcomes). First, we get the strongest estimates when using relational information displayed in Figure D1. The relation-based measures tend to remain stable for the very eldest generations. Second, when we shift methods to focus on larger samples based on the generation or generation * type of relation in Figures D2 and D3, this pattern is replaced by some slow continuous decline of associations even though it is still very stable. Importantly, in all these specifications including the HISCAM in Figure D4, the independent associations for all generations remain larger 
than zero and do not fit a simple Markov process. The associations estimated under mutual control also give a very similar findings, with significant associations $>0$ for all generations, with two exceptions: generation -5 for HISCAM and generation -6 for generation * relation type.

The main divide is between using the full relational information in method 1 (at the cost of small cell sizes) or focusing instead on generations in D2/D3; there is very little difference between methods 2 and 3. Our main conclusion is that the results we display as our main findings may be lower bound; it is possible that dynastic correlations are stronger, as if the relations themselves matter more. It would take a substantially larger sample than ours (at circa 75,000 descendants) to scrutinize this issue. We also note that these results are always stronger than using averages of the HISCAM (except for generation -6 , where the HISCAM is stronger than the generation * type), which are depicted in Figure D4.

One of the main points of the dynastic correlation approach of Adermon, Lindahl and Palme (2019) is that one can assess latent SES by averaging across ancestors within ancestor generations. Since we do not observe all ancestors of an individual, in most cases not even close to all theoretical ancestors (e.g., 64 in generation -6), the quality of the SES signal may be weaker relative to noise the fewer ancestor kin we observe. In Tables D3 and D4, we re-estimate the models by splitting the sample by into two halves around the median of the number of observed ancestors with valid occupation information. For more distant generations, we see a clear pattern that the larger kinship network we can observe is associated with higher persistence. We believe this is evidence of 1) that historical occupation measures are very noisy; 2) we get a less erroneous SES measurement when we can average over more kin (not least since size plays no clear role for cousin correlations in the next section, Part D). This would indicate that our main estimates still underestimate true persistence. It also suggests that the dynastic approach is a necessity in order to capture multigenerational correlations in the vertical transmission models, and that correlations between single ancestors and descendants will be downwardly biased. 

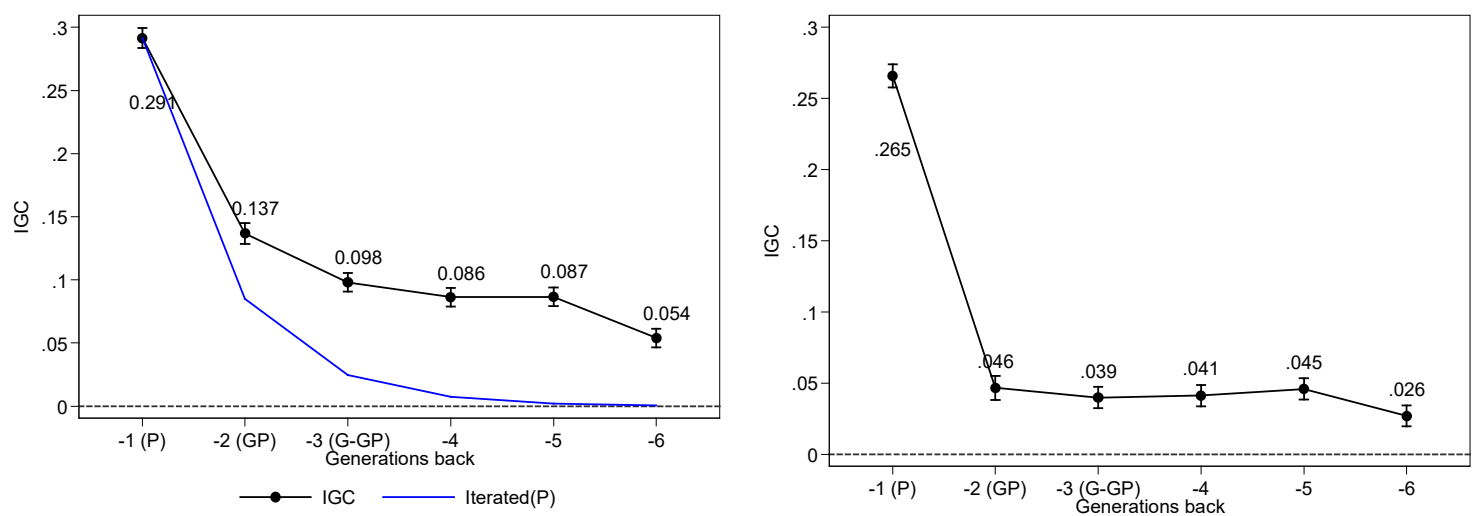

Figure D1. Dynastic correlations in years of education with scale estimated per relation. Separate (left) vs joint (right) regressions.
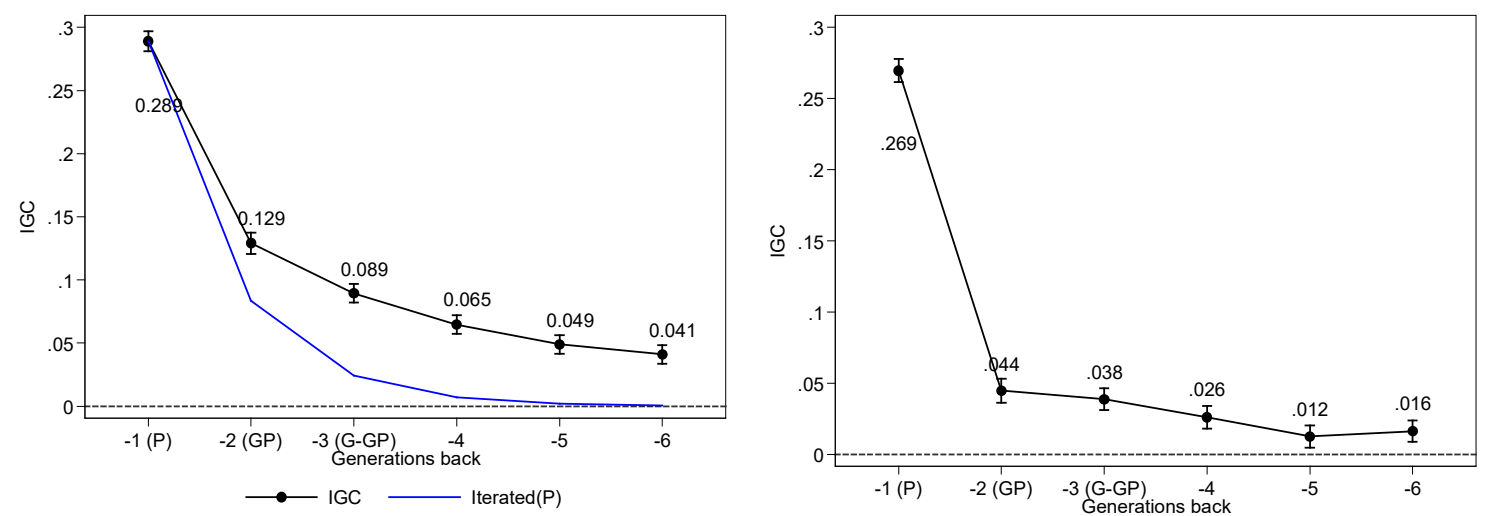

Figure D2. Dynastic correlations in years of education with scale estimated per generation. Separate (left) vs joint (right) regressions.
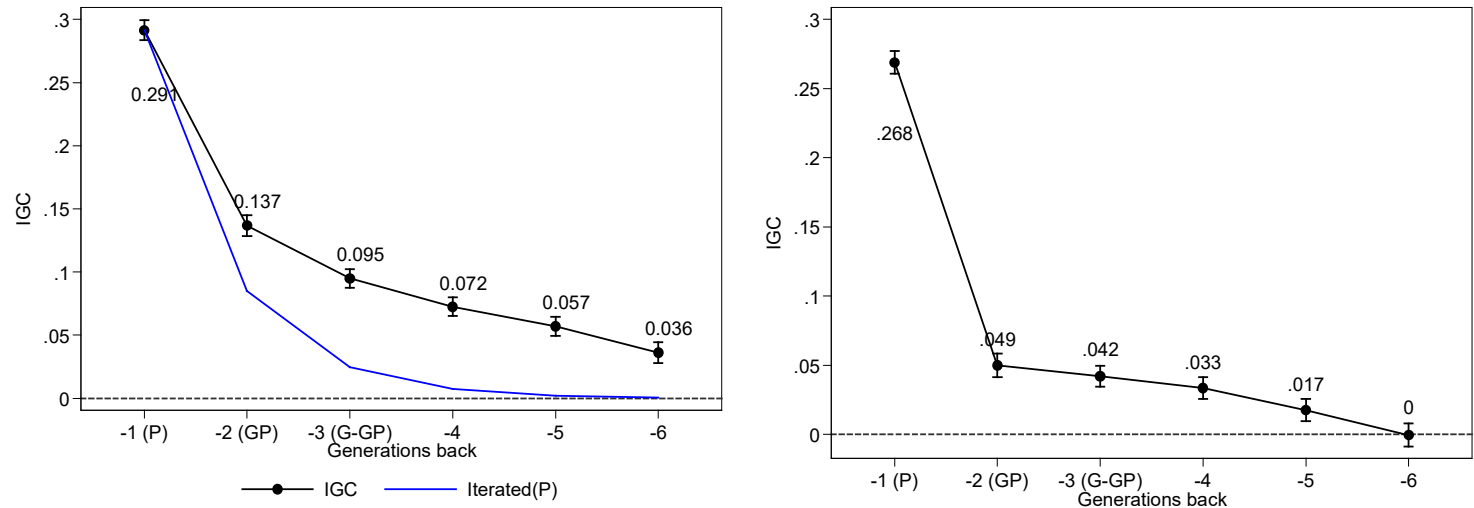

Figure D3. Dynastic correlations in years of education with scale estimated per generation type. Separate (left) vs joint (right) regressions. 

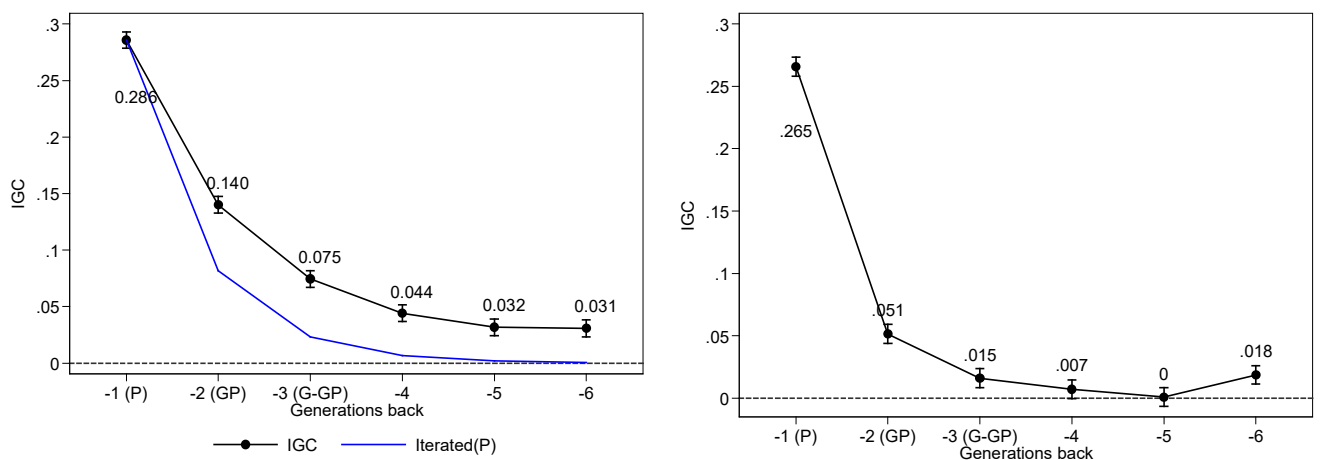

Figure D4. Dynastic correlations in years of education with average HISCAM. Separate (left) vs joint (right) regressions.

Table D1. Correlations across different kin class scales.

\begin{tabular}{|c|c|c|c|c|c|c|c|c|}
\hline \multicolumn{2}{|c|}{ Generation } & $-1(\mathrm{P})$ & $-2(\mathrm{GP})$ & -3 (G-GP) & -4 & -5 & & -6 \\
\hline \multicolumn{9}{|c|}{ Average HISCAM } \\
\hline & $-1(\mathrm{P})$ & 1 & & & & & & \\
\hline & $-2(\mathrm{GP})$ & 0.31 & 1 & & & & & \\
\hline & -3 (G-GP) & 0.15 & 0.24 & 1 & & & & \\
\hline & -4 & 0.08 & 0.11 & 0.29 & 1 & & & \\
\hline & -5 & 0.07 & 0.08 & 0.11 & 0.22 & 1 & & \\
\hline & -6 & 0.05 & 0.09 & 0.04 & 0.07 & 0.23 & 1 & \\
\hline \multicolumn{9}{|c|}{ Kin class scale } \\
\hline \multirow[t]{6}{*}{ Education } & $-1(\mathrm{P})$ & 1 & & & & & & \\
\hline & $-2(\mathrm{GP})$ & 0.34 & 1 & & & & & \\
\hline & -3 (G-GP) & 0.16 & 0.23 & 1 & & & & \\
\hline & -4 & 0.08 & 0.13 & 0.29 & 1 & & & \\
\hline & -5 & 0.10 & 0.11 & 0.18 & 0.32 & 1 & & \\
\hline & -6 & 0.22 & 0.24 & 0.15 & 0.20 & 0.34 & 1 & \\
\hline \multirow[t]{6}{*}{ Occupation } & $-1(\mathrm{P})$ & 1 & & & & & & \\
\hline & $-2(\mathrm{GP})$ & 0.37 & 1 & & & & & \\
\hline & -3 (G-GP) & 0.17 & 0.30 & 1 & & & & \\
\hline & -4 & 0.09 & 0.15 & 0.25 & 1 & & & \\
\hline & -5 & 0.09 & 0.09 & 0.13 & 0.25 & 1 & & \\
\hline & -6 & 0.2 & 0.23 & 0.14 & 0.20 & 0.29 & 1 & \\
\hline \multirow[t]{6}{*}{ Wealth } & $-1(\mathrm{P})$ & 1 & & & & & & \\
\hline & $-2(\mathrm{GP})$ & 0.2 & 1 & & & & & \\
\hline & -3 (G-GP) & 0.10 & 0.16 & 1 & & & & \\
\hline & -4 & 0.08 & 0.16 & 0.31 & 1 & & & \\
\hline & -5 & 0.07 & 0.10 & 0.20 & 0.34 & 1 & & \\
\hline & -6 & 0.05 & 0.08 & 0.15 & 0.21 & 0.29 & 1 & \\
\hline
\end{tabular}


Table D2. Full specification of dynastic correlations in rank education

\begin{tabular}{|c|c|c|c|c|c|c|c|c|}
\hline & $(1)$ & $(2)$ & (3) & (4) & (5) & $(6)$ & (7) & $(8)$ \\
\hline Aver. HISCAM (-1) & & $\begin{array}{l}0.074 * * * \\
(78.30)\end{array}$ & & & & & & $\begin{array}{l}0.068 * * * \\
(68.94)\end{array}$ \\
\hline Aver. HISCAM (-2) & & & $\begin{array}{l}0.036 * * * \\
(37.33)\end{array}$ & & & & & $\begin{array}{l}0.013 * * * \\
(13.16)\end{array}$ \\
\hline Aver. HISCAM (-3) & & & & $\begin{array}{l}0.020 * * * \\
(19.79)\end{array}$ & & & & $\begin{array}{l}0.004 * * * \\
(4.14)\end{array}$ \\
\hline Aver. HISCAM (-4) & & & & & $\begin{array}{l}0.012 * * * \\
(11.69)\end{array}$ & & & $\begin{array}{l}0.002 \\
(1.83)\end{array}$ \\
\hline Aver. HISCAM (-5) & & & & & & $\begin{array}{l}0.009 * * * \\
(8.41)\end{array}$ & & $\begin{array}{l}0 \\
(0.21)\end{array}$ \\
\hline Aver. HISCAM (-6) & & & & & & & $\begin{array}{l}0.008 * * * \\
(8.03)\end{array}$ & $\begin{array}{l}0.005^{* * *} \\
(4.94)\end{array}$ \\
\hline Gender $\times$ Birth year & Yes & Yes & Yes & Yes & Yes & Yes & Yes & Yes \\
\hline MGC & & 0.286 & 0.14 & 0.075 & 0.044 & 0.032 & 0.031 & \\
\hline Sum of MGC & & & & & & & & 0.360 \\
\hline$\Delta \mathrm{R} 2$ & & 0.079 & 0.019 & 0.005 & 0.002 & 0.001 & 0.001 & 0.083 \\
\hline Observations & 67,884 & 67,884 & 67,884 & 67,884 & 67,884 & 67,884 & 67,884 & 67,884 \\
\hline Adjusted R2 & 0.047 & 0.126 & 0.066 & 0.053 & 0.049 & 0.048 & 0.048 & 0.13 \\
\hline Kin class scale $(-1)$ & & $\begin{array}{l}0.075 * * * \\
(72.67)\end{array}$ & & & & & & $\begin{array}{l}0.069 * * * \\
(64.74)\end{array}$ \\
\hline Kin class scale $(-2)$ & & & $\begin{array}{l}0.036 * * * \\
(32.50)\end{array}$ & & & & & $\begin{array}{l}0.013 * * * \\
(11.64)\end{array}$ \\
\hline Kin class scale $(-3)$ & & & & $\begin{array}{l}0.025 * * * \\
(25.27)\end{array}$ & & & & $\begin{array}{l}0.011 * * * \\
(10.89)\end{array}$ \\
\hline Kin class scale $(-4)$ & & & & & $\begin{array}{l}0.019 * * * \\
(19.30)\end{array}$ & & & $\begin{array}{l}0.009 * * * \\
(8.40)\end{array}$ \\
\hline Kin class scale $(-5)$ & & & & & & $\begin{array}{l}0.017 * * * \\
(15.03)\end{array}$ & & $\begin{array}{l}0.005^{* * *} \\
(4.33)\end{array}$ \\
\hline Kin class scale $(-6)$ & & & & & & & $\begin{array}{l}0.009 * * * \\
(8.66)\end{array}$ & $\begin{array}{l}0 \\
(-0.11)\end{array}$ \\
\hline Gender $\times$ Birth year & Yes & Yes & Yes & Yes & Yes & Yes & Yes & Yes \\
\hline MGC & & 0.291 & 0.137 & 0.095 & 0.072 & 0.057 & 0.036 & \\
\hline Sum of MGC & & & & & & & & 0.411 \\
\hline$\Delta \mathrm{R} 2$ & & 0.069 & 0.015 & 0.009 & 0.005 & 0.003 & 0.001 & 0.076 \\
\hline Observations & 67,826 & 67,826 & 67,826 & 67,826 & 67,826 & 67,826 & 67,826 & 67,826 \\
\hline Adjusted R2 & 0.047 & 0.116 & 0.062 & 0.056 & 0.052 & 0.05 & 0.048 & 0.123 \\
\hline
\end{tabular}

Note: HISCAM/kin class scale is standardized to z-scores and outcome scaled to be in ranks 
Table D3. Dynastic correlation in rank education by HISCAM by number of kin in each generation.

\begin{tabular}{|c|c|c|c|c|c|c|c|c|c|c|c|c|c|c|}
\hline & Many & Few & Many & Few & Many & Few & Many & Few & Many & Few & Many & Few & Many & Few \\
\hline Aver. HISCAM (-1) & $\begin{array}{l}0.076^{* * *} \\
(78.54)\end{array}$ & $\begin{array}{l}0.074 * * * \\
(81.05)\end{array}$ & & & & & & & & & & & $\begin{array}{l}0.068 * * * \\
(49.83)\end{array}$ & $\begin{array}{l}0.068 * * * \\
(68.88)\end{array}$ \\
\hline Aver. HISCAM (-2) & & & $\begin{array}{l}0.039 * * * \\
(33.26)\end{array}$ & $\begin{array}{l}0.036^{* * *} \\
(38.58)\end{array}$ & & & & & & & & & $\begin{array}{l}0.011^{* * *} \\
(7.18)\end{array}$ & $\begin{array}{l}0.013^{* * *} \\
(13.13)\end{array}$ \\
\hline Aver. HISCAM (-3) & & & & & $\begin{array}{l}0.028 * * * \\
(16.48)\end{array}$ & $\begin{array}{l}0.019 * * * \\
(20.07)\end{array}$ & & & & & & & $\begin{array}{l}0.007 * * * \\
(3.35)\end{array}$ & $\begin{array}{l}0.004^{* * *} \\
(4.18)\end{array}$ \\
\hline Aver. HISCAM (-4) & & & & & & & $\begin{array}{l}0.021 * * * \\
(10.24)\end{array}$ & $\begin{array}{l}0.011 * * * \\
(11.44)\end{array}$ & & & & & $\begin{array}{l}0.004 * \\
(2.01)\end{array}$ & $\begin{array}{l}0.002 \\
(1.82)\end{array}$ \\
\hline Aver. HISCAM (-5) & & & & & & & & & $\begin{array}{l}0.014 * * * \\
(7.55)\end{array}$ & $\begin{array}{l}0.006^{* * *} \\
(6.61)\end{array}$ & & & $\begin{array}{l}0.004 * \\
(2.02)\end{array}$ & $\begin{array}{l}0.00 \\
(0.22)\end{array}$ \\
\hline Aver. HISCAM (-6) & & & & & & & & & & & $\begin{array}{l}0.016^{* * *} \\
(8.24)\end{array}$ & $\begin{array}{l}0.008 * * * \\
(7.84)\end{array}$ & $\begin{array}{l}0.012^{* * *} \\
(7.09)\end{array}$ & $\begin{array}{l}0.005^{* * *} \\
(4.97)\end{array}$ \\
\hline Gender $\times$ Birth year & Yes & Yes & Yes & Yes & Yes & Yes & Yes & Yes & Yes & Yes & Yes & Yes & Yes & Yes \\
\hline MGC & 0.291 & 0.287 & 0.142 & 0.14 & 0.073 & 0.073 & 0.051 & 0.042 & 0.037 & 0.024 & 0.043 & 0.03 & & \\
\hline Sum of MGC & & & & & & & & & & & & & 0.368 & 0.36 \\
\hline$\Delta \mathrm{R} 2$ & 0.08 & 0.08 & 0.027 & 0.019 & 0.011 & 0.005 & 0.008 & 0.002 & 0.005 & 0.001 & 0.001 & 0.001 & 0.079 & 0.083 \\
\hline Observations & 65,373 & 72,164 & 51,913 & 72,388 & 48,295 & 72,462 & 38,899 & 72,503 & 39,773 & 71,949 & 38,687 & 68,379 & 37,445 & 67,787 \\
\hline Adjusted R2 & 0.127 & 0.127 & 0.074 & 0.066 & 0.058 & 0.052 & 0.055 & 0.049 & 0.052 & 0.048 & 0.048 & 0.048 & 0.126 & 0.13 \\
\hline
\end{tabular}

Note: Many $=$ number of kin over or equal to median, Few $=$ number of kin under median. 
Table D4. Dynastic correlation in rank education by kin class scale by number of kin in each generation.

\begin{tabular}{|c|c|c|c|c|c|c|c|c|c|c|c|c|c|c|}
\hline & Many & Few & Many & Few & Many & Few & Many & Few & Many & Few & Many & Few & Many & Few \\
\hline Kin class scale $(-1)$ & $\begin{array}{l}0.077 * * * \\
(72.58)\end{array}$ & $\begin{array}{l}0.057 * * * \\
(20.03)\end{array}$ & & & & & & & & & & & $\begin{array}{l}0.066^{* * *} \\
(46.94)\end{array}$ & $\begin{array}{l}0.072 * * * \\
(44.20)\end{array}$ \\
\hline Kin class scale $(-2)$ & & & $\begin{array}{l}0.033 \text { *** } \\
(25.26)\end{array}$ & $\begin{array}{l}0.037 * * * \\
(21.25)\end{array}$ & & & & & & & & & $\begin{array}{l}0.008 * * * \\
(5.49)\end{array}$ & $\begin{array}{l}0.019 * * * \\
(11.41)\end{array}$ \\
\hline Kin class scale $(-3)$ & & & & & $\begin{array}{l}0.033 * * * \\
(21.91)\end{array}$ & $\begin{array}{l}0.018 * * * \\
(14.95)\end{array}$ & & & & & & & $\begin{array}{l}0.015^{* * *} \\
(9.27)\end{array}$ & $\begin{array}{l}0.008 * * * \\
(6.08)\end{array}$ \\
\hline Kin class scale $(-4)$ & & & & & & & $\begin{array}{l}0.030 * * * \\
(17.23)\end{array}$ & $\begin{array}{l}0.012 * * * \\
(11.37)\end{array}$ & & & & & $\begin{array}{l}0.008 * * * \\
(4.94)\end{array}$ & $\begin{array}{l}0.008 * * * \\
(5.87)\end{array}$ \\
\hline Kin class scale $(-5)$ & & & & & & & & & $\begin{array}{l}0.030^{* * *} \\
(14.95)\end{array}$ & $\begin{array}{l}0.009 * * * \\
(8.21)\end{array}$ & & & $\begin{array}{l}0.011^{* * *} \\
(5.25)\end{array}$ & $\begin{array}{l}0.002 \\
(1.23)\end{array}$ \\
\hline Kin class scale $(-6)$ & & & & & & & & & & & $\begin{array}{l}0.019 * * * \\
(8.92)\end{array}$ & $\begin{array}{l}0.005^{* * *} \\
(3.93)\end{array}$ & $\begin{array}{l}-0.002 \\
(-0.88)\end{array}$ & $\begin{array}{l}-0.001 \\
(-0.53)\end{array}$ \\
\hline Gender $\times$ Birth year & Yes & Yes & Yes & Yes & Yes & Yes & Yes & Yes & Yes & Yes & Yes & Yes & Yes & Yes \\
\hline MGC & 0.295 & 0.234 & 0.126 & 0.15 & 0.097 & 0.093 & 0.085 & 0.06 & 0.075 & 0.045 & 0.052 & 0.024 & & \\
\hline Sum of MGC & & & & & & & & & & & & & 0.385 & 0.435 \\
\hline$\Delta \mathrm{R} 2$ & 0.069 & 0.015 & 0.019 & 0.002 & 0.015 & -0.007 & 0.013 & -0.004 & 0.009 & 0 & 0.001 & -0.004 & 0.068 & 0.083 \\
\hline Observations & 65,481 & 7,410 & 52,005 & 21,106 & 48,320 & 24,860 & 38,898 & 34,326 & 39,751 & 32,636 & 38,650 & 29,789 & 38,519 & 29,307 \\
\hline Adjusted R2 & 0.116 & 0.062 & 0.066 & 0.049 & 0.062 & 0.04 & 0.06 & 0.043 & 0.056 & 0.047 & 0.049 & 0.043 & 0.115 & 0.13 \\
\hline
\end{tabular}

Note: Many $=$ number of kin over or equal to median, Few $=$ number of kin under median. 


\section{Part E. Size of kinship network}

Large differences in fertility in historical times led to considerable differences in the number of descendants some ancestors have produced (Table B2). This means a potential for substantial influence via quality-quantity tradeoffs (Becker and Barro 1988), but also that the data are dominated by a few, and possibly more influential, sets of families. We address both issues by using different weights when we produce our cousin correlations and estimate cousin correlations for size groups of the number of cousins. In principle, these are different types of populations, i.e., families vs. individuals.

Table E1 shows four sets of weights discussed by Solon, Page and Duncan (2000) that have been used in the literature over the years. The first weighs each family equally and thus minimizes any impact of very large families. In contrast, the last (third) weight treats each tie equally, meaning that large families will indeed dominate. However, Solon, Page and Duncan (2000) argue for using the second weight, which provides an intermediate form of down-weighting large families. They argue that larger families still contribute more information, and therefore all families should not be treated equally. The second weight also offers high efficiency. While the weights are originally specified on the number of siblings (left column), which deterministically produces sibling pairs, this is not the case for higher-order cousins. We have therefore converted the weights based on the number of cousin pairs (right column). Table E2 shows estimates for education using all these weights. Despite the huge differences in kinship size, the weights tend to give very similar results. There are some differences for $4^{\text {th }}$ and $5^{\text {th }}$ cousins where treating all families as equal (weight 1 ) produces larger correlations compared to the other weights. The second weight produces the largest t-values and is most efficient. All of our estimates presented above use the second weight, which seems to be a moderate and optimal choice, and more of a lower bound. The key conclusion is that it does not matter dramatically if we view the population as consisting of families or individuals. 
Table E3 shows estimates, using the second weight, where we have divided the sample into three groups depending on kinship size (from small to large), excluding siblings because of limited size variation. We find that there is no strong pattern. We conclude that kinship size is not a strong driver of the cousin correlations we observe.

Table E1. Weighting schemes for cousin correlations, per unique cousin tie

\begin{tabular}{lll}
\hline Scheme & $\begin{array}{l}\text { Original } \\
\text { specification }\end{array}$ & $\begin{array}{l}\text { Operational } \\
\text { specification }\end{array}$ \\
\hline$w_{1}$ (all families weighted equally) & {$[1 / 2 n(n-1)]^{-1}$} & {$[\text { pair }]^{-1}$} \\
$w_{2}$ (intermediate down-weighting) & {$\left[[1 / 2 n(n-1)]^{1 / 2}\right]^{-1}$} & {$\left[[\text { pair }]^{1 / 2}\right]^{-1}$} \\
$w_{3}$ (all ties weighted equally) & 1 & 1 \\
\hline
\end{tabular}

Note: $n=$ number of cousins, pair $=$ number of pairs. The weights are outlined by Solon, Page and Duncan (2000). 
Table E2. Cousin correlations in rank years of education by different weighting schemes.

\begin{tabular}{|c|c|c|c|c|c|c|c|c|c|c|}
\hline Weight & $\begin{array}{c}\text { Cousin } \\
\text { order }\end{array}$ & Rho & s.e. & $\mathrm{t}$ & CI- & $\mathrm{CI}+$ & $\begin{array}{l}\text { Iterated } \\
\text { (Sibling) }\end{array}$ & Difference & $\begin{array}{c}\text { Unique } \\
\text { Ancestors }\end{array}$ & No. ties \\
\hline 1 & 0 (sibs) & 0.318 & 0.005 & 57.9 & 0.307 & 0.329 & 0.318 & & 25,030 & 52,123 \\
\hline 2 & 0 & 0.323 & 0.006 & 57.8 & 0.312 & 0.334 & 0.323 & & 25,030 & 52,123 \\
\hline 3 & 0 & 0.333 & 0.008 & 43.8 & 0.318 & 0.348 & 0.333 & & 25,030 & 52,123 \\
\hline 1 & 1 & 0.128 & 0.004 & 30.4 & 0.119 & 0.136 & 0.101 & 0.026 & 12,573 & 251,396 \\
\hline 2 & 1 & 0.126 & 0.004 & 35.1 & 0.119 & 0.133 & 0.105 & 0.022 & 12,573 & 251,396 \\
\hline 3 & 1 & 0.127 & 0.006 & 22.6 & 0.116 & 0.138 & 0.111 & 0.016 & 12,573 & 251,396 \\
\hline 1 & 2 & 0.051 & 0.004 & 12.3 & 0.043 & 0.060 & 0.032 & 0.019 & 9,481 & $1,274,838$ \\
\hline 2 & 2 & 0.050 & 0.002 & 22.6 & 0.045 & 0.054 & 0.034 & 0.016 & 9,481 & $1,274,838$ \\
\hline 3 & 2 & 0.051 & 0.003 & 16.4 & 0.045 & 0.057 & 0.037 & 0.014 & 9,481 & $1,274,838$ \\
\hline 1 & 3 & 0.021 & 0.003 & 8.5 & 0.016 & 0.026 & 0.010 & 0.011 & 12,447 & $10,789,168$ \\
\hline 2 & 3 & 0.021 & 0.001 & 17.7 & 0.019 & 0.024 & 0.011 & 0.010 & 12,447 & $10,789,168$ \\
\hline 3 & 3 & 0.021 & 0.001 & 14.9 & 0.018 & 0.024 & 0.012 & 0.009 & 12,447 & $10,789,168$ \\
\hline 1 & 4 & 0.015 & 0.002 & 6.0 & 0.010 & 0.019 & 0.003 & 0.011 & 8,503 & $21,536,050$ \\
\hline 2 & 4 & 0.011 & 0.001 & 17.7 & 0.009 & 0.012 & 0.004 & 0.007 & 8,503 & $21,536,050$ \\
\hline 3 & 4 & 0.010 & 0.001 & 16.2 & 0.009 & 0.011 & 0.004 & 0.006 & 8,503 & $21,536,050$ \\
\hline 1 & 5 & 0.011 & 0.003 & 3.7 & 0.005 & 0.017 & 0.001 & 0.010 & 5,841 & $35,416,306$ \\
\hline 2 & 5 & 0.005 & 0.000 & 12.3 & 0.004 & 0.006 & 0.001 & 0.004 & 5,841 & $35,416,306$ \\
\hline 3 & 5 & 0.004 & 0.001 & 8.0 & 0.003 & 0.005 & 0.001 & 0.003 & 5,841 & $35,416,306$ \\
\hline
\end{tabular}

Note: * sample of pairs (see text for details). Weight 2 is used for all analyses shown elsewhere. 
Table E3. Cousin correlations in rank years of education by size of kinship network

\begin{tabular}{ccccccccc}
\hline $\begin{array}{l}\text { Cousin } \\
\text { order }\end{array}$ & $\begin{array}{c}\text { Kinship network } \\
\text { size group } \\
\text { tertiles) }^{\mathrm{a}}\end{array}$ & Rho & s.e. & $\mathrm{t}$ & CI- & CI+ & $\begin{array}{c}\text { Unique } \\
\text { Ancestors }\end{array}$ \\
\hline 1 & Small & 0.127 & 0.005 & 26.4 & 0.117 & 0.136 & 10,316 & 82,018 \\
& Middle & 0.126 & 0.008 & 16.6 & 0.112 & 0.141 & 1,740 & 85,298 \\
& Large & 0.124 & 0.010 & 12.0 & 0.104 & 0.145 & 517 & 84,080 \\
2 & Small & 0.050 & 0.003 & 14.6 & 0.043 & 0.056 & 8,242 & 425,345 \\
& Middle & 0.047 & 0.005 & 9.6 & 0.037 & 0.057 & 938 & 424,433 \\
& Large & 0.055 & 0.008 & 7.2 & 0.040 & 0.070 & 301 & 425,060 \\
3 & Small & 0.022 & 0.001 & 17.2 & 0.020 & 0.025 & 11,184 & $3,596,487$ \\
& Middle & 0.019 & 0.002 & 9.7 & 0.015 & 0.023 & 978 & $3,592,114$ \\
& Large & 0.019 & 0.003 & 5.7 & 0.013 & 0.026 & 285 & $3,600,567$ \\
& Small & 0.012 & 0.001 & 14.8 & 0.010 & 0.013 & 7,816 & $7,174,571^{*}$ \\
& Middle & 0.007 & 0.001 & 5.2 & 0.004 & 0.009 & 540 & $7,169,039^{*}$ \\
& Large & 0.011 & 0.002 & 7.1 & 0.008 & 0.015 & 147 & $7,192,440^{*}$ \\
& Small & 0.005 & 0.001 & 8.7 & 0.004 & 0.006 & 5,439 & $11,800,171^{*}$ \\
& Middle & 0.005 & 0.001 & 6.9 & 0.004 & 0.007 & 329 & $11,762,755^{*}$ \\
& Large & 0.002 & 0.001 & 2.4 & 0.000 & 0.003 & 73 & $11,853,380^{*}$ \\
\hline
\end{tabular}

Note: all estimates are based on weighting scheme $2 .{ }^{\text {a }}$ From smallest to largest, by thirds of the sample. ${ }^{*}$ sample of pairs (see text for details), but size defined on original number of pairs. 


\section{Part F. Within population heterogeneity in cousin correlations}

The cousin correlations we have computed may conceal important heterogeneity. One such possibility is lineage heterogeneity; i.e., that intergenerational relations are stronger along maternal than paternal lineages. This has been argued from an evolutionary perspective positing that less paternal than maternal investment is needed for offspring (Euler 2011), but family sociologists have instead emphasized that in the West, women often act as "kinkeepers" so that social relations between daughters and mothers are more cohesive (Rosenthal 1985). In historical settings, where inheritance rules are gendered by law or practice, matrilines and patrilines may have additional important differential effects. However, in their review of three generation mobility studies, Anderson, Sheppard and Monden (2018) found no differences in three-generation associations (grandparent child) by lineage. Table F1 shows cousin correlations where we have constrained the kinship sequences to go from index to ancestor via either maternal or paternal links. For 1st cousins, we can separate between maternal or paternal cousins, which is shown in the first two rows. Here, we have constrained parents (distance $=1$ from index) to be either male or female, and we can see somewhat higher cousin correlations on the maternal side. For 1 st cousins, we have applied the same constraint to both parents and grandparents (distance $=2$ from index), and we can see that same pattern for parents, but less so for grandparents. When we extend this exercise to higher-order cousins, we find that it does not matter much beyond 3rd cousins.

We follow up this result by analyzing gender-specific cousin correlations in Table F2. We tend to find that cousin correlations are somewhat stronger among males and weaker among females (despite gender being residualized) and mixed-gender cousins. This pattern also persists for higherorder cousin correlations.

In Table F3, we compare full sequences of maternal or paternal ancestors (not just positions as in Table F1). This exercise however limits data to some very few and specific lineages. For $4^{\text {th }}$ and $5^{\text {th }}$ cousins, we have used the total data and not the random sample of pairs to find sequences. We 
find some indication of higher correlations in maternal sequences, and no indication of higher correlations in paternal sequences in lower order cousins $\left(1^{\text {st }}\right.$ to $\left.3^{\text {rd }}\right)$. For higher order correlation, we find what appears to be merely noise. We thus conclude that there might be some stronger persistence in maternal lineages, but it is found only proximate to the index individual, not in the distant kinship structure. We find no evidence that paternal linages have higher correlations, e.g., as if privilege attached to certain surnames or goods inherited from father to son would create the persistence. This is not the case.

In Table F4, we focus on the age differences across cousins. As our birth cohort span is large, it could be suspected that cousins born far apart are less similar to each other (over and above the controls for birth cohort). We have computed the age differences for each sibling and cousin pair in the $\mathrm{n} \times \mathrm{n}$ matrix and then grouped this result into three categories of similar size (tertiles), capturing small, moderate, and large differences. We find that there is some substantial variation in sibling correlations by age differences, yet there is no clear pattern for cousins, especially higher order cousins.

Finally, turning to heterogeneity in cousin correlations by ancestors' SES, in Figure 5, we focused only on $2^{\text {nd }}$ to $5^{\text {th }}$ cousins. Figure F1 also includes siblings and $1^{\text {st }}$ cousins (which makes the graph more challenging to read for higher-order cousins). Still, the pattern with higher correlations for "upper" ancestors applies across all kin relations.

Table F5 shows sensitivity analyses for these cousin correlations divided by ancestors' SES. An often overlooked assumption of sibling and cousin correlations comparisons is that the group variances, i.e., the denominator of the correlation, are the same, i.e., that difference is driven only by the covariances. Table F5 shows that the variances across ancestor class groups are relatively stable and differ only a few percent. So differences in variances do not drive much of the cousin correlations differences. 
But there is also a more intricate question. The covariances are computed for cousin pairs: $\mathrm{Y}_{\text {cousin }} \mathrm{i}^{*} \mathrm{Y}_{\text {cousin } \mathrm{j}}(\mathrm{i} \neq \mathrm{j})$, where $\mathrm{Y}$ is measured in deviation-from-mean form. We residualize $\mathrm{Y}$ on the gender and birth year interaction, achieving a residual e with a mean of zero that we used as our Y measure. We do this residualization so that similarity in gender and birth year will not impact the correlations. This is what we call Method 1. When we compute ancestor class-specific correlations, we can also adjust for the ancestor group means, which we call Method 2. This is equivalent to splitting the sample. In the former case, cousins in the most privileged class will be more similar because their group mean is higher; in the latter case, they will not because we have controlled away that mean difference, so the covariances are limited to be around the group mean. Table F5 shows that this matters for our results. We still find that the "upper" correlations are high compared to other ancestor classes with Method 2, but they do not stand out as firmly as with Method 1.

Which of these methods is most correct? Researchers would dismiss sister or brother correlations (or female/male cousins) if not the gender differences are taken into account, otherwise the correlations would only be high because the subjects are jointly male or female. However, for ancestor class, removing the effect of being jointly higher class is not straightforward. Disregarding that descendants from particular ancestors are more similar because their outcomes are jointly higher would mean removing an important intergenerational transmission source. As we see it, the adjustment must depend on where the variation originates. Gender is random at birth and subject to present-day structural factors that strongly structure different outcomes for males and females. The birth cohort is similarly strongly linked to present-day structures, i.e., educational expansion, economic development, business cycle, etc., that have little bearing on relative mobility but strongly determine outcomes. But ancestor class has no relation to such present-day structures; this is only an influence from the distant past. And we are interested in the long-term effects of ancestor class, including a higher than average mean in the outcome. Thus, removing/controlling away their higher 
mean of $Y$ before computing the correlation would downplay the impact of ancestors. This is why we have preferred Method 1 as our main results. 
Table F1. Cousin correlations in rank years of education by maternal and paternal lineage constraint at different distance from index generation. Cousin Distance from Unique

\begin{tabular}{|c|c|c|c|c|c|c|c|c|c|}
\hline order & index ${ }^{\mathrm{a}}$ & Gender constraint & Rho & s.e. & $\mathrm{t}$ & CI- & $\mathrm{CI}+$ & Ancestors & No. ties \\
\hline 1 & 1 & Male & 0.121 & 0.005 & 26.3 & 0.112 & 0.130 & 9,464 & 126,560 \\
\hline (sibs) & 1 & Female & 0.132 & 0.005 & 26.8 & 0.122 & 0.141 & 9,534 & 124,836 \\
\hline \multirow[t]{4}{*}{2} & 1 & Male & 0.046 & 0.004 & 12.8 & 0.039 & 0.053 & 8,420 & 628,413 \\
\hline & 1 & Female & 0.053 & 0.003 & 21.4 & 0.049 & 0.058 & 8,565 & 646,425 \\
\hline & 2 & Male & 0.048 & 0.003 & 16.1 & 0.042 & 0.054 & 7,570 & 640,246 \\
\hline & 2 & Female & 0.051 & 0.003 & 17.7 & 0.046 & 0.057 & 7,674 & 634,592 \\
\hline \multirow[t]{6}{*}{3} & 1 & Male & 0.020 & 0.001 & 15.5 & 0.018 & 0.023 & 11,773 & $5,387,536$ \\
\hline & 1 & Female & 0.022 & 0.002 & 13.9 & 0.019 & 0.025 & 11,892 & $5,401,632$ \\
\hline & 2 & Male & 0.021 & 0.001 & 17.4 & 0.019 & 0.023 & 11,321 & $5,565,516$ \\
\hline & 2 & Female & 0.022 & 0.002 & 14.4 & 0.019 & 0.025 & 11,661 & $5,223,652$ \\
\hline & 3 & Male & 0.023 & 0.002 & 15.1 & 0.020 & 0.026 & 10,366 & $5,442,000$ \\
\hline & 3 & Female & 0.020 & 0.001 & 14.2 & 0.017 & 0.023 & 10,357 & $5,347,168$ \\
\hline \multirow[t]{8}{*}{4} & 1 & Male & 0.010 & 0.001 & 12.5 & 0.008 & 0.012 & 8,204 & $10,751,118^{*}$ \\
\hline & 1 & Female & 0.011 & 0.001 & 16.1 & 0.010 & 0.013 & 8,289 & $10,784,932 *$ \\
\hline & 2 & Male & 0.010 & 0.001 & 12.4 & 0.008 & 0.011 & 8,100 & $11,150,717^{*}$ \\
\hline & 2 & Female & 0.011 & 0.001 & 16.3 & 0.010 & 0.013 & 8,206 & $10,385,333^{*}$ \\
\hline & 3 & Male & 0.010 & 0.001 & 14.3 & 0.009 & 0.011 & 7,827 & $10,930,191 *$ \\
\hline & 3 & Female & 0.011 & 0.001 & 16.0 & 0.010 & 0.013 & 8,007 & $10,605,859 *$ \\
\hline & 4 & Male & 0.009 & 0.001 & 13.0 & 0.008 & 0.010 & 7,153 & $10,436,005^{*}$ \\
\hline & 4 & Female & 0.012 & 0.001 & 15.1 & 0.011 & 0.014 & 7,260 & $11,100,045^{*}$ \\
\hline \multirow[t]{10}{*}{5} & 1 & Male & 0.004 & 0.001 & 7.5 & 0.003 & 0.006 & 5,652 & $17,607,546^{*}$ \\
\hline & 1 & Female & 0.005 & 0.001 & 10.8 & 0.004 & 0.006 & 5,716 & $17,808,760^{*}$ \\
\hline & 2 & Male & 0.005 & 0.001 & 7.7 & 0.003 & 0.006 & 5,610 & $18,252,987^{*}$ \\
\hline & 2 & Female & 0.005 & 0.001 & 7.6 & 0.004 & 0.007 & 5,715 & $17,163,319 *$ \\
\hline & 3 & Male & 0.004 & 0.001 & 7.2 & 0.003 & 0.005 & 5,550 & $17,853,317^{*}$ \\
\hline & 3 & Female & 0.006 & 0.001 & 9.3 & 0.004 & 0.007 & 5,660 & $17,562,989 *$ \\
\hline & 4 & Male & 0.005 & 0.001 & 9.6 & 0.004 & 0.006 & 5,414 & $17,406,982 *$ \\
\hline & 4 & Female & 0.005 & 0.001 & 10.2 & 0.004 & 0.006 & 5,558 & $18,009,324 *$ \\
\hline & 5 & Male & 0.004 & 0.001 & 6.8 & 0.003 & 0.005 & 4,909 & $17,564,499 *$ \\
\hline & 5 & Female & 0.006 & 0.001 & 9.5 & 0.005 & 0.007 & 4,973 & $17,851,807^{*}$ \\
\hline
\end{tabular}

Note: all estimates are based on weighting scheme $2 .{ }^{a} 1$ = Parent, 2 = GP etc. ${ }^{*}$ sample of pairs (see text for details). 
Table F2. Cousin correlations in rank years of education by gender of index generation.

\begin{tabular}{ccccccccc}
\hline $\begin{array}{c}\text { Cousin } \\
\text { order }\end{array}$ & $\begin{array}{c}\text { Gender of cousin } \\
\text { pairs }\end{array}$ & Rho & s.e. & $\mathrm{t}$ & CI- & CI+ & $\begin{array}{c}\text { Unique } \\
\text { Ancestors }\end{array}$ \\
\hline 0 & Female & 0.345 & 0.010 & 33.5 & 0.325 & 0.365 & 8,376 & 12,493 \\
$($ sibs $)$ & Male & 0.355 & 0.010 & 35.5 & 0.336 & 0.375 & 9,015 & 13,565 \\
& Mixed & 0.297 & 0.007 & 43.7 & 0.284 & 0.310 & 15,212 & 26,065 \\
1 & Female & 0.127 & 0.008 & 16.7 & 0.112 & 0.142 & 8,757 & 60,087 \\
& Male & 0.140 & 0.006 & 23.7 & 0.129 & 0.152 & 8,973 & 65,438 \\
& Mixed & 0.119 & 0.004 & 28.3 & 0.111 & 0.127 & 11,530 & 125,871 \\
2 & Female & 0.044 & 0.003 & 13.3 & 0.037 & 0.050 & 7,934 & 305,672 \\
& Male & 0.059 & 0.004 & 15.1 & 0.051 & 0.066 & 8,079 & 331,700 \\
& Mixed & 0.048 & 0.003 & 15.4 & 0.042 & 0.054 & 9,202 & 637,466 \\
4 & Female & 0.018 & 0.001 & 14.9 & 0.016 & 0.020 & 11,239 & $2,595,204$ \\
& Male & 0.026 & 0.002 & 17.5 & 0.023 & 0.029 & 11,295 & $2,800,715$ \\
& Mixed & 0.020 & 0.001 & 15.5 & 0.018 & 0.023 & 12,280 & $5,393,249$ \\
& Female & 0.010 & 0.001 & 10.2 & 0.008 & 0.012 & 7,916 & $5,185,518 *$ \\
& Male & 0.012 & 0.001 & 13.3 & 0.010 & 0.014 & 7,989 & $5,584,749 *$ \\
& Mixed & 0.010 & 0.001 & 14.4 & 0.009 & 0.011 & 8,434 & $10,765,783^{*}$ \\
& Female & 0.005 & 0.001 & 6.0 & 0.003 & 0.006 & 5,481 & $8,487,260^{*}$ \\
& Male & 0.006 & 0.001 & 7.6 & 0.005 & 0.008 & 5,539 & $9,226,064 *$ \\
& Mixed & 0.004 & 0.001 & 8.8 & 0.003 & 0.005 & 5,822 & $17,702,982^{*}$ \\
\hline
\end{tabular}

Note: all estimates are based on weighting scheme $2 .{ }^{*}$ sample of pairs (see text for details). 
Table F3. Cousin correlations in rank years of education by maternal and paternal lineage sequences.

\begin{tabular}{ccccccccc}
\hline $\begin{array}{l}\text { Cousin } \\
\text { order }\end{array}$ & Sequence & Rho & s.e. & $\mathrm{t}$ & CI- & CI+ & $\begin{array}{c}\text { Unique } \\
\text { Ancestors }\end{array}$ \\
\hline 1 & Maternal & 0.144 & 0.008 & 18.9 & 0.129 & 0.159 & 5,558 & 65,338 \\
& Mixed 1 & 0.118 & 0.007 & 17.8 & 0.105 & 0.131 & 7,041 & 59,498 \\
& Mixed 2 & 0.112 & 0.007 & 16.0 & 0.099 & 0.126 & 7,044 & 60,606 \\
& Paternal & 0.129 & 0.007 & 19.0 & 0.116 & 0.143 & 5,511 & 65,954 \\
2 & Maternal & 0.063 & 0.007 & 9.5 & 0.050 & 0.076 & 2,964 & 85,976 \\
& Mixed 1 & 0.039 & 0.009 & 4.4 & 0.022 & 0.056 & 3,633 & 72,990 \\
& Mixed 2 & 0.044 & 0.007 & 6.2 & 0.030 & 0.058 & 3,642 & 73,153 \\
& Paternal & 0.046 & 0.007 & 6.8 & 0.033 & 0.059 & 2,896 & 80,474 \\
3 & Maternal & 0.030 & 0.007 & 4.1 & 0.016 & 0.044 & 2,638 & 166,192 \\
& Mixed 1 & 0.020 & 0.006 & 3.2 & 0.008 & 0.032 & 3,787 & 158,508 \\
& Mixed 2 & 0.029 & 0.005 & 5.9 & 0.019 & 0.038 & 3,822 & 157,788 \\
& Paternal & 0.018 & 0.006 & 2.9 & 0.006 & 0.029 & 2,630 & 189,549 \\
& Maternal & 0.004 & 0.005 & 0.7 & -0.007 & 0.015 & 1,616 & 219,075 \\
& Mixed 1 & 0.017 & 0.006 & 2.9 & 0.006 & 0.029 & 2,232 & 201,486 \\
& Mixed 2 & 0.013 & 0.005 & 2.4 & 0.003 & 0.024 & 2,222 & 198,319 \\
& Paternal & 0.001 & 0.006 & 0.1 & -0.010 & 0.012 & 1,573 & 223,178 \\
& Maternal & -0.003 & 0.005 & -0.6 & -0.013 & 0.007 & 991 & 257,952 \\
& Mixed 1 & 0.006 & 0.006 & 1.0 & -0.006 & 0.019 & 1,347 & 210,526 \\
& Mixed 2 & 0.000 & 0.005 & 0.0 & -0.011 & 0.011 & 1,334 & 203,901 \\
& Paternal & -0.001 & 0.006 & -0.2 & -0.013 & 0.011 & 898 & 235,875 \\
\hline
\end{tabular}

Note: maternal (paternal) is that both persons in pair are linked via only maternal (paternal) sequences; e.g., for 3rd cousins both persons are linked via the line mmmf $/ \mathrm{mmmm}$ (last position does not matter). Mixed 1 and 2 means that first (second) person in pair follows paternal line and second (first) maternal line. 
Table F4. Cousin correlations in rank years of education by age differences between cousins.

\begin{tabular}{ccccccccc}
\hline $\begin{array}{c}\text { Cousin } \\
\text { order }\end{array}$ & $\begin{array}{c}\text { Age difference } \\
\text { group }\end{array}$ & Rho & s.e. & $\mathrm{t}$ & CI- & CI+ & $\begin{array}{c}\text { Unique } \\
\text { Ancestors }\end{array}$ \\
\hline 0 & Small & 0.368 & 0.009 & 41.3 & 0.350 & 0.385 & 9,998 & 12,451 \\
(sibs) & Middle & 0.327 & 0.007 & 44.2 & 0.313 & 0.342 & 15,545 & 21,171 \\
& Large & 0.282 & 0.010 & 29.1 & 0.263 & 0.301 & 10,029 & 18,501 \\
1 & Small & 0.130 & 0.005 & 27.1 & 0.121 & 0.140 & 10,317 & 71,909 \\
& Middle & 0.128 & 0.005 & 24.2 & 0.118 & 0.139 & 10,998 & 83,637 \\
& Large & 0.121 & 0.006 & 19.5 & 0.109 & 0.133 & 9,087 & 95,850 \\
2 & Small & 0.052 & 0.003 & 16.7 & 0.046 & 0.058 & 8,767 & 388,616 \\
& Middle & 0.051 & 0.004 & 14.1 & 0.044 & 0.058 & 8,749 & 410,145 \\
& Large & 0.047 & 0.003 & 14.2 & 0.040 & 0.053 & 7,572 & 476,077 \\
& Small & 0.021 & 0.001 & 16.5 & 0.019 & 0.024 & 12,091 & $3,578,949$ \\
& Middle & 0.022 & 0.002 & 12.9 & 0.019 & 0.025 & 11,761 & $3,500,660$ \\
& Large & 0.020 & 0.001 & 16.8 & 0.018 & 0.023 & 10,231 & $3,709,559$ \\
& Small & 0.011 & 0.001 & 11.8 & 0.009 & 0.012 & 8,383 & $6,667,957^{*}$ \\
& Middle & 0.011 & 0.001 & 13.4 & 0.009 & 0.012 & 8,165 & $7,490,788^{*}$ \\
& Large & 0.011 & 0.001 & 11.7 & 0.009 & 0.012 & 7,089 & $7,377,305^{*}$ \\
& Small & 0.005 & 0.001 & 6.8 & 0.004 & 0.007 & 5,809 & $10,337,441^{*}$ \\
& Middle & 0.005 & 0.001 & 7.8 & 0.004 & 0.006 & 5,634 & $13,107,917 *$ \\
& Large & 0.005 & 0.001 & 9.4 & 0.004 & 0.006 & 4,749 & $11,970,948 *$ \\
\hline
\end{tabular}

Note: all estimates are based on weighting scheme 2. Small, middle and large refers to thirds of the sample. ${ }^{*}$ sample of pairs (see text for details). 
Table F5. Sensitivity analysis of cousin correlations in rank years of education by class position of ancestor.

\begin{tabular}{|c|c|c|c|c|c|c|c|c|c|c|}
\hline \multirow[b]{2}{*}{$\begin{array}{l}\text { Cousin } \\
\text { order }\end{array}$} & \multirow[b]{2}{*}{$\begin{array}{c}\text { Class of ancestor } \\
\text { defining cousins }\end{array}$} & \multicolumn{2}{|c|}{ Covariance } & \multicolumn{3}{|c|}{ Variance } & \multicolumn{3}{|c|}{ Rho } & \multirow[b]{2}{*}{$\begin{array}{l}\text { Average of education } \\
\text { rank among } \\
\text { descendants } \\
\end{array}$} \\
\hline & & Method 1 & Method 2 & Method 1 & Method 2 & $\begin{array}{c}\text { Percent } \\
\text { difference }\end{array}$ & Method 1 & Method 2 & $\begin{array}{c}\text { Percent } \\
\text { difference }\end{array}$ & \\
\hline 0 & Farm & 0.018 & 0.017 & 0.063 & 0.065 & 3.7 & 0.284 & 0.262 & -8.0 & 0.58 \\
\hline \multirow[t]{4}{*}{ (sibs) } & Service & 0.017 & 0.017 & 0.063 & 0.060 & -4.0 & 0.277 & 0.282 & 1.7 & 0.63 \\
\hline & Skilled & 0.019 & 0.016 & 0.063 & 0.059 & -5.1 & 0.304 & 0.274 & -10.1 & 0.56 \\
\hline & Lower/Unskilled & 0.022 & 0.017 & 0.063 & 0.062 & -0.6 & 0.348 & 0.274 & -21.3 & 0.54 \\
\hline & Upper & 0.027 & 0.017 & 0.063 & 0.054 & -13.0 & 0.433 & 0.307 & -29.3 & 0.71 \\
\hline \multirow{4}{*}{1} & Service & 0.011 & 0.009 & 0.064 & 0.061 & -4.4 & 0.170 & 0.152 & -10.3 & 0.64 \\
\hline & Skilled & 0.008 & 0.008 & 0.064 & 0.061 & -4.3 & 0.126 & 0.132 & 4.1 & 0.59 \\
\hline & Lower/Unskilled & 0.008 & 0.008 & 0.064 & 0.063 & -0.3 & 0.128 & 0.122 & -5.3 & 0.58 \\
\hline & Upper & 0.013 & 0.010 & 0.064 & 0.060 & -6.1 & 0.212 & 0.175 & -17.5 & 0.65 \\
\hline \multirow[t]{3}{*}{2} & Farm & 0.003 & 0.003 & 0.063 & 0.063 & 0.0 & 0.045 & 0.045 & 0.0 & 0.61 \\
\hline & Service & 0.004 & 0.003 & 0.063 & 0.061 & -2.9 & 0.062 & 0.046 & -26.0 & 0.64 \\
\hline & Skilled & 0.004 & 0.004 & 0.063 & 0.062 & -1.3 & 0.067 & 0.068 & 1.3 & 0.60 \\
\hline \multirow[t]{5}{*}{3} & Farm & 0.001 & 0.001 & 0.063 & 0.062 & -0.5 & 0.020 & 0.020 & -2.5 & 0.61 \\
\hline & Service & 0.002 & 0.001 & 0.063 & 0.062 & -0.6 & 0.025 & 0.022 & -9.4 & 0.61 \\
\hline & Skilled & 0.002 & 0.002 & 0.063 & 0.062 & -0.6 & 0.023 & 0.024 & 1.7 & 0.60 \\
\hline & Lower/Unskilled & 0.001 & 0.001 & 0.063 & 0.064 & 1.3 & 0.021 & 0.020 & -3.4 & 0.60 \\
\hline & Upper & 0.003 & 0.002 & 0.063 & 0.064 & 2.7 & 0.047 & 0.027 & -42.5 & 0.64 \\
\hline \multirow[t]{5}{*}{4} & Farm & 0.001 & 0.001 & 0.063 & 0.062 & -1.7 & 0.011 & 0.010 & -5.5 & 0.61 \\
\hline & Service & 0.001 & 0.001 & 0.063 & 0.063 & 0.6 & 0.014 & 0.013 & -7.3 & 0.62 \\
\hline & Skilled & 0.000 & 0.000 & 0.063 & 0.064 & 2.2 & 0.002 & 0.002 & 0.0 & 0.61 \\
\hline & Lower/Unskilled & 0.001 & 0.001 & 0.063 & 0.063 & 0.3 & 0.010 & 0.010 & 1.0 & 0.61 \\
\hline & Upper & 0.001 & 0.001 & 0.063 & 0.065 & 3.7 & 0.019 & 0.012 & -40.2 & 0.63 \\
\hline \multirow[t]{5}{*}{5} & Farm & 0.000 & 0.000 & 0.063 & 0.062 & -2.1 & 0.005 & 0.005 & -12.7 & 0.62 \\
\hline & Service & 0.000 & 0.000 & 0.063 & 0.064 & 1.4 & -0.002 & -0.002 & 22.2 & 0.62 \\
\hline & Skilled & 0.000 & 0.000 & 0.063 & 0.064 & 1.7 & -0.002 & -0.002 & 13.3 & 0.61 \\
\hline & Lower/Unskilled & 0.000 & 0.000 & 0.063 & 0.061 & -2.4 & 0.004 & 0.004 & 5.3 & 0.61 \\
\hline & Upper & 0.001 & 0.000 & 0.063 & 0.063 & -0.5 & 0.013 & 0.007 & -48.5 & 0.63 \\
\hline
\end{tabular}

Note: Method 1 uses covariances and variance based on the grand mean. Method 2 used covariances based on ancestor specific means (equal to ancestor group fixed effects when residualizing the outcome). All estimates are based on weighting scheme 2. 
Figure F1. Sibling and Cousin correlations in years of education by ancestor's SES.

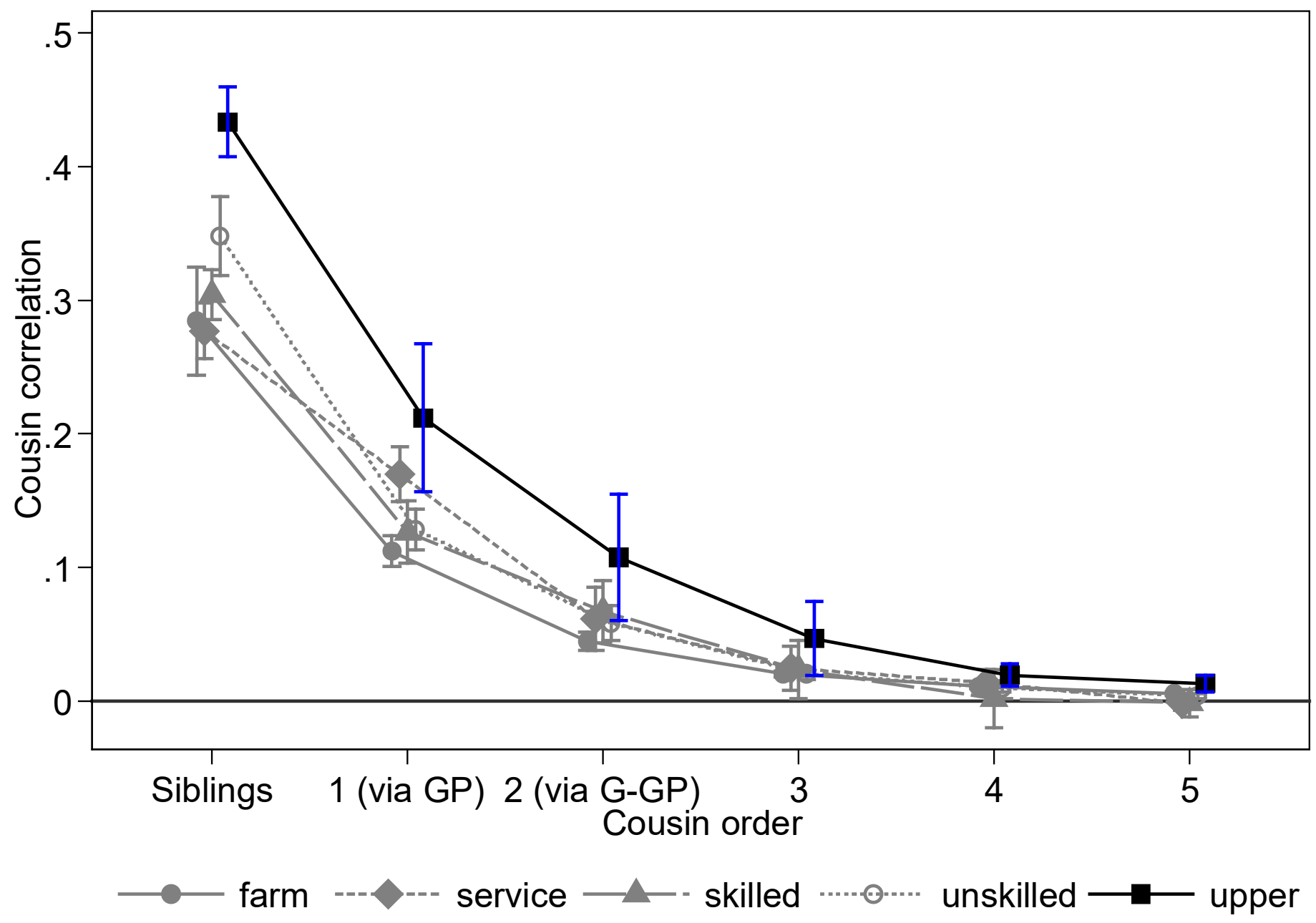

Note: Men and women born 1940-1987 in Sweden with a 5th generation descendant in Northern Sweden. 


\section{Part G. Cousin Marriages}

Cousin marriage was more prevalent in historical times, and our study region is known for its higher prevalence of cousin marriage. Until 1680, 1st cousin marriages were prohibited in Sweden; from 1680-1844, royal permission was needed; and from 1844 onward, they were generally allowed. Egerbladh and Bittles (2008) observed a significant increase in 1st cousin marriages post-1844, and found that 1 st cousin marriages were strongly favored by freeholders and peasant landowning families, with some generational persistence in 1 st cousin marriage. They also found some higher incidences of stillbirths and more deaths in infancy and early childhood due to cousin marriage.

The phenomenon may impact our results, as cousins may be more close kin than we presume, and there may also be negative effects following inbreeding. We have traced cousin and other types of kinship marriage by identifying individuals who have multiple kin relations to our index individual and then tracing back to where this relation arose. Table G1 shows that prevalence is indeed substantial. We can observe a history of at least one kin marriage within the kinship network of around $1 / 3$ of the sample. The lower part of the Table shows the type of kin marriage relation and the distance from the index individual where we observe this. Almost half of the kin marriages are between 1st cousins, and the rest are generally between higherorder cousins. The prevalence is higher the further back we go in the kinship network. The question is how this may impact our estimates, and we have therefore re-estimated cousin correlations and dynastic correlations with the $1 / 3$ of the sample with kin marriage removed. When we compare Table G2 with Table 1, differences in cousin correlations are not systematic and therefore negligible. When we compare Table G3 with Table 2, we find that this conclusion also holds for dynastic correlations. We conclude that cousin or kin marriages are unlikely to drive our main findings. 
Table G1. Prevalence of inbreeding and cousin marriages

\begin{tabular}{|c|c|c|c|c|c|c|}
\hline Any duplicate kin in network? & No. & & & & & \\
\hline No & 51,437 & & & & & \\
\hline Yes & 23,977 & & & & & \\
\hline \multirow[t]{2}{*}{ Total } & 75,414 & & & & & \\
\hline & Type of & in marriag & (distance & etween $\mathrm{k}$ & & \\
\hline $\begin{array}{l}\text { Kin marriage, } \\
\text { by distance from index }\end{array}$ & Mixed & $\begin{array}{l}1 \text { st } \\
\text { cousin }\end{array}$ & $\begin{array}{l}2 \mathrm{nd} \\
\text { cousin }\end{array}$ & $\begin{array}{l}\text { 3rd } \\
\text { cousin }\end{array}$ & $\begin{array}{l}4 \text { th } \\
\text { cousin }\end{array}$ & Total \\
\hline Gen -1, Parent & 0 & 298 & 903 & 1,314 & 931 & 3,446 \\
\hline Gen -2, GP & 0 & 2,004 & 3,289 & 2,191 & 0 & 7,484 \\
\hline Gen -3, Gr-GP & 0 & 4,556 & 3,623 & 0 & 0 & 8,179 \\
\hline Gen -4, Gr-Gr-GP & 15 & 4,846 & 0 & 0 & 0 & 4,861 \\
\hline Gen -5, Gr-Gr-Gr-GP & 7 & 0 & 0 & 0 & 0 & 7 \\
\hline Total & 22 & 11,704 & 7,815 & 3,505 & 931 & 23,977 \\
\hline
\end{tabular}

Note: ${ }^{\mathrm{a}}$ number refers to number of affected index individuals 
Table G2. Cousin correlations excluding families with any kin marriage

\begin{tabular}{|c|c|c|c|c|c|c|c|c|c|}
\hline Outcome & $\begin{array}{c}\text { Cousin } \\
\text { order }\end{array}$ & $\begin{array}{c}\text { Any kin } \\
\text { marriage? }\end{array}$ & Rho & s.e. & $\mathrm{t}$ & CI- & $\mathrm{CI}+$ & $\begin{array}{c}\text { Unique } \\
\text { Ancestors }\end{array}$ & No. ties \\
\hline \multirow[t]{12}{*}{ Education } & \multirow[t]{2}{*}{0} & No & 0.329 & 0.006 & 55.8 & 0.318 & 0.341 & 17,064 & 34,819 \\
\hline & & Yes & 0.316 & 0.008 & 38.5 & 0.300 & 0.332 & 7,740 & 16,548 \\
\hline & \multirow[t]{2}{*}{1} & No & 0.138 & 0.005 & 25.9 & 0.127 & 0.148 & 7,975 & 118,322 \\
\hline & & Yes & 0.131 & 0.009 & 14.1 & 0.113 & 0.149 & 4,000 & 75,915 \\
\hline & \multirow[t]{2}{*}{2} & No & 0.054 & 0.004 & 15.3 & 0.047 & 0.060 & 6,750 & 484,397 \\
\hline & & Yes & 0.049 & 0.004 & 11.4 & 0.040 & 0.057 & 4,261 & 313,930 \\
\hline & \multirow[t]{2}{*}{3} & No & 0.023 & 0.002 & 12.9 & 0.020 & 0.027 & 10,101 & $3,348,566$ \\
\hline & & Yes & 0.021 & 0.002 & 10.7 & 0.017 & 0.025 & 7,447 & $2,662,108$ \\
\hline & \multirow[t]{2}{*}{4} & No & 0.011 & 0.001 & 8.1 & 0.008 & 0.013 & 7,590 & $5,871,286$ \\
\hline & & Yes & 0.012 & 0.001 & 10.2 & 0.010 & 0.015 & 6,122 & $5,450,140$ \\
\hline & \multirow[t]{2}{*}{5} & No & 0.004 & 0.001 & 5.5 & 0.003 & 0.006 & 5,509 & $9,933,159$ \\
\hline & & Yes & 0.005 & 0.001 & 5.9 & 0.004 & 0.007 & 4,485 & $8,254,868$ \\
\hline \multirow[t]{24}{*}{ Occupation } & \multirow[t]{2}{*}{0} & No & 0.291 & 0.007 & 42.8 & 0.277 & 0.304 & 16,402 & 32,738 \\
\hline & & Yes & 0.290 & 0.009 & 33.0 & 0.273 & 0.308 & 7,499 & 15,721 \\
\hline & \multirow[t]{2}{*}{1} & No & 0.127 & 0.006 & 21.2 & 0.115 & 0.139 & 7,872 & 111,446 \\
\hline & & Yes & 0.116 & 0.007 & 17.5 & 0.103 & 0.129 & 3,959 & 72,427 \\
\hline & \multirow[t]{2}{*}{2} & No & 0.055 & 0.004 & 15.6 & 0.048 & 0.062 & 6,700 & 456,715 \\
\hline & & Yes & 0.042 & 0.005 & 9.1 & 0.033 & 0.051 & 4,225 & 300,998 \\
\hline & \multirow[t]{2}{*}{3} & No & 0.024 & 0.002 & 13.9 & 0.020 & 0.027 & 10,046 & $3,153,533$ \\
\hline & & Yes & 0.018 & 0.002 & 9.9 & 0.014 & 0.021 & 7,407 & $2,545,507$ \\
\hline & \multirow[t]{2}{*}{4} & No & 0.011 & 0.001 & 12.8 & 0.010 & 0.013 & 7,561 & $5,519,853$ \\
\hline & & Yes & 0.009 & 0.001 & 6.9 & 0.006 & 0.012 & 6,099 & $5,194,048$ \\
\hline & \multirow[t]{2}{*}{5} & No & 0.005 & 0.001 & 5.9 & 0.003 & 0.006 & 5,483 & $9,334,442$ \\
\hline & & Yes & 0.006 & 0.001 & 7.9 & 0.005 & 0.008 & 4,476 & $7,879,628$ \\
\hline & \multirow[t]{2}{*}{0} & No & 0.309 & 0.009 & 36.3 & 0.292 & 0.325 & 16,276 & 32,321 \\
\hline & & Yes & 0.300 & 0.010 & 28.9 & 0.280 & 0.321 & 7,430 & 15,443 \\
\hline & \multirow[t]{2}{*}{1} & No & 0.080 & 0.006 & 14.1 & 0.069 & 0.091 & 7,853 & 109,620 \\
\hline & & Yes & 0.076 & 0.006 & 11.9 & 0.064 & 0.089 & 3,944 & 71,348 \\
\hline & \multirow[t]{2}{*}{2} & No & 0.030 & 0.003 & 9.0 & 0.023 & 0.036 & 6,695 & 450,582 \\
\hline & & Yes & 0.028 & 0.004 & 6.6 & 0.020 & 0.037 & 4,215 & 296,048 \\
\hline & \multirow[t]{2}{*}{3} & No & 0.012 & 0.002 & 7.6 & 0.009 & 0.015 & 10,044 & $3,105,660$ \\
\hline & & Yes & 0.015 & 0.002 & 8.1 & 0.011 & 0.018 & 7,403 & $2,501,063$ \\
\hline & \multirow[t]{2}{*}{4} & No & 0.007 & 0.001 & 7.3 & 0.005 & 0.008 & 7,557 & $5,433,381$ \\
\hline & & Yes & 0.010 & 0.001 & 9.9 & 0.008 & 0.012 & 6,091 & $5,098,404$ \\
\hline & \multirow[t]{2}{*}{5} & No & 0.003 & 0.001 & 4.4 & 0.002 & 0.004 & 5,479 & $9,185,438$ \\
\hline & & Yes & 0.008 & 0.001 & 11.4 & 0.007 & 0.009 & 4,474 & $7,742,396$ \\
\hline
\end{tabular}

Note: all estimates are based on ranks and weighting scheme 2. Pairs with mixed occurrence of kin marriage are excluded. 
Table G3. Dynastic correlations excluding families with any kin marriage

\begin{tabular}{|c|c|c|c|c|c|c|c|c|c|c|c|c|c|c|c|}
\hline & \multicolumn{5}{|c|}{ Education } & \multicolumn{5}{|c|}{ Occupation } & \multicolumn{5}{|c|}{ Wealth } \\
\hline & $\mathrm{MGC}^{\mathrm{a}}$ & s.e. & $\Delta \mathrm{R} 2$ & $\mathrm{R} 2$ & $\mathrm{~N}$ & $\mathrm{MGC}^{\mathrm{a}}$ & s.e. & $\Delta \mathrm{R} 2$ & $\mathrm{R} 2$ & $\mathrm{~N}$ & $\mathrm{MGC}^{\mathrm{a}}$ & s.e. & $\Delta \mathrm{R} 2$ & $\mathrm{R} 2$ & $\mathrm{~N}$ \\
\hline \multicolumn{16}{|l|}{ Average HISCAM } \\
\hline Empty (only controls) & & & & 0.042 & 45,296 & & & & 0.008 & 43,995 & & & & 0.005 & 45,126 \\
\hline Generation $-1, \mathrm{P}$ & 0.302 & 0.004 & 0.089 & 0.131 & 45,296 & 0.321 & 0.004 & 0.1 & 0.108 & 43,995 & 0.124 & 0.004 & 0.015 & 0.02 & 45,126 \\
\hline Generation -2, GP & 0.154 & 0.004 & 0.023 & 0.065 & 45,296 & 0.166 & 0.004 & 0.027 & 0.035 & 43,995 & 0.068 & 0.004 & 0.005 & 0.01 & 45,126 \\
\hline Generation -3, G-GP & 0.084 & 0.004 & 0.007 & 0.049 & 45,296 & 0.091 & 0.004 & 0.008 & 0.016 & 43,995 & 0.038 & 0.004 & 0.001 & 0.007 & 45,126 \\
\hline Generation -4 & 0.048 & 0.004 & 0.002 & 0.044 & 45,296 & 0.059 & 0.004 & 0.003 & 0.011 & 43,995 & 0.033 & 0.004 & 0.001 & 0.006 & 45,126 \\
\hline Generation -5 & 0.033 & 0.004 & 0.001 & 0.043 & 45,296 & 0.03 & 0.004 & 0.001 & 0.009 & 43,995 & 0.035 & 0.004 & 0.001 & 0.006 & 45,126 \\
\hline Generation -6 & 0.025 & 0.004 & 0.001 & 0.043 & 45,296 & 0.021 & 0.004 & 0 & 0.008 & 43,995 & 0.026 & 0.004 & 0.001 & 0.006 & 45,126 \\
\hline Generation -1 to -6 jointly ${ }^{a}$ & 0.37 & & 0.093 & 0.135 & 45,296 & 0.394 & & 0.105 & 0.113 & 43,995 & 0.188 & & 0.017 & 0.022 & 45,126 \\
\hline \multicolumn{16}{|l|}{ Kin class scale } \\
\hline Empty (only controls) & & & & 0.042 & 45,248 & & & & 0.008 & 43,947 & & & & 0.005 & 45,078 \\
\hline Generation $-1, \mathrm{P}$ & 0.303 & 0.004 & 0.077 & 0.119 & 45,248 & 0.322 & 0.004 & 0.089 & 0.096 & 43,947 & 0.128 & 0.004 & 0.016 & 0.021 & 45,078 \\
\hline Generation -2, GP & 0.145 & 0.005 & 0.016 & 0.058 & 45,248 & 0.184 & 0.005 & 0.025 & 0.033 & 43,947 & 0.083 & 0.004 & 0.006 & 0.012 & 45,078 \\
\hline Generation -3 , G-GP & 0.099 & 0.004 & 0.010 & 0.052 & 45,248 & 0.1 & 0.004 & 0.01 & 0.018 & 43,947 & 0.081 & 0.004 & 0.007 & 0.012 & 45,078 \\
\hline Generation -4 & 0.073 & 0.004 & 0.005 & 0.047 & 45,248 & 0.077 & 0.004 & 0.006 & 0.014 & 43,947 & 0.050 & 0.004 & 0.002 & 0.008 & 45,078 \\
\hline Generation -5 & 0.056 & 0.004 & 0.003 & 0.045 & 45,248 & 0.051 & 0.004 & 0.003 & 0.01 & 43,947 & 0.040 & 0.004 & 0.002 & 0.007 & 45,078 \\
\hline Generation -6 & 0.033 & 0.005 & 0.001 & 0.043 & 45,248 & 0.04 & 0.004 & 0.001 & 0.009 & 43,947 & 0.028 & 0.004 & 0.001 & 0.006 & 45,078 \\
\hline Generation -1 to -6 jointly ${ }^{\text {a }}$ & 0.419 & & 0.084 & 0.126 & 45,248 & 0.457 & & 0.097 & 0.105 & 43,947 & 0.243 & & 0.023 & 0.028 & 45,078 \\
\hline
\end{tabular}

Note: all outcomes are in rank form. $\mathrm{MGC}=\mathrm{b}^{*}[\mathrm{SD}(\mathrm{X}) / \mathrm{SD}(\mathrm{Y})] .{ }^{\mathrm{a}}$ For the joint specification, the MGC is summed over all generations. 


\section{Part H. Comparisons for national data with the national reference population}

We have also conducted comparisons to the Swedish reference population. In order to construct such a population to be compared to a native multigenerational sample, we use an administrative register of the full population and then create different versions where we (i) keep everyone with identified parents born in the same birth interval, (ii) additionally drop all 1st and 2nd generation immigrants, and (iii) additionally drop individuals who cannot be linked to grandparents. Table $\mathrm{H} 1$ shows descriptive statistics for our analytical sample compared to the three versions of the reference population. First, the analytical sample is slightly younger than the unconstrained population, but once the restrictions are applied, this changes to our sample being slightly older. Figure H1 shows the distribution of birth years and illustrates a dilemma with multigenerational studies. Once we have a condition on the existence of a grandparent, the sample becomes biased toward younger individuals in the cohort span. Because of limited information on grandparents in population data, the birth year distribution does not match very well. Despite this, Figures H2 and H3 show the distribution of education (in years) and occupational ISEI, respectively, where the constrained population is indistinguishable from the analytical sample. In terms of wealth, it is meaningless to plot wealth, given its extreme skew, but we can compare percentiles in Table H1. Although the mean is higher in the population, it is influenced by outliers (and the risk of observing an outlier is dependent on the number of observations, so the mean and standard deviation are not useful), and we find that median wealth is higher in our sample. The wealth of the 75 th and 90th percentiles is also higher in our sample than in the population as a whole.

We have also conducted sensitivity analyses where we computed sibling and 1 st cousin correlations with the modern population registers. The reference population is all Swedish inhabitants with different restrictions, but we also included estimates for those individuals in our analytical sample. For this group, to achieve maximum comparability, kinship was only 
determined from the modern register, and we did not utilize the historical data (we have also computed the cousin correlation between one sampled individual and one outside the sample). The results are displayed in Table H2. We already know from previous research that vertical two-generation income mobility is higher than average in our sample region (Brandén 2018), although this may largely reflect the homogenous cultural background of our study area. This finding is repeated in our analyses: both the sibling and the 1st cousin correlation are weaker than in the population. This holds for all three outcomes, even though the differences are smaller for wealth. Table $\mathrm{H} 2$ also reveals the definition of the reference population influencing the estimates. Sibling correlations are higher in the general population compared to the 1 st cousin subpopulation. Only sibling and cousin correlations estimated for the same reference population will be comparable. The procedure of iterating correlations to evaluate the 1st order Markov assumptions will fail if this is not met. Using a sibling correlation estimated using the whole of Sweden would not be very informative when iterating to make projections for 1 st cousin correlations. 


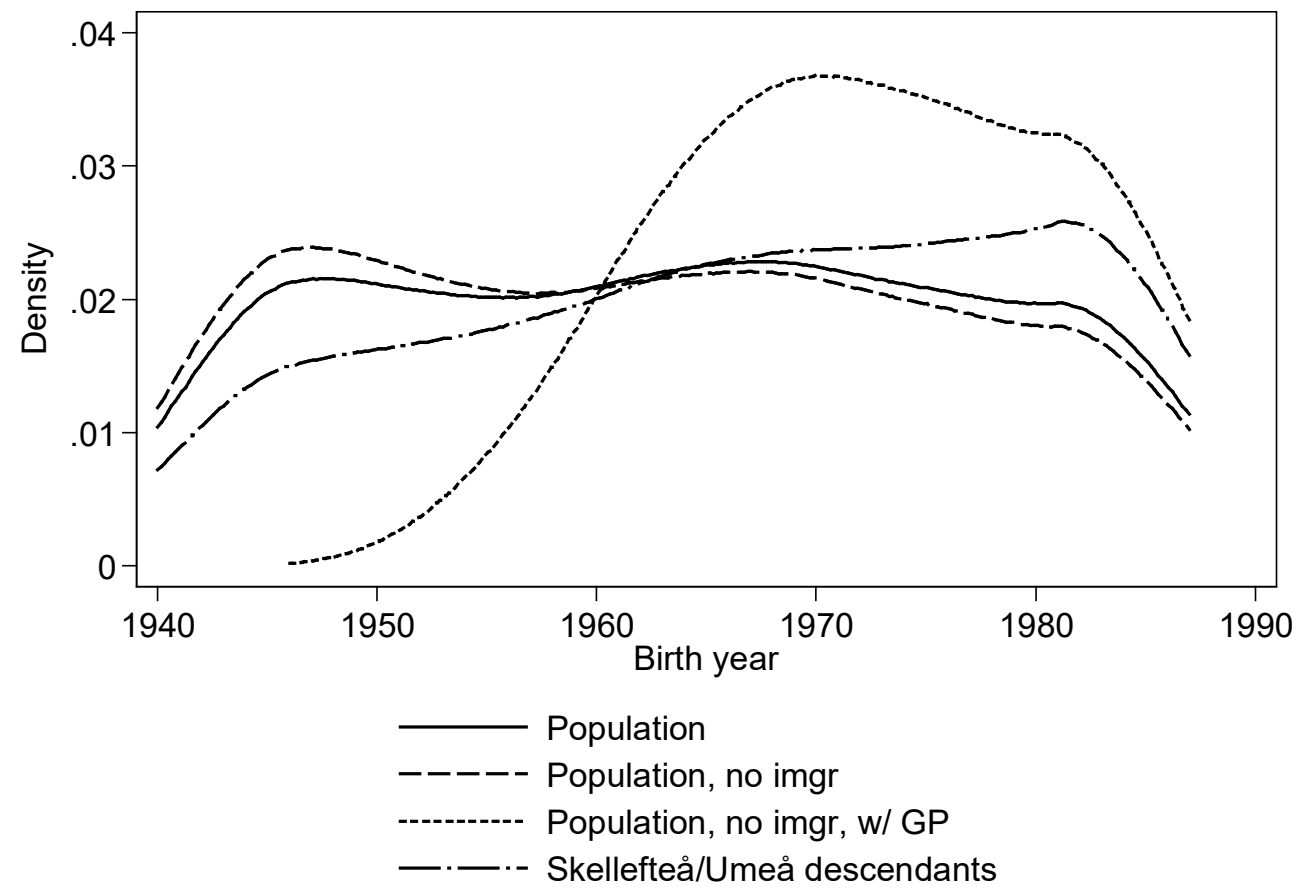

Figure H1. Density of index generation's birth years in sample vs. reference population Note: individuals born 1940-1987 in sample vs. whole of Sweden.

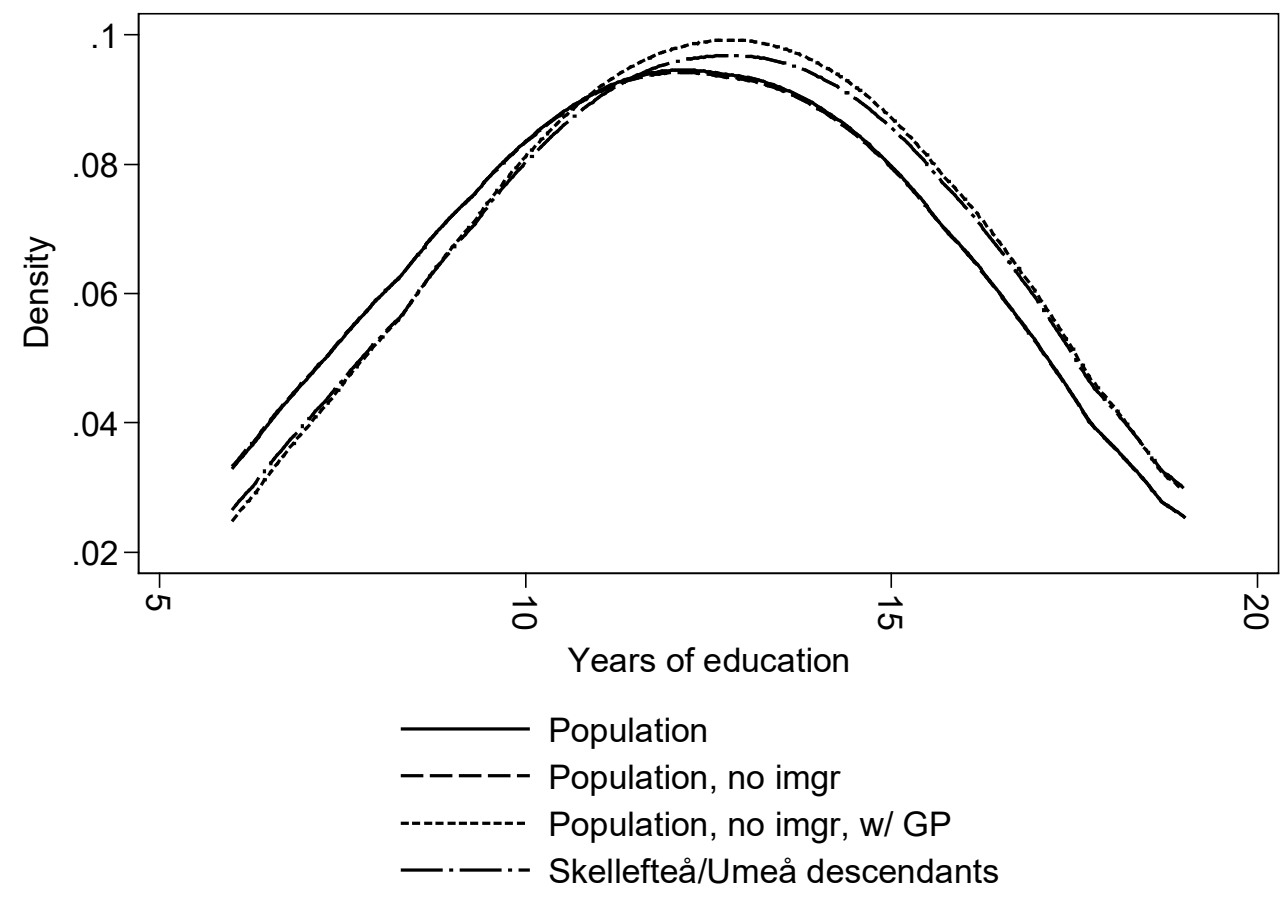

Figure H2. Density of index generation's years of education in sample vs. reference population

Note: individuals born 1940-1987 in sample vs. whole of Sweden. 

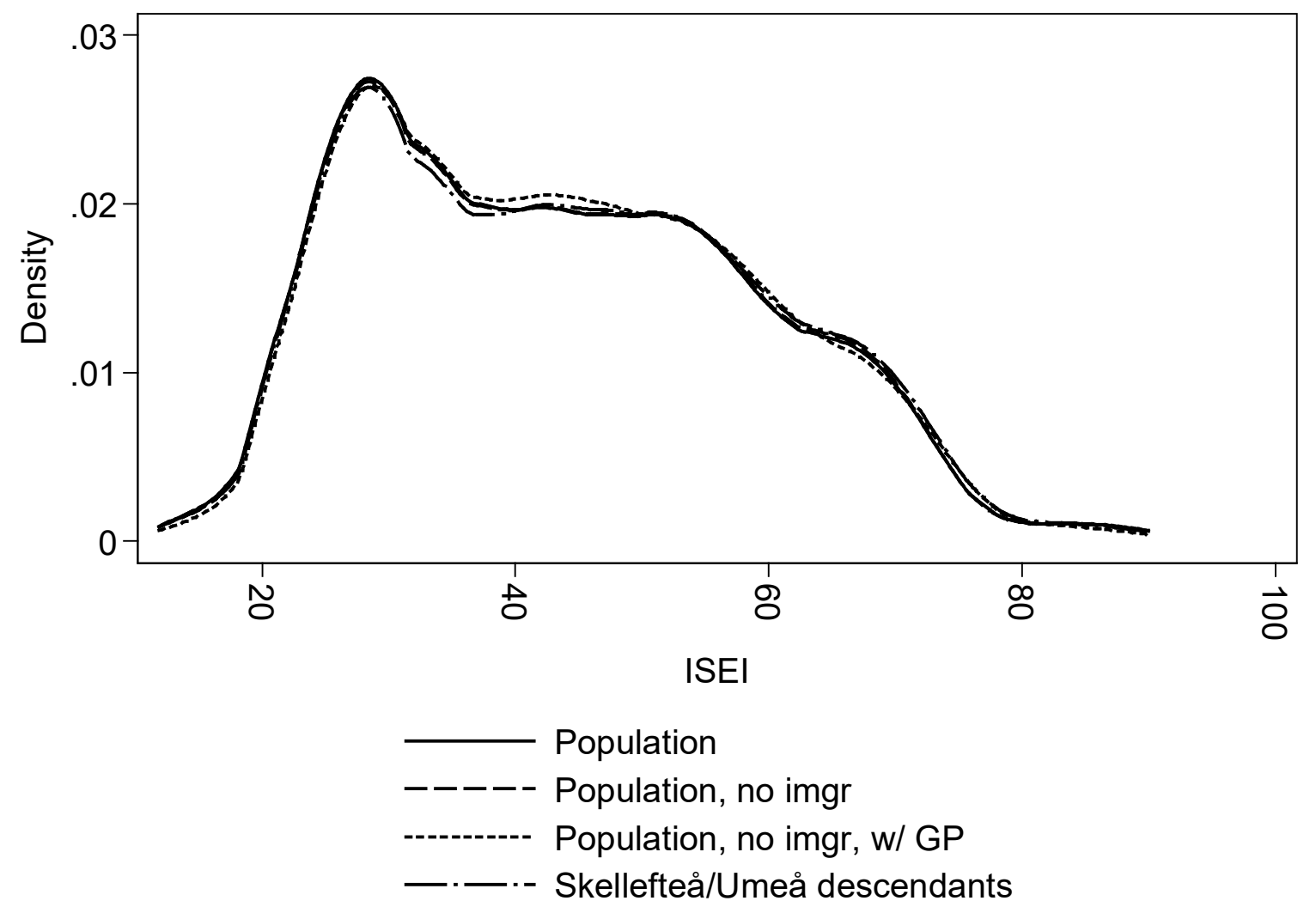

Figure H3. Density of index generation's ISEI in sample vs. reference population Note: individuals born 1940-1987 in sample vs. whole of Sweden. 
Table H1. Descriptive statistics for index generation

\begin{tabular}{|c|c|c|c|c|c|c|c|c|c|c|}
\hline & Mean & SD & Min & p10 & p25 & p50 & p75 & p90 & Max & Count \\
\hline \multicolumn{11}{|l|}{ Skellefteå/Umeå sample } \\
\hline Birth year & 1966.26 & $(13.55)$ & 1940 & 1946 & 1955 & 1967 & 1978 & 1984 & 1987 & 75,414 \\
\hline Female & 0.49 & $(0.50)$ & 0 & 0 & 0 & 0 & 1 & 1 & 1 & 75,414 \\
\hline Years of education & 12.66 & $(2.47)$ & 6 & 10 & 11 & 12 & 15 & 16 & 19 & 73,241 \\
\hline ISEI & 44.00 & $(15.41)$ & 11.9 & 25 & 30 & 43 & 56 & 66 & 90 & 71,233 \\
\hline Wealth (thousand SEK) & 280.18 & $(1003.95)$ & $-9700^{a}$ & -110 & -15 & 62 & 331 & 845 & $80,700^{a}$ & 72,908 \\
\hline \multicolumn{11}{|c|}{ Swedish reference population, constrained by birth years } \\
\hline Birth year & 1963.61 & $(13.60)$ & 1940 & 1945 & 1952 & 1964 & 1975 & 1983 & 1987 & $5,219,004$ \\
\hline Female & 0.49 & $(0.50)$ & 0 & 0 & 0 & 0 & 1 & 1 & 1 & $5,219,004$ \\
\hline Years of education & 12.21 & $(2.64)$ & 6 & 9 & 11 & 12 & 14 & 16 & 19 & $4,995,984$ \\
\hline ISEI & 43.65 & $(15.32)$ & 11.9 & 25 & 30 & 42 & 55 & 66 & 90 & $4,822,841$ \\
\hline Wealth (thousand SEK) & 452.94 & $(21701.62)$ & $-170000^{a}$ & -114 & -15 & 94 & 484 & 1217 & $4.70 * 10^{7 a}$ & $4,961,184$ \\
\hline \multicolumn{11}{|c|}{ Swedish reference population, constrained by birth years, no immigrants } \\
\hline Birth year & 1962.57 & $(13.66)$ & 1940 & 1944 & 1950 & 1963 & 1974 & 1982 & 1987 & $4,369,759$ \\
\hline Female & 0.49 & $(0.50)$ & 0 & 0 & 0 & 0 & 1 & 1 & 1 & $4,369,759$ \\
\hline Years of education & 12.19 & $(2.67)$ & 6 & 9 & 11 & 12 & 14 & 16 & 19 & $4,269,618$ \\
\hline ISEI & 43.75 & $(15.29)$ & 11.9 & 25 & 30 & 42 & 55 & 66 & 90 & $4,140,564$ \\
\hline Wealth (thousand SEK) & 484.66 & $(23425.06)$ & $-170000^{a}$ & -110 & -11 & 115 & 525 & 1286 & $4.70 * 10^{7 a}$ & $4,236,770$ \\
\hline \multicolumn{11}{|c|}{ Swedish reference population, constrained by birth years, no immigrants, GP links exist } \\
\hline Birth year & 1972.54 & $(8.73)$ & 1946 & 1961 & 1966 & 1973 & 1980 & 1985 & 1987 & $2,422,912$ \\
\hline Female & 0.49 & $(0.50)$ & 0 & 0 & 0 & 0 & 1 & 1 & 1 & $2,422,912$ \\
\hline Years of education & 12.78 & $(2.25)$ & 6 & 10 & 11 & 12 & 15 & 16 & 19 & $2,375,585$ \\
\hline ISEI & 43.93 & $(15.06)$ & 11.9 & 25 & 31 & 43 & 55 & 66 & 90 & $2,305,287$ \\
\hline Wealth (thousand SEK) & 209.63 & $(2818.58)$ & $-49000^{a}$ & -132 & -33 & 31 & 230 & 626 & $2300000^{a}$ & $2,372,138$ \\
\hline
\end{tabular}

${ }^{a}$ these numbers have been truncated to 0 if negative. 
Table H2. Sibling and cousin correlation in reference population and sample.

\begin{tabular}{|c|c|c|c|c|c|c|c|c|c|c|c|}
\hline Outcome & $\begin{array}{c}\text { Cousin } \\
\text { order }\end{array}$ & Reference population ${ }^{a}$ & Rho & s.e. & $\mathrm{t}$ & CI- & $\mathrm{CI}+$ & $\begin{array}{c}\text { Iterated } \\
\text { (Sibling) }\end{array}$ & Difference & $\begin{array}{c}\text { Unique } \\
\text { Ancestors }\end{array}$ & No. ties \\
\hline \multirow{10}{*}{ Education } & \multirow{5}{*}{0 (sibs) } & Population, birth years & 0.364 & 0.001 & 606.5 & 0.363 & 0.365 & 0.364 & & $1,789,563$ & $4,461,965$ \\
\hline & & Population, birth years, no imgr & 0.365 & 0.001 & 521.3 & 0.364 & 0.366 & 0.365 & & $1,530,006$ & $3,733,221$ \\
\hline & & Population, birth years, no imgr, w/ GP & 0.341 & 0.001 & 341.3 & 0.339 & 0.343 & 0.341 & & 926,875 & $1,992,465$ \\
\hline & & In sample & 0.319 & 0.005 & 65.0 & 0.309 & 0.328 & 0.319 & & 25,325 & 58,635 \\
\hline & & Mixed & 0.299 & 0.006 & 51.6 & 0.288 & 0.310 & 0.299 & & 19,036 & 39,055 \\
\hline & \multirow[t]{5}{*}{1} & Population, birth years & 0.157 & 0.001 & 313.8 & 0.156 & 0.158 & 0.132 & 0.024 & 643,567 & $8,099,317$ \\
\hline & & Population, birth years, no imgr & 0.155 & 0.001 & 221.6 & 0.154 & 0.156 & 0.133 & 0.022 & 587,508 & $7,094,024$ \\
\hline & & Population, birth years, no imgr, w/ GP & 0.155 & 0.001 & 258.5 & 0.154 & 0.156 & 0.116 & 0.039 & 587,508 & $7,094,024$ \\
\hline & & In sample & 0.118 & 0.004 & 26.2 & 0.109 & 0.127 & 0.101 & 0.016 & 8,535 & 110,691 \\
\hline & & Mixed & 0.137 & 0.003 & 44.3 & 0.131 & 0.143 & 0.089 & 0.048 & 19,061 & 209,484 \\
\hline \multirow[t]{10}{*}{ Occupation } & \multirow[t]{5}{*}{0 (sibs) } & Population, birth years & 0.314 & 0.001 & 522.8 & 0.313 & 0.315 & 0.314 & & $1,713,471$ & $4,136,402$ \\
\hline & & Population, birth years, no imgr & 0.315 & 0.001 & 524.5 & 0.314 & 0.316 & 0.315 & & $1,472,191$ & $3,491,732$ \\
\hline & & Population, birth years, no imgr, w/ GP & 0.310 & 0.001 & 344.6 & 0.308 & 0.312 & 0.310 & & 891,537 & $1,868,486$ \\
\hline & & In sample & 0.286 & 0.006 & 48.5 & 0.274 & 0.297 & 0.286 & & 24,436 & 55,385 \\
\hline & & Mixed & 0.283 & 0.007 & 42.3 & 0.270 & 0.297 & 0.283 & & 18,308 & 36,799 \\
\hline & \multirow[t]{5}{*}{1} & Population, birth years & 0.139 & 0.001 & 197.9 & 0.137 & 0.140 & 0.098 & 0.040 & 635,006 & $7,586,827$ \\
\hline & & Population, birth years, no imgr & 0.137 & 0.001 & 228.7 & 0.136 & 0.138 & 0.099 & 0.038 & 579,987 & $6,672,315$ \\
\hline & & Population, birth years, no imgr, w/ GP & 0.137 & 0.001 & 196.0 & 0.136 & 0.139 & 0.096 & 0.041 & 579,987 & $6,672,315$ \\
\hline & & In sample & 0.112 & 0.004 & 26.6 & 0.104 & 0.120 & 0.082 & 0.030 & 8,435 & 105,027 \\
\hline & & Mixed & 0.122 & 0.004 & 28.5 & 0.114 & 0.131 & 0.080 & 0.042 & 18,778 & 197,974 \\
\hline \multirow[t]{10}{*}{ Wealth } & \multirow[t]{5}{*}{0 (sibs) } & Population, birth years, & 0.309 & 0.001 & 441.9 & 0.308 & 0.311 & 0.309 & & $1,695,782$ & $4,060,265$ \\
\hline & & Population, birth years, no imgr & 0.311 & 0.001 & 518.3 & 0.310 & 0.312 & 0.311 & & $1,457,506$ & $3,429,037$ \\
\hline & & Population, birth years, no imgr, w/ GP & 0.313 & 0.001 & 347.6 & 0.311 & 0.315 & 0.313 & & 886,986 & $1,851,248$ \\
\hline & & In sample & 0.302 & 0.006 & 54.0 & 0.291 & 0.313 & 0.302 & & 24,262 & 54,561 \\
\hline & & Mixed & 0.282 & 0.006 & 47.8 & 0.271 & 0.294 & 0.282 & & 18,237 & 36,535 \\
\hline & \multirow[t]{5}{*}{1} & Population, birth years, & 0.095 & 0.001 & 158.3 & 0.094 & 0.096 & 0.096 & -0.001 & 634,254 & $7,523,723$ \\
\hline & & Population, birth years, no imgr & 0.094 & 0.001 & 188.4 & 0.093 & 0.095 & 0.097 & -0.003 & 579,376 & $6,619,595$ \\
\hline & & Population, birth years, no imgr, w/ GP & 0.094 & 0.001 & 188.4 & 0.093 & 0.095 & 0.098 & -0.004 & 579,376 & $6,619,595$ \\
\hline & & In sample & 0.069 & 0.005 & 12.7 & 0.058 & 0.079 & 0.091 & -0.023 & 8,428 & 104,439 \\
\hline & & Mixed & 0.071 & 0.004 & 17.7 & 0.063 & 0.079 & 0.080 & -0.009 & 18,761 & 196,809 \\
\hline
\end{tabular}

Note: all estimates are based on ranks and weighting scheme 2. " "Population" delimited to (i) people born 1940-1987 with identifiable parents, (ii) + immigrants removed, (iii) + with identifiable grandparents. "In sample" refers to individuals we observe as index individuals in the analytical sample, but their kinship links are from register only, not historical data (and estimates are therefore not identical to cousin correlations displayed in the main analysis). "Mixed" refers to correlations between one cousin in sample and the other in population. 


\section{Part I. Residential migration and lineage extinction.}

Our data set is local in nature, even though we loosen this constraint when we get into modern registers in the mid-20th century. The local nature means that our data will be biased toward residentially stable kinship lineages. Individuals moving in and out are traced by the church books, but due to the fact that only the church books from our study sites are preserved and digitalized, we cannot follow their movements after they leave our region. Although we cannot adjust for this fundamental structure of our data, we have conducted some analyses of migration patterns. Table I1 is based on all individuals in the church books, i.e., those living in the region, regardless of whether they are in our kinship networks or not. The table shows the migration patterns by occupational class and birth cohort. In the early period (born 1700-1750), migration is low and does not differ much by occupational classes (as previously noted, non-farm occupations are a small part of the data set). In the next period, 1750-1799, migration has increased, with a small dominance of out-migration over in-migration. There is a large influx of unskilled workers, but except for that, there is little variation across occupational classes. From 1800-1849, migration has increased even more; the pattern is largely the same across occupational classes, but migration is now substantially lower among farmers. At the end of the 19th century, migration increased even more, and except for farmers, few stay in the study region. This suggests that our sample primarily has a bias toward land-owning farmers, which is what we allude to in the paper's title.

In Table I2, we take this analysis further, and examine whether there are inter- or multigenerational effects on migration. Here, we have used prospective matching, starting from an ancestor and then tracing their descendants in the data. This data set is delimited to ancestors born from 1700-1850. Table I2 shows that there indeed are associations between ancestors' occupational classes and their descendants' out-migration over one, two, and three generations. Farmers are the reference in the analysis, and other occupational classes show relatively higher 
levels of out-migration. One exception is 4th generation descendants of unskilled workers, who are more residentially stable. We can also see associations between the ancestor's own migration experiences and the risk of a descendant's out-migration, even if this becomes weak for 4th generation descendants. If the ancestor was residentially stable, there is a lower risk of out-migration (net of their occupational class). These findings reinforce our conclusion that there is a farm bias in our sample, but there is also a bias toward individuals who have stayed regardless of farm ownership. The reasons for this can be subject to speculation, but some form of region-specific material or immaterial capital may be a likely explanation. 
Table I1. Migration pattern in study region by social class

\begin{tabular}{|c|c|c|c|c|c|c|c|c|}
\hline \multirow[b]{2}{*}{ HISCLASS } & \multicolumn{4}{|c|}{$1700-1749$} & \multicolumn{4}{|c|}{$1750-1799$} \\
\hline & In & Out & In-Out & Stayer & In & Out & In-Out & Stayer \\
\hline Higher managers & 7.7 & 7.7 & 7.7 & 76.9 & 10.4 & 10.4 & 6 & 73.1 \\
\hline Higher professionals & 17.4 & 4.3 & 0 & 78.3 & 15.5 & 15.5 & 3.1 & 66 \\
\hline Lower managers & 3.1 & 9.4 & 12.5 & 75 & 11.3 & 7.5 & 9.4 & 71.7 \\
\hline Lower prof and clerical, sales & 14.3 & 14.3 & 0 & 71.4 & 20.4 & 12.2 & 6.1 & 61.2 \\
\hline Lower clerical and sales & 0 & 0 & 0 & 100 & 17.4 & 13 & 4.3 & 65.2 \\
\hline Foremen & 0 & 0 & 0 & 100 & 40 & 0 & 0 & 60 \\
\hline Skilled workers & 5.6 & 5.6 & 0 & 88.9 & 12.3 & 8.2 & 8.2 & 71.2 \\
\hline Farmers & 2.4 & 8.8 & 0.6 & 88.1 & 5.7 & 12.4 & 2.4 & 79.6 \\
\hline Lower skilled workers & 1.4 & 10 & 0.5 & 88.2 & 13 & 10.8 & 2.8 & 73.3 \\
\hline Lower skilled farm workers & 28.6 & 0 & 0 & 71.4 & 16.7 & 7.9 & 1.8 & 73.7 \\
\hline Unskilled workers & 0 & 0 & 0 & 100 & 36.4 & 0 & 0 & 63.6 \\
\hline Unskilled farm workers & 11.7 & 9.4 & 2.2 & 76.7 & 8.2 & 13.4 & 3.4 & 74.9 \\
\hline \multirow[t]{2}{*}{ Total } & 5.6 & 8.8 & 1.5 & 84.1 & 8.7 & 12.3 & 3.2 & 75.8 \\
\hline & \multicolumn{4}{|c|}{$1800-1849$} & \multicolumn{4}{|c|}{$1850-1900$} \\
\hline HISCLASS & In & Out & In-Out & Stayer & In & Out & In-Out & Stayer \\
\hline Higher managers & 18.8 & 13 & 15.9 & 52.2 & 21.1 & 10.6 & 44.4 & 23.9 \\
\hline Higher professionals & 18.9 & 11.3 & 15.3 & 54.5 & 16.5 & 19.4 & 33.5 & 30.6 \\
\hline Lower managers & 22.7 & 11.2 & 12.8 & 53.3 & 24.5 & 11.8 & 38.8 & 24.9 \\
\hline Lower prof and clerical, sales & 18.2 & 12.9 & 15.4 & 53.4 & 20.6 & 19.7 & 28.3 & 31.4 \\
\hline Lower clerical and sales & 17.9 & 8.9 & 8.9 & 64.3 & 17.4 & 24 & 30 & 28.6 \\
\hline Foremen & 18.4 & 14.3 & 18.4 & 49 & 22.8 & 15.5 & 19.1 & 42.6 \\
\hline Skilled workers & 18.2 & 11 & 14 & 56.8 & 20.6 & 18.5 & 23.2 & 37.6 \\
\hline Farmers & 8 & 7.8 & 2.7 & 81.5 & 9.1 & 14.2 & 4.6 & 72 \\
\hline Lower skilled workers & 15.6 & 15.2 & 5.2 & 64 & 20.6 & 17.6 & 20.1 & 41.7 \\
\hline Lower skilled farm workers & 9.7 & 11 & 2.8 & 76.4 & 13.9 & 16.7 & 6.9 & 62.6 \\
\hline Unskilled workers & 6.7 & 15.4 & 4.2 & 73.8 & 17.4 & 14 & 25.5 & 43.2 \\
\hline Unskilled farm workers & 11.3 & 17.7 & 4.9 & 66.1 & 12 & 29.7 & 13.5 & 44.8 \\
\hline Total & 10.6 & 12.1 & 4.7 & 72.6 & 14.1 & 18.8 & 14.9 & 52.3 \\
\hline
\end{tabular}

Note: Sample is delimited to individuals born in Skellefteå/Umeå in 1700-1900 (not necessarily becoming ancestors in our analytical sample, but belonging to same generations). Each row of In, Out, In-Out and Stayer sums to 100 percent. 
Table I2. Risk of descendants' out-migration by ancestors' SES social class and migration experience

\begin{tabular}{|c|c|c|c|c|c|c|c|c|c|}
\hline & \multicolumn{3}{|c|}{ 2nd generation moving out } & \multicolumn{3}{|c|}{ 3rd generation moving out } & \multicolumn{3}{|c|}{ 4th generation moving out } \\
\hline & (1) & $(2)$ & (3) & (4) & (5) & (6) & (7) & $(8)$ & (9) \\
\hline \multirow[t]{2}{*}{ Higher managers } & $0.218 * * *$ & & $0.192 * * *$ & $0.140 * * *$ & & $0.140 * * *$ & $0.068^{*}$ & & $0.067 *$ \\
\hline & $(6.67)$ & & $(6.73)$ & $(4.70)$ & & $(4.66)$ & $(2.32)$ & & $(2.28)$ \\
\hline \multirow[t]{2}{*}{ Higher professionals } & $0.091 * * *$ & & $0.065 * *$ & 0.035 & & 0.036 & 0.007 & & 0.007 \\
\hline & $(3.74)$ & & $(3.25)$ & $(1.75)$ & & $(1.78)$ & $(0.37)$ & & $(0.37)$ \\
\hline \multirow[t]{2}{*}{ Lower managers } & $0.100 * * *$ & & $0.081 * * *$ & $0.099 * * *$ & & $0.096^{* * *}$ & 0.02 & & 0.019 \\
\hline & $(4.50)$ & & $(4.07)$ & $(4.32)$ & & $(4.19)$ & $(0.84)$ & & $(0.79)$ \\
\hline \multirow[t]{2}{*}{ Lower prof and clerical, sales } & $0.190 * * *$ & & $0.144 * * *$ & $0.146 * * *$ & & $0.144 * * *$ & $0.074 * *$ & & $0.073 * *$ \\
\hline & $(7.37)$ & & $(6.59)$ & $(5.50)$ & & $(5.45)$ & $(2.62)$ & & $(2.59)$ \\
\hline \multirow[t]{2}{*}{ Lower clerical and sales } & 0.108 & & 0.06 & $0.143 * *$ & & $0.135 * *$ & 0.067 & & 0.065 \\
\hline & $(1.93)$ & & $(0.94)$ & $(2.98)$ & & $(2.71)$ & $(1.28)$ & & $(1.26)$ \\
\hline \multirow[t]{2}{*}{ Foremen } & $0.136^{*}$ & & $0.121 *$ & 0.13 & & 0.129 & $0.195 * * *$ & & $0.187 * * *$ \\
\hline & $(2.15)$ & & $(2.41)$ & $(1.39)$ & & $(1.37)$ & $(3.92)$ & & $(3.80)$ \\
\hline \multirow[t]{2}{*}{ Skilled workers } & $0.113 * * *$ & & $0.100 * * *$ & $0.096 * * *$ & & $0.095 * * *$ & 0.013 & & 0.012 \\
\hline & $(5.75)$ & & $(5.51)$ & $(4.78)$ & & $(4.76)$ & $(0.59)$ & & $(0.56)$ \\
\hline \multirow[t]{2}{*}{ Lower skilled workers } & $0.071 * * *$ & & $0.066 * * *$ & $0.023 *$ & & 0.022 & $0.045^{* * *}$ & & $0.044 * * *$ \\
\hline & $(5.67)$ & & $(5.77)$ & $(1.99)$ & & $(1.87)$ & $(3.78)$ & & $(3.67)$ \\
\hline \multirow[t]{2}{*}{ Lower skilled farm workers } & 0.016 & & 0.009 & -0.009 & & -0.009 & -0.01 & & -0.011 \\
\hline & $(0.79)$ & & $(0.47)$ & $(-0.41)$ & & $(-0.44)$ & $(-0.41)$ & & $(-0.43)$ \\
\hline \multirow[t]{2}{*}{ Unskilled workers } & $0.163 * *$ & & $0.154 * *$ & $0.188 * *$ & & $0.188 * *$ & 0.039 & & 0.04 \\
\hline & $(3.29)$ & & $(3.24)$ & $(2.63)$ & & $(2.61)$ & $(0.60)$ & & $(0.63)$ \\
\hline \multirow[t]{2}{*}{ Unskilled farm workers } & $0.076^{* * *}$ & & $0.069 * * *$ & $0.027^{*}$ & & $0.026^{*}$ & $0.024 *$ & & 0.023 \\
\hline & $(6.76)$ & & $(6.75)$ & $(2.37)$ & & $(2.25)$ & $(2.01)$ & & $(1.94)$ \\
\hline \multirow[t]{2}{*}{ 1st generation in-migration } & & $0.070 * * *$ & $0.060 * * *$ & & $0.040 * * *$ & $0.028 * *$ & & $0.021 *$ & 0.01 \\
\hline & & $(6.60)$ & $(5.53)$ & & $(3.85)$ & $(2.65)$ & & $(1.99)$ & $(0.86)$ \\
\hline \multirow[t]{2}{*}{ 1st generation out-migration } & & $0.372 * * *$ & $0.352 * * *$ & & 0.023 & 0.018 & & -0.01 & -0.005 \\
\hline & & $(30.32)$ & $(26.97)$ & & $(1.82)$ & $(1.33)$ & & $(-0.99)$ & $(-0.43)$ \\
\hline \multirow[t]{2}{*}{ 1st generation in-out-migration } & & $0.431 * * *$ & $0.402 * * *$ & & $0.055^{*}$ & 0.039 & & 0.012 & 0.003 \\
\hline & & $(18.51)$ & $(17.16)$ & & $(2.42)$ & $(1.66)$ & & $(0.48)$ & $(0.10)$ \\
\hline Birth year & Yes & Yes & Yes & Yes & Yes & Yes & Yes & Yes & Yes \\
\hline Observations & 30,422 & 33,921 & 30,422 & 41,535 & 46,536 & 41,535 & 42,711 & 50,239 & 42,711 \\
\hline Adjusted R2 & 0.036 & 0.095 & 0.1 & 0.044 & 0.044 & 0.044 & 0.038 & 0.049 & 0.038 \\
\hline
\end{tabular}

Note: t-vales in parentheses. Reference is farm class and residential stability. Sample is delimited to individuals born in Skellefteå/Umeå born in 1700-1850 and their prospectively matched descendants (in contrast to our retrospective matched analytical sample, which conditions on descendants not moving out). 


\section{Part J. Simulation of multigenerational correlations under selection.}

Since our historical data is regional men and women that leave our region are not observed. Therefore out-migration of individuals during the $19^{\text {th }}$ and early $20^{\text {th }}$ century will cause the sample to be selected of descendants that are stayers in the region. We, therefore, examined if any kind of selectivity of out-migration by occupational class may affect our findings utilizing microsimulations (see also Appendix G). We provide the Stata code for our simulations below. We are particularly interested in if the higher out-migration of high-status groups may affect our findings. We produce a multigeneration dataset with pre-specified correlation structure using random draws from a multivariate normal distribution. For simplicity, we create kinship structures with only one observation per generation. We assume that the correlation structure is either two-generational following $1^{\text {st }}$ order Markov or decay at a slower rate across generations using a decay function (more similar to our main results). Since we have a complete network structure, we can measure the multigenerational correlations perfectly. We then remove linages depending on their outcomes in intermediate generations, and measure the multigenerational correlations in this selected data. We repeat this procedure 1000 times, and assess the average differences across estimates. Since our local region is rural and dominated by agriculture, our main suspicion is that people that have a propensity for high SES will need to move out from the region to realize this SES. Given how our data is constructed, the groups most exposed to this out-migration risk is descendants closest to the ancestor, i.e., the $2^{\text {nd }}$ and $3^{\text {rd }}$ generations. For later descendants, the selection in our data is not as strong. We use three selection processes: (a) we lose all of the most advantaged of the $2^{\text {nd }}$ generation of descendants, i.e., those above the $75^{\text {th }}$ percentile; (b) we lose all of the most advantaged of the $2^{\text {nd }}$ AND $3^{\text {rd }}$ generation of descendants; and (c), a weaker and more realistic model where we lose an increasingly large share of the $2^{\text {nd }}$ generation by their SES level. We display our code in Table I2. 
Table $\mathrm{J} 2$ displays the results of our simulations. The simulations unanimously show that the bias due to selection is downwards. That means that an overrepresentation of high-status individuals among out-migrants (which is likely empirically what we observe) will, on average, mean that we will underestimate multigenerational correlations compared to a hypothetical scenario in which such individuals did not out-migrate (or we had national data). Everything else equal, we argue that this mechanism, therefore, means that we will underestimate persistence in our main results. The magnitude depends on the strength of the selection process and appears to increase, in relative terms, by the multigenerational distance. To give an example, we use the estimates for $\mathrm{IGC}=0.5$, decay ratio $=1$ (Markov) where selection is on G2 with SES over $75^{\text {th }}$ percentile lost. Comparing before and after selection for the G1 vs. G2 correlation yields a difference of 22 percent. For the G1 vs G4 correlation, this number is 42 percent and for G1 vs. G6 it is 67 percent. The results are also the same for Markov and non-Markov transmissions. These stylized results suggest that our selected sample likely has a strong component of downward bias. This does not preclude, however, that other selection processes are also at play and generate biases in different directions. 
Table J1. Stata code for simulation.

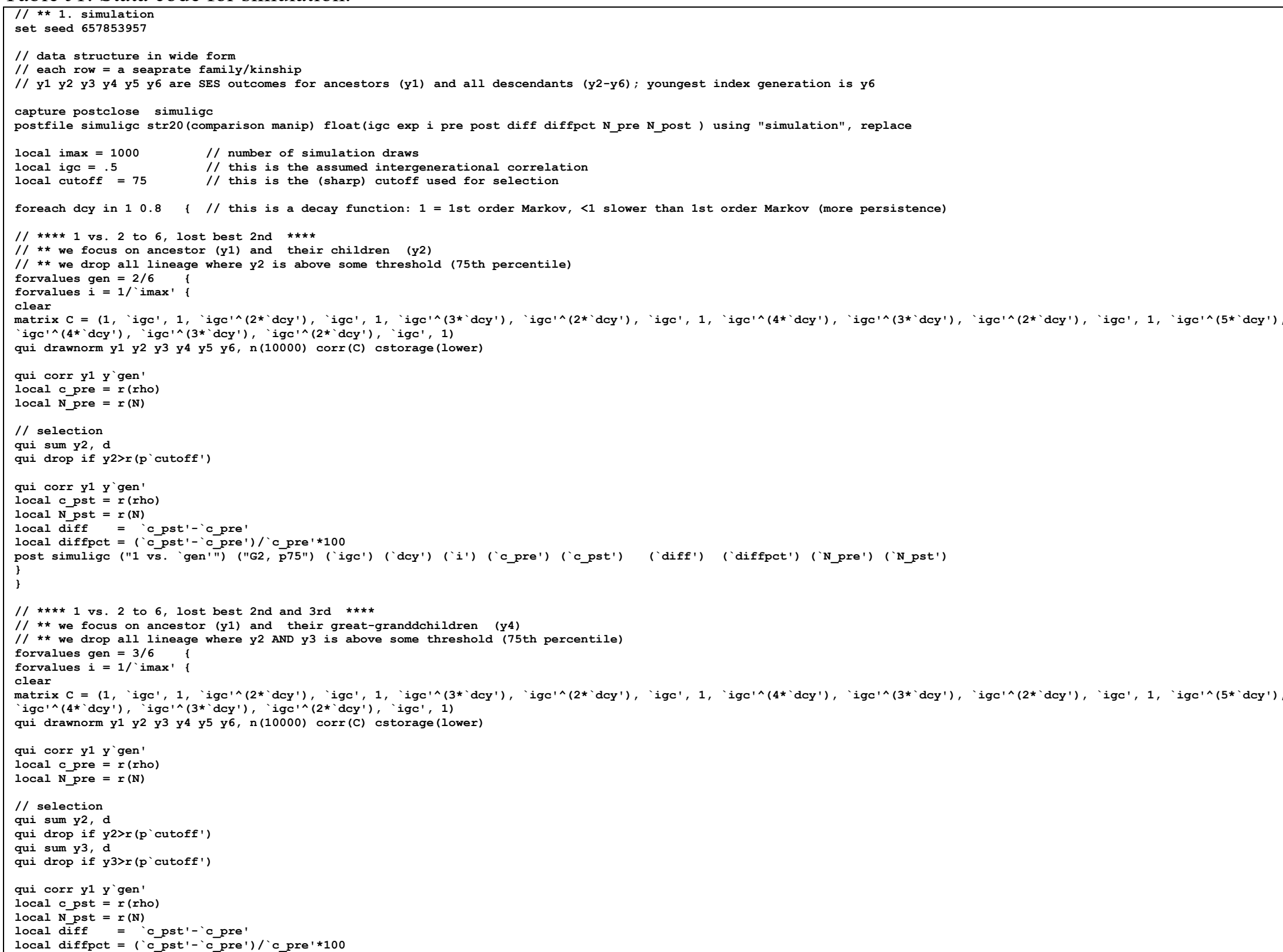




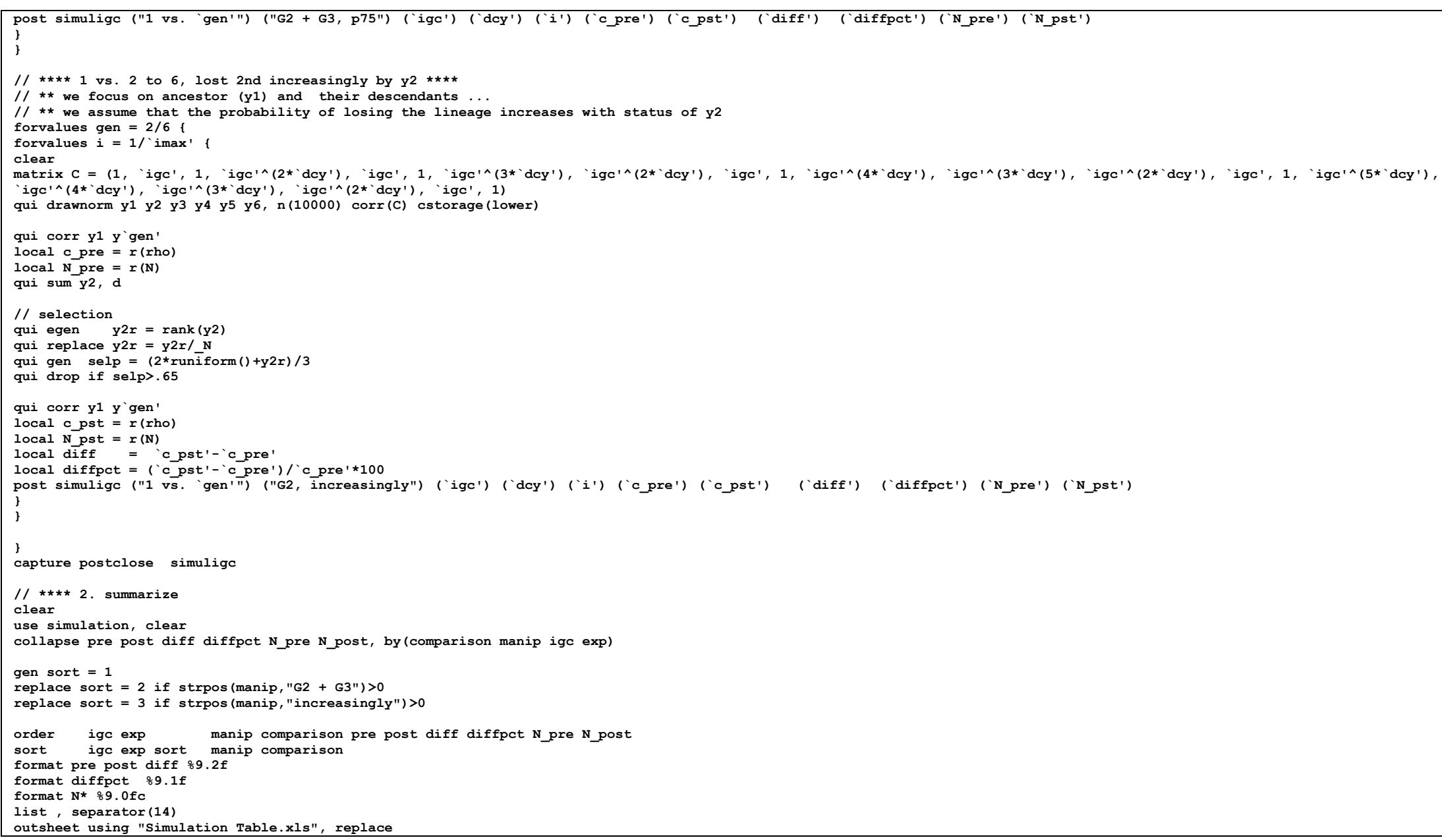


Table J2. Simulation results if impact of selection on multigenerational correlations.

\begin{tabular}{|c|c|c|c|c|c|c|c|c|c|c|}
\hline \multicolumn{3}{|c|}{ Fixed parameters } & \multirow[b]{2}{*}{ Selection Process } & \multicolumn{3}{|c|}{ Estimated correlation } & \multirow[b]{2}{*}{ Difference } & \multirow[b]{2}{*}{$\begin{array}{c}\text { Difference } \\
\text { (Percent) }\end{array}$} & \multicolumn{2}{|c|}{$\mathrm{N}$} \\
\hline IGC & Decay $^{\mathrm{a}}$ & & & $\begin{array}{l}\text { Multigenerational } \\
\text { distance }\end{array}$ & $\begin{array}{c}\text { Before } \\
\text { selection }\end{array}$ & $\begin{array}{c}\text { After } \\
\text { selection }\end{array}$ & & & $\begin{array}{c}\text { Before } \\
\text { selection }\end{array}$ & $\begin{array}{c}\text { After } \\
\text { selection }\end{array}$ \\
\hline \multirow[t]{14}{*}{0.5} & & 0.8 & $\mathrm{G} 2$, lose all $>$ P75 & 1 vs. 2 & 0.50 & 0.39 & -0.11 & -22.2 & 10,000 & 7,500 \\
\hline & & & & 1 vs. 3 & 0.33 & 0.24 & -0.09 & -26.8 & 10,000 & 7,500 \\
\hline & & & & 1 vs. 4 & 0.19 & 0.12 & -0.07 & -35.1 & 10,000 & 7,500 \\
\hline & & & & 1 vs. 5 & 0.11 & 0.07 & -0.04 & -36.6 & 10,000 & 7,500 \\
\hline & & & & 1 vs. 6 & 0.06 & 0.04 & -0.02 & -37.2 & 10,000 & 7,500 \\
\hline & & & $\mathrm{G} 2+\mathrm{G} 3$, lose all $>\mathrm{P} 75$ & 1 vs. 3 & 0.33 & 0.20 & -0.13 & -40.5 & 10,000 & 5,625 \\
\hline & & & & 1 vs. 4 & 0.19 & 0.09 & -0.10 & -54.9 & 10,000 & 5,625 \\
\hline & & & & 1 vs. 5 & 0.11 & 0.04 & -0.07 & -62.0 & 10,000 & 5,625 \\
\hline & & & & 1 vs. 6 & 0.06 & 0.02 & -0.04 & -64.4 & 10,000 & 5,625 \\
\hline & & & G2, lose increasingly & 1 vs. 2 & 0.50 & 0.49 & -0.01 & -1.4 & 10,000 & 7,252 \\
\hline & & & with Y & 1 vs. 3 & 0.33 & 0.32 & -0.01 & -1.9 & 10,000 & 7,250 \\
\hline & & & & 1 vs. 4 & 0.19 & 0.18 & 0.00 & -2.5 & 10,000 & 7,249 \\
\hline & & & & 1 vs. 5 & 0.11 & 0.11 & 0.00 & -2.8 & 10,000 & 7,251 \\
\hline & & & & 1 vs. 6 & 0.06 & 0.06 & 0.00 & -2.9 & 10,000 & 7,248 \\
\hline \multirow[t]{14}{*}{0.5} & & 1 & $\mathrm{G} 2$, lose all $>\mathrm{P} 75$ & 1 vs. 2 & 0.50 & 0.39 & -0.11 & -22.2 & 10,000 & 7,500 \\
\hline & & & & 1 vs. 3 & 0.25 & 0.15 & -0.10 & -39.7 & 10,000 & 7,500 \\
\hline & & & & 1 vs. 4 & 0.12 & 0.07 & -0.05 & -42.5 & 10,000 & 7,500 \\
\hline & & & & 1 vs. 5 & 0.06 & 0.04 & -0.03 & -43.8 & 10,000 & 7,500 \\
\hline & & & & 1 vs. 6 & 0.03 & 0.02 & -0.01 & -66.9 & 10,000 & 7,500 \\
\hline & & & $\mathrm{G} 2+\mathrm{G} 3$, lose all $>\mathrm{P} 75$ & 1 vs. 3 & 0.25 & 0.13 & -0.12 & -48.0 & 10,000 & 5,625 \\
\hline & & & & 1 vs. 4 & 0.12 & 0.05 & -0.08 & -62.4 & 10,000 & 5,625 \\
\hline & & & & 1 vs. 5 & 0.06 & 0.02 & -0.04 & -65.0 & 10,000 & 5,625 \\
\hline & & & & 1 vs. 6 & 0.03 & 0.01 & -0.02 & -71.3 & 10,000 & 5,625 \\
\hline & & & $\mathrm{G} 2$, lose increasingly & 1 vs. 2 & 0.50 & 0.49 & -0.01 & -1.4 & 10,000 & 7,250 \\
\hline & & & with Y & 1 vs. 3 & 0.25 & 0.24 & -0.01 & -2.9 & 10,000 & 7,249 \\
\hline & & & & 1 vs. 4 & 0.13 & 0.12 & 0.00 & -3.2 & 10,000 & 7,251 \\
\hline & & & & 1 vs. 5 & 0.06 & 0.06 & 0.00 & -3.2 & 10,000 & 7,250 \\
\hline & & & & 1 vs. 6 & 0.03 & 0.03 & 0.00 & -4.6 & 10,000 & 7,248 \\
\hline
\end{tabular}

Note: ${ }^{\text {a }}$ Decay $=1$ is $1^{\text {st }}$ order Markov, Decay $<1$ is higher persistence, with multigenerational effects 


\section{Part K. Kinship effects vs. parish cluster effects.}

One concern may be the possibility that the dynastic correlations and cousin correlations is an artifact of clustering by the parish. The parishes may have had slightly different natural endowments (better land, closer to transportation routes, inland vs. coast; better access to sawmill or mining jobs etc). This would mean that we, as part of the kinship effect, capture geographical clustering. A question like this is to some extent, philosophical, as individuals, as they live through history, are not exogenously assigned geography but do so endogenously. It isn't easy to know if their success was caused by their geography or if they endogenously choose their location. Conceptually, one may regard such clustering by the parish as physical capital ("quality of land") that we would consider as real sources of multigenerational kinship advantage. Nonetheless, we have no data on more exact location within the parish nor of the ancestor's physical capital.

We have addressed this clustering argument by introducing fixed effects of ancestor's parish when we pre-residualize outcomes in our cousin correlation methodology (for cousin correlation not to be driven by, e.g., similarity in the year of birth or gender, we regress the outcomes on these factors, and use residual in the further analysis). It should be noted that this strategy may (over and above conceptually) over-control away kinship because some parishes are small and therefore collinearity between locality and person will arise. The number of parishes are low, and only 10 , which also limits how effective this strategy is. In table K1, we find that parish FE does not explain away cousin correlations to any larger degree. In most cases, at least 70 to 80 percent of the correlation remains, which we take as evidence that however, we view the causality between geography and kinship, our estimated kinship effects exist beyond clustering and cannot be reduced to geography in disguise. To sort out the role of ancestor's location in any greater detail would require data that is still unimaginable to us, i.e., some exogeneous variation in location. 
Table K1. Effects of ancestor parish on cousin correlations: Ratio of cousin correlation with and without controls for parish of residence (cousin correlation as in Table 1 but where we also include residualization for ancestor parish, divided by cousin correlation as in Table 1)

\begin{tabular}{llll} 
& Education & ISEI & Wealth \\
\hline sibs & 0.858 & 0.854 & 1.143 \\
cous1st & 0.911 & 0.878 & 0.959 \\
cous2nd & 0.871 & 0.814 & 0.842 \\
cous3rd & 0.774 & 0.704 & 0.643 \\
cous4th & 0.840 & 0.787 & 0.684 \\
cous5th & 0.878 & 0.886 & 0.694 \\
\hline
\end{tabular}

Note: Ancestor parish $=$ the parish of the cousin base (=ancestor generating cousins). Example: a ratio of .80 suggest that $80 \%$ of the cousin correlation remains after parish fixed effects have been controlled. 


\section{References to Web Appendix}

Adermon, Adrian, Mikael Lindahl, and Mårten Palme. 2019. "Dynastic human capital, inequality and intergenerational mobility." IZA Discussion Paper No. 12300.

Alm Stenflo, Gun 1994. Demographic description of the Skelleftea and Sundsvall regions during the 19th century: Univ., Demografiska databasen.

Anderson, Lewis R., Paula Sheppard, and Christiaan W.S. Monden. 2018. "Grandparent effects on educational outcomes: a systematic review." Sociological Science 5:114-142.

Becker, Gary S., and Robert J. Barro. 1988. "A Reformulation of the Economic Theory of Fertility." The Quarterly Journal of Economics 103:1-25.

Björklund, Anders, and Marianne Sundström. 2006. "Parental Separation and Children's Educational Attainment: A Siblings Analysis on Swedish Register Data." Economica 73:605-624.

Brandén, Gunnar. 2018. "Paper I. Does inequality reduce mobility? The Great Gatsby Curve and its mechanisms." Dissertation, Department of Economics, Uppsala University.

Edvinsson, S. 2000. "The Demographic Data Base at Umeå University—a resource for historical studies." Handbook of international historical microdata for population research:231-248.

Egerbladh, Inez, and Alan H. Bittles. 2008. "The Influence of Consanguineous Marriage on Reproductive Behavior and Early Mortality in Northern Coastal Sweden, 1780-1899." Pp. 205-224 in Kinship and Demographic Behavior in the Past, edited by Tommy Bengtsson and Geraldine P. Mineau. Dordrecht: Springer Netherlands.

Engberg, Elisabeth, Annika Westberg, and Sören Edvinsson. 2016. "A Unique Source for Innovative Longitudinal Research: The POPLINK Database." Historical Life Course Studies 3:20-31.

Euler, Harald A. 2011. "Grandparents and extended kin." Pp. 181-210 in The Oxford handbook of evolutionary family psychology. Oxford University Press, New York, edited by Catherine Salmon and Todd K. Shackelford.

Hällsten, Martin, and Fabian T. Pfeffer. 2017. "Grand Advantage. Family Wealth and Grandchildren's Educational Achievement in Sweden." American Sociological Review 82:328-360.

Kolk, Martin. 2011. "Deliberate birth spacing in nineteenth century northern Sweden." European Journal of Population 27:337-359.

Murphy, Mike. 2004. "Tracing very long-term kinship networks using SOCSIM." Demographic research 10:171-196.

Nilsdotter Jeub, Ulla. 1993. Parish records - 19th century ecclesiastical registers. Umeå, Sweden: Demographic Database.

Rosenthal, Carolyn J. 1985. "Kinkeeping in the Familial Division of Labor." Journal of Marriage and Family 47:965-974.

Solon, Gary, Marianne E. Page, and Greg J. Duncan. 2000. "Correlations between Neighboring Children in Their Subsequent Educational Attainment." The Review of Economics and Statistics 82:383-392.

Statistics Sweden. 1999. Befolkningsutvecklingen under 250 år - Historisk statistik för Sverige. [Population changes during 250 years. Historical statistics for Sweden]. Stockholm: Statistiska Centralbyrån.

—. 2010. "Flergenerationsregistret [the multigeneration register]." http://www.scb.se/Pages/List_257501.aspx, accessed 2010-03-02. 